\title{
ARMAZENAGEM SOB CONDIÇÕES DE INCERTEZA: O CASO DO ARROZ NO BRASIL
}

\author{
Ana Lúcia de Aguiar \\ Economista
}

Orientador: Prof. Dr. Geraldo Sant'Ana de Camargo Barros

Dissertação apresentada à Escoia Superior de Agricultura "Luiz de Queiroz", da Universidade de São Paulo, para obtenção do título de Mestre em Agronomia. Área de concentração: Economia Agrária.

PIRACICABA

Estadơ đê São Paulo - Brasil

Fevereiro de 1992 
Ficha catalográfica preparada pela Seção de Livros da Divisão de Biblioteca e Documentação - PCAP/USP

\section{Aguiar. Ana Lúcia de}

A282a Armazenagem sob condiçöes de incerteza; o caso do ar roz no Brasil. Piracicaba, 1992.

$134 \mathrm{p}$.

Diss.(Mestre) - ESALQ

Bibliografia.

1. Arroz - Abastecimento - Brasil 2. Arroz - Armazena mento - Custo 3. Arroz - Mercado - Brasil I. Escola Superior de Agricultura Luiz de Queiroz, Piracicaba

$\operatorname{CDD} \quad 338.17318$ 


\title{
ARMAZENAGEM SOB CONDIÇÕES DE INCERTEZA: O CASO DO ARROZ NO BRASIL
}

\author{
Ana Lúcia de Aguiar
}

Aprovada em: 04-05-1992

Comissão Julgadora:

Prof. Dr. Geraldo Sant'Ana de Camargo Barros - ESALQ/USP

Prof. Dr. Fernando Curi Perez - ESALQ/USP

Prof. Dr. Flávio Conde de Carvalho - FIPE/USP

Prof. Dr. Geraldo Sant'Ana de Camargo Barros Ornentador 


\section{Agradecimentos}

A todos aqueles - familiares, colegas, professores, amigos - que de alguma forma, seja através de crítica construtiva, de sugestões ou outras contribuições enriquecedoras colaboraram para que esse objetivo fosse alcançado.

De modo particular estendo meus agradecimentos ao Dr. José Ubirajara Coelho de Souza Tim, dirigente, à época, da extinta SUDEPE, e a Dra. Tânia Maria T. Munhoz, então Presidenta do IBAMA, ambos, quando no exercício de suas respectivas funções concederam-me a liberação necessária, dando-me, assim, oportunidade de concluir o presente estudo.

Ao colega e amigo - Marco A urélio Rodrigues Veloso - os meus agradecimentos por ter permitido, em duas oportunidades distintas, que o trabalho não fosse interrompido.

Dessa vitória, compartilho com o Prof. Geraldo Sant'Ana de Camargo Barros, que com competência - e muita tolerância - soube orientar-me em toda a jornada.

E, finalmente, a cara irmã Raquel - Analista de Sistemas da Faculdade de Engenharia Mecânica da UNICAMP - a quem coube o árduo trabalho de digitação e formatação final do trabalho, ao que acrescento o apoio afetivo dado. 


\section{Conteúdo}

Lista de Figuras $\ldots \ldots \ldots \ldots \ldots \ldots \ldots$

Lista de Tabelas . . . . . . . . . . . . . . . . . . . 11

Resumo . . . . . . . . . . . . . . . . . . . 12

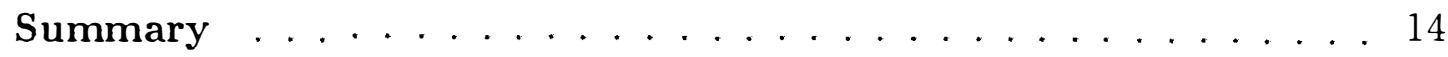

1 Introdução 16

2 O mercado do arroz $\quad 19$

2.1 Produção . . . . . . . . . . . . . . . . . . . 19

2.2 Preços e abastecimento . . . . . . . . . . . . . . . . . 25

2.3 Armazenamento . . . . . . . . . . . . . . . . 31

3 Metodologia $\quad 32$

3.1 Teoria da Armazenagem Competitiva sob Condições de Incerteza . . 32

3.1.1 Demanda de Produtos para Armazenamento . . . . . . . . 34

3.1.2 Oferta de Produtos para Armazenamento . . . . . . . . . . 37

3.1.3 Equilíbrio Competitivo e Formação de Preços . . . . . . . . . 39

3.1.4 Custos e Benefícios da Armazenagem Competitiva . . . . . . . 44

3.1.5 Eficiência Econômica da Armazenagem Competitiva . . . . . 49

3.1.6 Efeitos Distributivos de Políticas de Preços . . . . . . . . . 50

3.2 Descrição dos dados . . . . . . . . . . . . . . . . . . . . 54

4 Resultados $\quad 58$

4.1 Resultados das simulações da armazenagem competitiva (elasticidades estimadas empiricamente) $\ldots \ldots \ldots \ldots . \ldots 58$

4.1.1 Década de $70(1971 / 80) \ldots \ldots \ldots \ldots . \ldots \ldots$

4.1 .2 Década de $80(1980 / 90) \ldots \ldots \ldots . \ldots 69$

4.1.3 Efeitos de uma Política de Completa Estabilização de Preços . 79

4.1.4 Efeitos de uma Política de Estabilização Parcial de Preços . . 84

4.2 Análise de Sensibilidade . . . . . . . . . . . . . . . . 9 90 
5 Resumo e Conclusões $\quad 93$

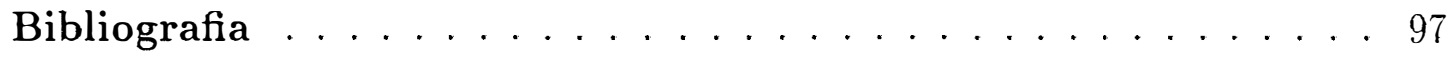
Apêndice A . . . . . . . . . . . . . . . . 100

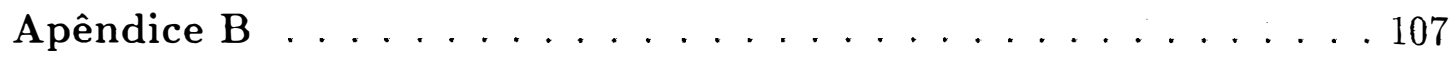

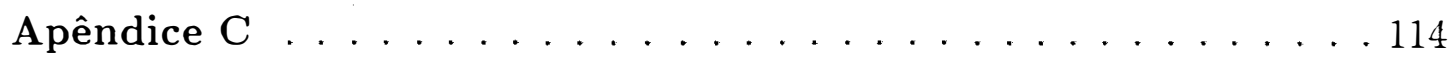
Apêndice D . . . . . . . . . . . . . . . . . . . 1 . . . . . . . . . Apêndice $\mathbf{E} \ldots \ldots \ldots \ldots \ldots$ 


\section{Lista de Figuras}

2.1 ARROZ-Produção dos principais Estados produtores de sequeiro e

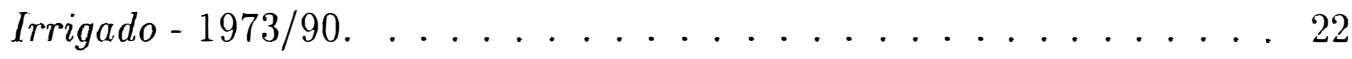

2.2 ARROZ - Preços reais nos meses de safra (março a maio) - 1971/90. 28

3.1 Derivação gráfica da Demanda de Produtos para Armazenamento . . 36

3.2 Derivação gráfica da Oferta de Produtos para Armazenamento . . . 38

3.3 Equilíbrio competitivo e formação de preços no caso $I_{0}=0 \ldots 41$

3.4 Equilíbrio competitivo e formação de preços no caso $0<I_{0} \leq I_{00} \quad$. . 42

3.5 Equilíbrio competitivo e formação de preços no caso $I_{0}>I_{00} \ldots \ldots 43$

3.6 Representação gráfica do excedente dos consumidores e produtores . . 45

3.7 Ganhos (perdas) esperadas no t-ésimo período por consumidores (produtores) com armazenamento competitivo . . . . . . . . . 47

3.8 Efeitos de políticas governamentais de estabilização de preços, comparativamente à armazenagem competitiva . . . . . . . . 51 


\section{Lista de Tabelas}

2.1 ARROZ - Produção e produtividade dos principais estados produtores de sequeiro e irrigado $-1973 / 79 \ldots \ldots \ldots$. . . . . . . . . 21

2.2 ARROZ-Evolução da produção brasileira por região - 1973/90 . . . . 23

2.3 ARROZ-Concentração da produção brasileira por região - 1973/90 . . 24

2.4 ARROZ-Preços médios reais recebidos pelos produtores e preços mínimos reais, na safra (março a maio) - 1971/90 . . . . . . . . 27

2.5 ARROZ-Aquisições do Governo Federal (AGFs), Emprestimos do Governo Federal (EGFs) e nível de preços - 1971/90 . . . . . . . . 29

2.6 ARROZ-Estimativas de Suprimento (safras 1970/71 a 1989/90)(1) . 30

3.1 ARROZ - Preços médios reais anuais: preços recebidos pelos produtores, preços mínimos do sequeiro, preços mínimos do irrigado e preços mínimos médios - Brasil 1971/90 . . . . . . . . . . 56

4.1 Estimativas de estoques, preços, oferta e demanda de arroz para o

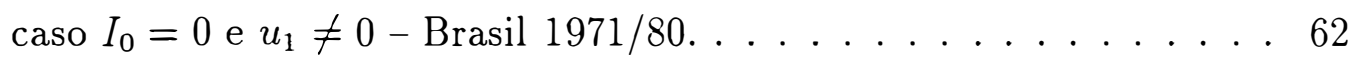

4.2 Estimativas de estoques, preços, oferta e demanda de arroz para o

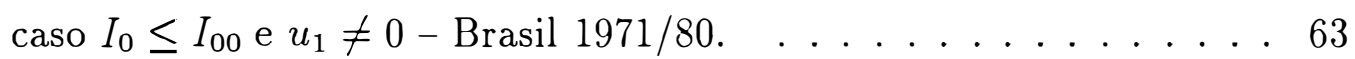

4.3 Estimativas de estoques, preços, oferta e demanda de arroz para o caso $I_{0}>I_{00}$ e $u_{1} \neq 0-$ Brasil $1971 / 80 \ldots \ldots \ldots \ldots$. . . . . 64

4.4 Estimativas de estoques, preços, oferta e demanda de arroz para o caso $I_{0}=0$ e $u_{1}=0$ - Brasil 1971/80 . . . . . . . . . 65

4.5 Estimativas de estoques, preços, oferta e demanda de arroz para o caso $I_{0} \leq I_{00}$ e $u_{1}=0-$ Brasil $1971 / 80 \ldots \ldots \ldots 6$

4.6 Estimativas de estoques, preços, oferta e demanda de arroz para o caso $I_{0}>I_{00}$ e $u_{1}=0-$ Brasil $1971 / 80 \ldots \ldots \ldots 67$

4.7 Efeitos distributivos da armazenagem competitiva no mercado de arroz comparativamente ao não armazenamento - Brasil 1971/80 . . . 68 
4.8 Estimativas de estoques, preços, oferta e demanda de arroz para o caso $I_{0}=0$ e $u_{1} \neq 0$ - Brasil 1981/90 . . . . . . . . . . . . . 72

4.9 Estimativas de estoques, preços, oferta e demanda de arroz para o caso $I_{0} \leq I_{00}$ e $u_{1} \neq 0$ - Brasil 1981/90. . . . . . . . . . . . 73

4.10 Estimativas de estoques, preços, oferta e demanda de arroz para o caso $I_{0}>I_{00}$ e $u_{1} \neq 0$ - Brasil 1981/90. . . . . . . . . . . . . . 74

4.11 Estimativas de estoques, preços, oferta e demanda de arroz para o caso $I_{0}=0$ e $u_{1}=0$ - Brasil 1981/90. . . . . . . . . . . 75

4.12 Estimativas de estoques, preços, oferta e demanda de arroz para o caso $I_{0} \leq I_{00}$ e $u_{1}=0-$ Brasil 1981/90. . . . . . . . . . . . . 76

4.13 Estimativas de estoques, preços, oferta e demanda de arroz para o caso $I_{0}>I_{00}$ e $u_{1}=0-$ Brasil $1981 / 90$. . . . . . . . . . . . . 77

4.14 Efeitos distributivos da armazenagem competitiva no mercado de arroz comparativamente ao não armazenamento - Brasil 1981/90. . . . 78

4.15 Efeitos da política de estabilização de preços no mercado de arroz: "Ganhos Mínimos dos Produtores" e "Perdas Máximas dos Consumidores" - Brasil 1971/80.

4.16 Efeitos da política de estabilização de preços no mercado de arroz: "Ganhos Mínimos" e "Perdas Máximas" - Brasil 1981/90.

4.17 Efeitos da política de estabilização de preços: quantidade total de arroz a ser armazenada $\left(I_{1}\right)$, pelos empresários armazenadores $\left(I_{1 \mathrm{~A}}\right)$ e pelo governo $\left(I_{1 G}\right)$ - Brasil 1971/80 . . . . . . . . . . . . . 82

4.18 Efeitos da política de estabilização de preços: quantidade total de arroz a ser armazenada $\left(I_{1}\right)$, pelos empresários armazenadores $\left(I_{1 A}\right)$ e pelo governo $\left(I_{1 G}\right)$ - Brasil 1981/90)

4.19 Efeitos da política de estabilização parcial de preços no mercado de arroz: "Ganhos Mínimos dos Produtores" e "Perdas Máximas dos Consumidores" - Brasil 1971/80.

4.20 Efeitos da política de estabilização parcial de preços no mercado de arroz: "Ganhos Mínimos dos Produtores" e "Perdas Máximas dos Consumidores" - Brasil 1981/90.

4.21 Efeitos da política de estabilização parcial de preços: quantidades total de arroz a ser armazenada $\left(I_{1}\right)$ pelos empresários $\left(I_{1 \mathrm{~A}}\right)$ e pelo governo $\left(I_{1 G}-\right.$ Brasil 1971/80. . . . . . . . . . . . . . .

4.22 Efeitos da política de estabilização parcial de preços: quantidades total de arroz a ser armazenada $\left(I_{1}\right)$ pelos empresários $\left(I_{1 A}\right)$ e pelo governo $\left(I_{1 G}-\right.$ Brasil 1981/90. 
A.1 Estimativas das quantidades de arroz a serem armazenadas $\left(I_{1}\right)$ e dos volumes a serem liberados $\left(i_{12}, i_{13}, \ldots, i_{1 n}\right)$ no caso $I_{0}=0$ e $u_{1} \neq 0-$ Brasil 1981/90 . . . . . . . . . . . . . . . . . 101

A.2 Estimativas das quantidades de arroz a serem armazenadas $\left(I_{1}\right)$ e dos volumes a serem liberados $\left(i_{12}, i_{13}, \ldots, i_{1 n}\right)$ no caso $I_{0} \leq I_{00}$ e $u_{1} \neq 0$ - Brasil 1981/90. . . . . . . . . . . . . . . . . 102

A.3 Estimativas das quantidades de arroz a serem armazenadas $\left(I_{1}\right)$ e dos volumes a serem liberados $\left(i_{12}, i_{13}, \ldots, i_{1 n}\right)$ no caso $I_{0}>I_{00}$ e $u_{1} \neq 0$ - Brasil 1981/90.

A.4 Estimativas das quantidades de arroz a serem armazenadas $\left(I_{1}\right)$ e dos volumes a serem liberados $\left(i_{12}, i_{13}, \ldots, i_{1 n}\right)$ no caso $I_{0}=0$ e $u_{1}=0-$ Brasil 1981/90. . . . . . . . . . . . . . . . . . 104

A.5 Estimativas das quantidades de arroz a serem armazenadas $\left(I_{1}\right)$ e dos volumes a serem liberados $\left(i_{12}, i_{13}, \ldots, i_{1 n}\right)$ no caso $I_{0}<I_{00}$ e $u_{1}=0$ - Brasil 1981/90.

A.6 Estimativas das quantidades de arroz a serem armazenadas $\left(I_{1}\right)$ e dos volumes a serem liberados $\left(i_{12}, i_{13}, \ldots, i_{1 n}\right)$ no caso $I_{0} \geq 0$ e $u_{1}=0-$ Brasil 1981/90. . . . . . . . . . . . . . . 106

B.1 Estimativas dos preços esperados para o arroz no caso $I_{0}=0$ e $u_{1} \neq 0$ - Brasil 1981/90. . . . . . . . . . . . . . . . 108

B.2 Estimativas dos preços esperados para o arroz no caso $I_{0}<I_{00} \mathrm{e}$ $u_{1} \neq 0$ - Brasil 1981/90 . . . . . . . . . . . . . 109

B.3 Estimativas dos preços esperados para o arroz no caso $I_{0}>I_{00}$ e $u_{1} \neq 0$ - Brasil 1981/90. . . . . . . . . . . . . . 110

B.4 Estimativas dos preços esperados para o arroz no caso $I_{0}=0$ e $u_{1}=0$ - Brasil 1981/90 . . . . . . . . . . . . . . . . . . 111

B.5 Estimativas dos preços esperados para o arroz no caso $I_{0} \leq I_{00} \mathrm{e}$

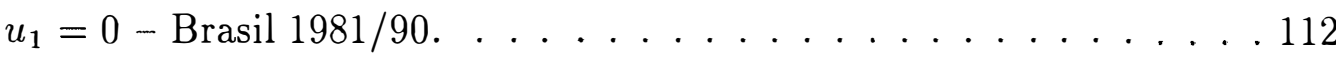

B.6 Estimativas dos preços esperados para o arroz no caso $I_{0}>I_{00}$ e

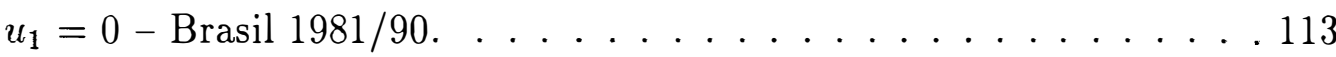

C.1 Estimativas das quantidades de arroz que se espera que sejam demandadas no caso $I_{0}=0$ e $u_{1} \neq 0$ - Brasil 1981/90 . . . . . . . 115

C.2 Estimativas das quantidades de arroz que se espera que sejam demandadas no caso $I_{0} \leq I_{00}$ e $u_{1} \neq 0$ - Brasil 1981/90 . . . . . . . 116

C.3 Estimativas das quantidades de arroz que se espera que sejam demandadas no caso $I_{0}>I_{00}$ e $u_{1} \neq 0$ - Brasil 1981/90 . . . . . . 117 
C.4 Estimativas das quantidades de arroz que se espera que sejam demandadas no caso $I_{0}=0$ e $u_{1}=0$ - Brasil 1981/90 . . . . . . . 118

C.5 Estimativas das quantidades de arroz que se espera que sejam demandadas no caso $I_{0} \leq I_{00}$ e $u_{1}=0$ - Brasil 1981/90 . . . . . . . . 119

C.6 Estimativas das quantidades de arroz que se espera que sejam demandadas no caso $I_{0}>I_{00}$ e $u_{1}=0-$ Brasil 1981/90 . . . . . . . 120

D.1 Estimativas das quantidades de arroz que se espera que sejam produzidas no caso $I_{0}=0$ e $u_{1} \neq 0$ - Brasil 1981/90 . . . . . . . . 122

D.2 Estimativas das quantidades de arroz que se espera que sejam produzidas no caso $I_{0} \leq I_{00}$ e $u_{1} \neq 0$ - Brasil 1981/90 . . . . . . . . . 123

D.3 Estimativas das quantidades de arroz que se espera que sejam produzidas no caso $I_{0}>I_{00}$ e $u_{1} \neq 0$ - Brasil 1981/90. . . . . . . . . 124

D.4 Estimativas das quantidades de arroz que se espera que sejam produzidas no caso $I_{0}=0$ e $u_{1}=0$ - Brasil 1981/90. . . . . . . . . 125

D.5 Estimativas das quantidades de arroz que se espera que sejam produzidas no caso $I_{0} \leq I_{00}$ e $u_{1}=0-$ Brasil 1981/90. . . . . . . . . 126

D.6 Estimativas das quantidades de arroz que se espera que sejam produzidas no caso $I_{0}>I_{00}$ e $u_{1}=0$ - Brasil 1981/90. . . . . . . . . 127

E.1 Efeitos distributivos da armazenagem competitiva no mercado de arroz no caso $I_{0}=0$ e $u_{1} \neq 0$ - Brasil 1981/90. . . . . . . . . . 129

E.2 Efeitos distributivos da armazenagem competitiva no mercado de arroz no caso $I_{0} \leq I_{00}$ e $u_{1} \neq 0$ - Brasil 1981/90 . . . . . . . . 130

E.3 Efeitos distributivos da armazenagem competitiva no mercado de arroz no caso $I_{0}>I_{00}$ e $u_{1} \neq 0-$ Brasil 1981/90 . . . . . . . . 131

E.4 Efeitos distributivos da armazenagem competitiva no mercado de arroz no caso $I_{0}=0$ e $u_{1}=0$ - Brasil 1981/90. . . . . . . . . 132

E.5 Efeitos distributivos da armazenagem competitiva no mercado de arroz no caso $I_{0} \leq I_{00}$ e $u_{1}=0-$ Brasil $1981 / 90 \ldots \ldots \ldots 133$

E.6 Efeitos distributivos da armazenagem competitiva no mercado de arroz no caso $I_{0}>I_{00}$ e $u_{1}=0-$ Brasil 1981/90 . . . . . . . 134 


\section{ARMAZENAGEM SOB CONDIÇÕES DE INCERTEZA: O CASO DO ARROZ NO BRASIL}

Autora: Ana Lúcia de Aguiar

Orientador: Prof. Dr. Geraldo Sant'Ana de Camargo Barros.

\section{RESUMO}

Com objetivo de se comparar analiticamente alternativas de estabilização do mercado de arroz no Brasil, através de políticas de armazenagem, utilizou-se a Teoria da Armazenagem sob Condições de Incerteza cujo modelo é formado pelas funções de oferta e demanda de produtos para armazenamento.

Pressupondo que as expectativas sejam racionais, ou seja, que os agentes econômicos façam suas previsões com base nos valores esperados de equilíbrio, demonstrou-se como preços, estoques, quantidades consumidas e produzidas são determinadas para um período temporal $(t, t+1, \ldots, t+n)$, onde $t+n$ é o período esperado de armazenamento.

Foram feitas simulações de política de armazenagem competitiva com base nas elasticidades preços da oferta e da demanda empiricamenteestimadas em estudos anteriores para os valores médios do consumo aparente e do preço recebido pelos produtores, obtidos a partir dos valores observados nas décadas de 70 e de 80 . A análise de sensibilidade foi feita para valores observados na década de $80 \mathrm{com}$ base em elasticidades aleatórias (sem fundamentação empírica).

As alternativas de estabilização do mercado de arroz consideradas foram: política de estabilização completa de preços e política de estabilização parcial de preços.

Os efeitos distributivos das políticas foram mensurados sob a ótica da Teoria do Bem-Estar: a política de armazenagem competitiva comparativamente ao nào armazenamento e as políticas de estabilizaçào comparativamente à competitiva.

As estimativas mostraram que a política de armazenagem competitiva é 
socialmente recomendável. Os ganhos dela decorrentes são suficientes para compensar os indivíduos que perdem com ela e ainda resulta em ganhos líquidos para a sociedade.

Quanto às políticas de estabilização do mercado de arroz, as estimativas demonstram que para implementá-las o Estado têm, obrigatoriamente, que assumir a função de armazenador; seja sozinho, alijando a iniciativa privada da atividade, ou seja dividindo o mercado com ela. Em todos os casos simulados o quantum a ser armazenado é sempre superior ao quantum competitivo. 


\section{STORAGE UNDER UNCERTAINTY: THE CASE OF RICE IN BRAZIL}

Author: Ana Lúcia de Aguiar

Adviser : Dr. Geraldo Sant'Ana de Camargo Barros.

SUMMARY

Alternatives for stabilization of rice market in Brazil were analytically compared. To do so, the "Theory of Storage under Uncertain Conditions" was the employed. This theory is based on supply and demand functions of products to be stored.

It was assumed that expectations are rational, i.e. that the economic agents base their forecasts on expected equilibrium values. It was demonstrated that the sale value of rice, their storage costs, and produced and consumed quantities were determined by a "temporal period" $(t, t+1, \ldots, t+n)$, where $t+n$ is the expected period of storage. Simulations of policies of competitive storage were done.

These simulations were done based on supply and demand price of elasticity. The price of elasticity were empirically estimated in previous studies by comparing the average values of the apparent consuption and price paid to producers. These values were noted in $70 \mathrm{~s}$ and $80 \mathrm{~s}$. The sensitivity analysis was performed to observed values in the $80 \mathrm{~s}$ based on random elasticities, i.e. without empirical basis.

Stabilization alternatives to the rice market were: politicies of complete and partial price stabilization.

The distributive effects were measured under the perspective of the "Welfare Theory": a competitive storage politicy was compared to a no storage and stabilization politicies.

Estimates have shown that a competitive storage policy is socially advisable. The gains resulting from this policy are enough to compensate the losses. This 
policy also provides net gains to the entire society.

It has been estimated to establish the stabilization policies of the rice market, the State has to be in charge of storage. The State can do this alone or jointly with the private sector. In all simulated cases the quantum to be storage is always more then the competitive quantum. 


\section{Capítulo 1}

\section{Introdução}

A participação do Estado brasileiro no problema abastecimento/armazenamento teve início na década de 60 , quando pressionado pela alta do custo de alimentação, estruturou o Sistema Nacional de Abastecimento, criando a Superintendência Nacional de Abastecimento - SUNAB, a Companhia Brasileira de Alimentação - COBAL e a Companhia Brasileira de Armazenagem - CIBRAZEM.

Estas instituições, articuladas com a já criada Comissão de Financiamento da Produção - CFP, tinham como objetivo precípuo resolver o problema de abastecimento interno de alimentos. Em particular, cabia à CIBRAZEM executar os planos de abastecimento elaborados pelo governo, no que respeita à armazenagem de gêneros alimentícios, agindo como elemento regulador de mercado e atendendo de forma supletiva, às áreas não suficientemente atendidas pela iniciativa privada (PUZZI, 1986).

O Programa Nacional de Armazenagem - PRONAZEM, aprovado pelo Decreto n. 75688 de 1975 foi o marco histórico da política nacional de armazenamento de grãos. Com vistas a dar suporte à agricultura, o Programa tinha como objetivo estruturar um sistema de armazenagem intermediária e terminal, bem como a nível de propriedade rural. Dos recursos alocados, $70 \%$ foram destinados à iniciativa privada especialmente às cooperativas e empresas de armazens gerais e $30 \%$ a CIBRAZEM, para ampliação de sua capacidade estática de armazenamento e desenvolvimento de pesquisas na área de armazenagem.

Segundo PUZZI (1986), o que se verificou na prática foi uma crescente intervenção do poder público no setor armazenador, passando o Estado a atuar como empresário prestador de serviços. A ação da iniciativa privada no setor ficou praticamente restrita ao suporte da comercialização e da industrialização e, fundamentalmente, às cooperativas. 
As crescentes taxas de crescimento apresentadas pelo setor agrícola nos primeiros anos da década de 80 , em especial a supersafra de $1985-57$ milhões de toneladas de grãos - levaram o Estado a repensar a política nacional de armazenagem principalmente quanto a capacidade/localização da capacidade de armazenagem existente.

Assim, o I Plano Nacional de Desenvolvimento da Nova República (1986/89) previa um incremento de 15,5 milhões de toneladas na capacidade estática de armazenagem. Mais detalhado, o Plano de Metas relativo às acões para "Expansão e Desenvolvimento do Sistema Nacional de Armazenagem", no biênio 1986/87 (autorizado pela Exposição de Motivos no 136 de 18 de novembro de 1986), elaborado para dar suporte ao Plano de Estabilização Econômica, criou o "Programa de Expansão de Armazenagem", cuja meta era aumentar a capacidade estática de armazenagem em 5,3 milhões de toneladas.

Por outro lado, o Plano definiu ações no sentido de descentralizar e privatizar, progressivamente, as atividades de armazenagem. Assim, para concretização da meta de incremento da capacidade estática de armazenamento foram previstos: operacionalização de linhas de crédito (1,3 milhão de toneladas); aporte de recursos privados (3,0 milhões de toneladas); e aporte de recursos privados (1,0 milhão de toneladas) com garantia de aluguel por parte do governo por um período de 5 (cinco) anos, quando construídos em áreas de produção com graves problemas de armazenagem.

Quanto à implementação deste Plano, é de conhecimento que, dado o comprometimento financeiro da CIBRAZEM e o agravamento do déficit público, o que se fez foi desativar ou repassar a terceiros, através de aluguel ou comodato, alguns armazens de propriedade do Estado.

Neste início de década, dentro do Programa de Reforma Administrativa, o governo promoveu a fusão das três empresas ligadas aos setores de comercialização e abastecimento de gêneros alimentícios - CFP, COBAL e CIBRAZEM - criando a Companhia Nacional de Abastecimento - CONAB, ligada ao Ministério de Agricultura e Reforma Agrária - MARA.

Paralelamente ao processo de fusão, e em consonância com a filosofia de liberalização econômica do atual governo, que revê o papel regulador do Estado nos mercados através de políticas de privatização, foi elaborado o "Plano de Racionalização de Ativos" da extinta CIBRAZEM.

Em resumo, em relação à armazenagem, a principal politica de curto prazo do atual governo tem como objetivo repassar à iniciativa privada, através de alienação por venda, o equivalente a aproximadamente 2,0 milhões de toneladas estáticas 
de armazenamento em ambiente natural. Isto significa dizer que, implementado o referido plano, a rede de armazenamento do Estado, a ser gerida pela CONAB, terá uma capacidade estática, em ambiente natural, da ordem de 1,5 milhão de toneladas.

Tendo em vista as propostas recentes de maior liberalização da comercialização bem como a redução do papel do Estado como empresário prestador de serviços, torna-se relevante analisar as vantagens ou desvantagens dessas políticas, bem como a distribuição de ganhos e/ou perdas dela decorrentes, entre os vários segmentos econômicos como produtores, consumidores, etc.

Assim, neste trabalho procura-se comparar analiticamente algumas alternativas de estabilização do mercado de arroz no Brasil, através de política de armazenagem. O interesse de se estudar o mercado de arroz decorre da constante preocupação do Estado com o abastecimento desse produto, dada a sua importância para o consumidor brasileiro.

Essa análise será conduzida para o mercado do arroz no Brasil, mercado que tem sido submetido a uma alta presença do Estado, particularmente nas duas últimas décadas. Nessa análise será utilizado o modelo de armazenagem competitiva sob condições de incerteza admitindo-se que os agentes econômicos tomem suas decisões com base nos pressupostos da Teoria de Expectativas Racionais, onde:

a) serão demonstradas as conseqüências distributivas e a eficiência econômica da armazenagem competitiva; e,

b) os efeitos das políticas de estabilizaçào comparativamente à armazenagem competitiva. 


\section{Capítulo 2}

\section{O mercado do arroz}

O objetivo aqui não é descrever com detalhes, todos os aspectos do mercado de arroz no Brasil, mas fornecer uma visão histórica geral de seu comportamento nos últimos 20 anos.

Em particular, pretende-se levantar alguns aspectos desse mercado, reflexo das inúmeras intervenções estatais diretas (tabelamentos) ou indiretas (políticas de preço, de comercialização, de abastecimento, etc.) a que tem sido submetido.

\subsection{Produção}

A produção arrozeira nacional é baseada em quatro sistemas de produção; o de terras baixas com irrigação controlada; o de terras baixas com irrigação não controlada; o de terras baixas sem irrigação; e, o de terras firmes sem irrigação ou cultivo de sequeiro.

Estes sistemas, genericamente chamados de irrigado ou sequeiro, apesar de não constarem das estatísticas oficiais da produção (nível nacional), são fatores de fundamental importância, sendo responsáveis pelo dualismo que caracteriza a produção brasileira deste cereal.

Produzido em praticamente, todas as regiões, o sequeiro apresenta características peculiares em cada uma delas. Nas Regiões Sul e Sudeste é plantado em caráter comercial em áreas já cultivadas. Nas Regiões Norte e Nordeste é utilizado, quase sempre, como cultura de subsistência, em situações tecnológicas bastante precárias e em pequenas áreas ou em consórcio com outras culturas. E, na Região Centro-Oeste, zona da fronteira agrícola, é utilizado como cultura de transição e de minimização de custos, precedendo à formação de pastagens ou instalação de cultura economicamente mais atraente.

O irrigado é preponderantemente cultivado na Região Sul, notadamente 
no Estado do Rio Grande do Sul, onde o sistema de produção utilizado - irrigação controlada por inundação - proporciona rendimentos significativos, mesmo se comparado ao de países onde o cultivo encontra-se bastante desenvolvido.

Ao nível de estado, as estatísticas fazem a distinçăo entre os dois cultivos. Assim, a Tabela 2.1 e consequente Figura 2.1 mostram a condição dicotômica da produção de arroz no Brasil decorrente do dualismo técnico que se antepõe às lavouras altamente tecnificadas do Rio Grande do Sul às de subsistência no Maranhão ou às da fronteira agrícola em Goiás.

Observa-se que o sequeiro, além de apresentar baixa rentabilidade, apresenta grandes e frequentes variações nas quantidades produzidas entre anos e entre os dois maiores estados produtores. Ao contrário, o irrigado apresenta tendência crescente de produção e produtividade.

A nível nacional e regional, a Tabela 2.2 mostra a evolução histórica da produção brasileira de arroz. Segundo REZENDE (1989) a taxa anual de crescimento da produção de arroz, no período de $1973 / 81$ foi de $1,0 \%$ passando para $2,8 \%$ no período de 1979/88 (taxas obtidas por ajustamento exponencial das quantidades produzidas). A produção atípica de 1990 , aproximadamente $33 \%$ inferior a obtida no ano anterior, mostra a entrada do setor rizícola no processo recessivo em que vive o País.

A Tabela 2.3 mostra a concentração da produção nas cinco regiões brasileiras. A Região Sul, historicamente, apresenta o maior índice de concentração; superior a $40 \%$ da produção nacional, nos anos 80. Segundo o GEIPOT (1982), a densidade de produção é o mais importante parâmetro para medir o grau da necessidade de planejamento dos sistemas de transporte e armazenagem. 
Tabela 2.1: ARROZ - Produção e produtividade dos principais estados produtores de sequeiro e irrigado - 1973/79

\begin{tabular}{|c|c|c|c|c|c|c|}
\hline \multirow[b]{2}{*}{ Ano } & \multicolumn{2}{|c|}{ Maranhão ( sequeiro) } & \multicolumn{2}{|c|}{ Goiás ( sequeiro) } & \multicolumn{2}{|c|}{ Rio Grande do Sul (irrigado) } \\
\hline & $\begin{array}{l}\text { Produção } \\
(1000 t)\end{array}$ & $\begin{array}{l}\text { Produtividade } \\
\qquad(\mathrm{kg} / \mathrm{ha})\end{array}$ & $\begin{array}{l}\text { Produção } \\
(1000 \mathrm{t})\end{array}$ & $\begin{array}{l}\text { Produtividade } \\
\qquad(\mathrm{kg} / \mathrm{ha})\end{array}$ & $\begin{array}{l}\text { Produção } \\
(1000 \text { t) }\end{array}$ & $\begin{array}{c}\text { Produtividade } \\
\text { (kg/ha) }\end{array}$ \\
\hline 1973 & 765,3 & 1.297 & $1.265,8$ & 1.263 & $1.433,9$ & 3.447 \\
\hline 1974 & 653,1 & 1.320 & 958,9 & 960 & $1.550,0$ & 3.558 \\
\hline 1975 & 907,5 & 1.469 & 868,2 & 916 & $1.803,6$ & 3.849 \\
\hline 1976 & 953,1 & 1.427 & $1.319,4$ & 1.153 & $1.975,6$ & 3.603 \\
\hline 1977 & $1.138,6$ & 1.509 & 620,5 & 798 & $2.105,0$ & 3.719 \\
\hline 1978 & $1.143,7$ & 1.474 & 621,1 & 825 & $2.009,1$ & 3.728 \\
\hline 1979 & $1.070,2$ & 1.253 & $1.155,1$ & 1.240 & $1.675,0$ & 3.190 \\
\hline 1980 & $1.281,3$ & 1.296 & $1.455,4$ & 1.226 & $2.293,4$ & 3.829 \\
\hline 1981 & $1.028,2$ & 1.488 & 920,6 & 821 & $2.455,4$ & 4.006 \\
\hline 1982 & $1.575,0$ & 1.349 & $1.396,9$ & 1.237 & $2.589,9$ & 4.149 \\
\hline 1983 & 431,0 & 596 & $1.080,7$ & 1.097 & $2.220,5$ & 3.488 \\
\hline 1984 & $1.145,5$ & 1.396 & $1.037,7$ & 1.008 & $3.119,0$ & 4.304 \\
\hline 1985 & 622,8 & 970 & $1.116,3$ & 1.297 & $3.207,0$ & 4.448 \\
\hline 1986 & $1.291,9$ & 1.379 & $1.358,5$ & 1.268 & $2.987,6$ & 4.110 \\
\hline 1987 & 595,8 & 640 & $1.501,0$ & 1.270 & $3.561,5$ & 4.435 \\
\hline 1988 & $1.294,3$ & 1.386 & $1.551,4$ & 1.411 & $3.881,3$ & 4.785 \\
\hline 1989 & $1.094,3$ & 1.172 & $1.294,7$ & 1.546 & $3.968,9$ & 4.936 \\
\hline 1990 & 464,8 & $\cdots \quad 684$ & 307,8 & 1.039 & $3.194,4$ & 4.642 \\
\hline
\end{tabular}

Fonte: Fundação Instituto Brasileiro de Geografia e Estatistica - IBGE. 

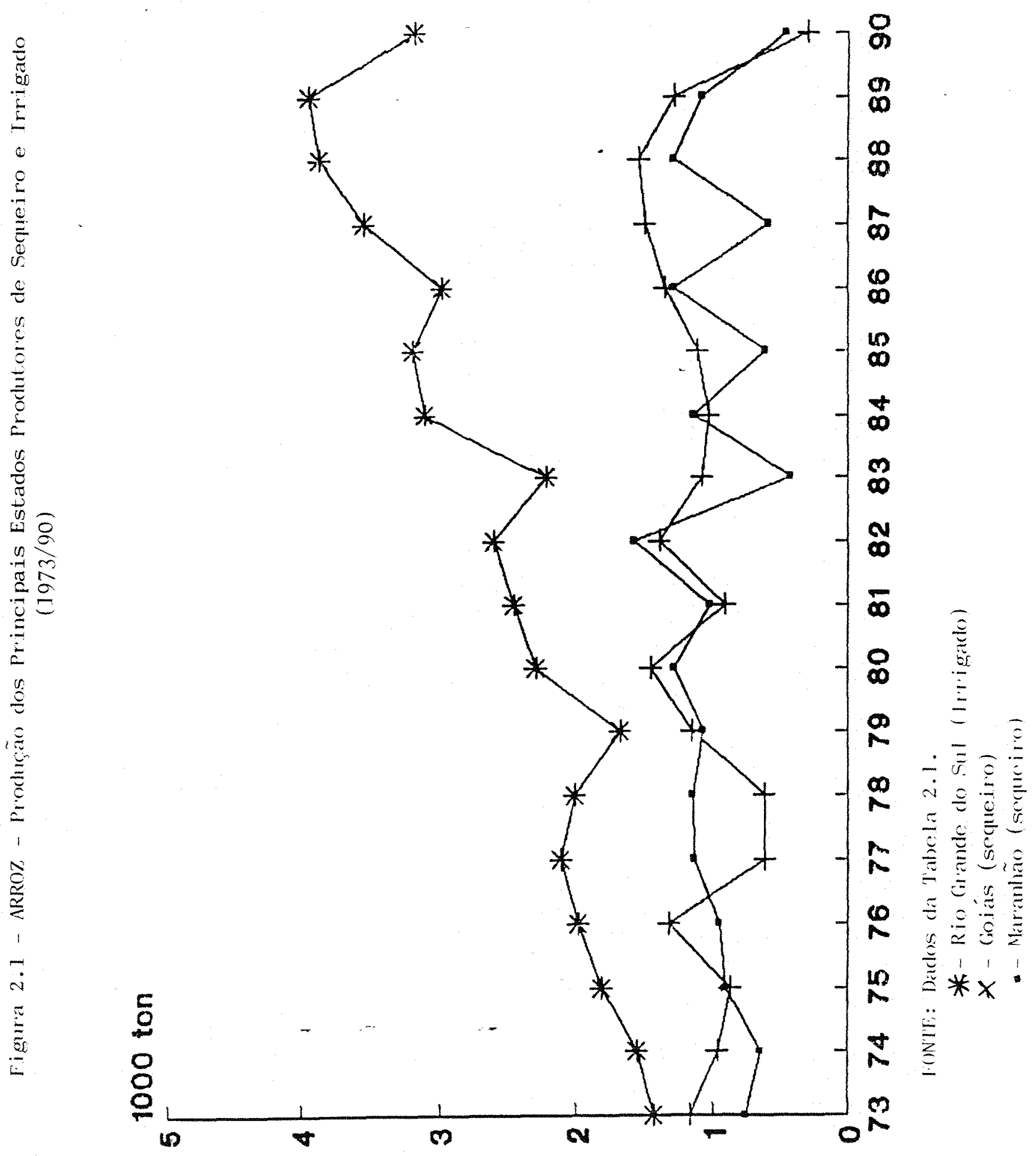
Tabela 2.2: ARROZ-Evolução da produção brasileira por região - 1973/90

\begin{tabular}{r|r|r|c|r|r|r}
\hline Ano & Brasil & Centro Oeste & Sul & Sudeste & Nordeste & Norte \\
\hline 1973 & $7.167,1$ & $1.948,8$ & $2.317,4$ & $1.641,6$ & $1.125,3$ & 134,0 \\
1974 & $6.764,0$ & $1.773,3$ & $2.453,4$ & $1.482,2$ & 909,2 & 145,9 \\
1975 & $7.781,5$ & $1.872,4$ & $2.946,9$ & $1.425,0$ & $1.292,0$ & 245,1 \\
1976 & $9.757,1$ & $2.947,2$ & $3.382,7$ & $1.929,4$ & $1.228,7$ & 269,0 \\
1977 & $8.993,7$ & $2.716,8$ & $3.342,8$ & $1.147,3$ & $1.493,5$ & 293,9 \\
1978 & $7.296,0$ & $2.021,1$ & $2.498,3$ & $1.068,2$ & $1.444,5$ & 263,9 \\
1979 & $7.595,2$ & $2.593,5$ & $2.221,5$ & $1.102,2$ & $1.343,7$ & 334,3 \\
1980 & $9.775,9$ & $3.147,3$ & $3.360,3$ & $1.395,8$ & $1.483,7$ & 388,8 \\
1981 & $8.228,3$ & $2.328,2$ & $3.353,1$ & $1.213,3$ & 899,2 & 434,5 \\
1982 & $9.734,5$ & $2.756,0$ & $3.221,2$ & $1.359,4$ & $1.980,7$ & 417,2 \\
1983 & $7.749,1$ & $2.334,3$ & $2.984,1$ & $1.569,5$ & 622,7 & 238,4 \\
1984 & $9.027,4$ & $2.104,4$ & $3.814,6$ & $1.174,3$ & $1.539,5$ & 394,7 \\
1985 & $9.024,5$ & $1.970,6$ & $3.949,8$ & $1.556,8$ & $1.138,7$ & 408,7 \\
1986 & $10.374,0$ & $2.438,5$ & $3.644,5$ & $1.722,5$ & $2.078,5$ & 507,6 \\
1987 & $10.435,1$ & $2.901,9$ & $4.409,1$ & $1.687,1$ & $1.019,4$ & 417,6 \\
1988 & $11.809,5$ & $2.863,7$ & $4.751,3$ & $1.605,7$ & $2.080,3$ & 508,4 \\
1989 & $11.043,2$ & $2.455,6$ & $4.830,4$ & $1.452,0$ & $1.782,3$ & 522,9 \\
1990 & $7.425,0$ & 914,7 & $4.022,1$ & $1.029,6$ & 855,3 & 603,3 \\
\hline & - & $-\cdots$ & & & &
\end{tabular}

Fonte: Fundação Instituto Brasileiro de Geografia e Estatistica - IBGE 
Tabela 2.3: ARROZ-Concentração da produção brasileira por região - 1973/90

\begin{tabular}{r|r|c|r|r|r}
\hline \multicolumn{1}{|c|}{ Ano } & Centro Oeste & Sul & Sudeste & Nordeste & Norte \\
\hline 1973 & 27,19 & 32,32 & 22,81 & 15,68 & 2,00 \\
1974 & 26,21 & 36,26 & 21,91 & 13,43 & 2,16 \\
1975 & 24,06 & 35,71 & 18,31 & 16,60 & 3,15 \\
1976 & 30,20 & 34,67 & 19,77 & 12,60 & 2,75 \\
1977 & 30,20 & 37,17 & 12,75 & 16,60 & 3,20 \\
1978 & 27,70 & 34,23 & 14,64 & 19,79 & 3,62 \\
1979 & 34,14 & 29,24 & 14,51 & 17,69 & 4,40 \\
1980 & 32,19 & 34,37 & 14,27 & 15,18 & 3,98 \\
1981 & 28,29 & 40,75 & 14,75 & 10,93 & 5,27 \\
1982 & 28,31 & 33,09 & 13,96 & 20,35 & 4,28 \\
1983 & 30,12 & 37,86 & 20,25 & 8,04 & 3,07 \\
1984 & 23,30 & 42,26 & 13,00 & 17,05 & 4,37 \\
1985 & 21,84 & 43,77 & 17,25 & 12,62 & 14,05 \\
1986 & 23,50 & 35,12 & 16,60 & 20,03 & 4,90 \\
1987 & 27,81 & 42,95 & 16,17 & 9,76 & 4,00 \\
1988 & 24,25 & 40,23 & 13,60 & 17,61 & 4,30 \\
1989 & 22,24 & 43,74 & 13,15 & 16,14 & 4,74 \\
1990 & 12,32 & 54,17 & 13,87 & 11,51 & 8,12 \\
\hline & & & & &
\end{tabular}

Fonte: Dados da Tabela 2.2. 


\subsection{Preços e abastecimento}

A importância do arroz como produto alimentar e/ou a necessidade de estabilizar a economia e controlar a inflação, tem levado o governo a intervir sistematicamente no mercado de arroz, através de políticas de comercialização, de tabelamentos, de importações e de política comercial de contingenciamento das exportações.

Estas políticas, segundo LOPES (1986), foram responsáveis pelo comportamento dos preços reais recebidos pelos produtores de arroz nos meses de safra (março a maio) nos últimos 20 anos, conforme mostrado na Tabela 2.4 e Figura 2.2 .

Observa-se que os preços recebidos sobem rapidamente atingindo um máximo em 1975 para então cair nos 2 (dois) anos subsequentes e voltar a subir atingindo em 1980 o nível do preço médio dos 5 (cinco) primeiros anos da série. A partir daí verifica-se uma queda constante dos preços recebidos que, após 1986, assume aspecto de derrocada.

Os preços mínimos reais do sequeiro apresentam comportamento semelhante até 1975 , para depois cair continuamente até 1980 . Da mesma forma o preço mínimo do irrigado, instituído em 1975, cai continuamente até 1980. De maneira geral, os preços mínimos reais na década de 70 apresentam-se em níveis bastante inferiores aos preços recebidos pelos rizicultores. Já nos anos 80, apesar da tendência decrescente dos preços recebidos, os preços mínimos estiveram muito próximos destes.

$\mathrm{Na}$ proposição de que a queda generalizada dos preços, nos anos 80 , espelharia os efeitos dos instrumentos da Política de Garantia de Preços Mínimos PGPM, a Tabela 2.5 mostra o comportamento das variáveis que refletem, em parte, estes efeitos: Aquisições do Governo Federal (AGFs), Empréstimos do Governo Federal (EGFs) e nível de preços.

Observa-se que na década de 70 os produtores recorreram mais à linha de crédito de comercialização do que às aquisições governamentais. Apenas nos anos de supersafra - 1976/77 - a política de preços mínimos serviu efetivamente para atenuar as flutuações de preços. Nestes anos, as AGFs, representaram $6,7 \%$ e $13 \%$ da produção, respectivamente.

O fato dos preços mínimos, até a safra 1981/82, serem definidos 2 (dois) mèses antes do plantio, embutindo-se no preço uma expectativa de inflação geralmente subestimada, que não sofria qualquer correção até o início da colheita, quando então entrava em vigor, destituia-o da função de apoio ao produtor, o que explica a não utilização das AGFs pelos produtores. 
A intervenção do governo no mercado de arroz na década de 70 deu-se através de sistemáticas colocaçòes do produto em regime de tabelamento.

No primeiro quinquênio da década de 80 a unificação dos preços mínimos em todo o território nacional e indexados à inflação a partir da safra 1981/82, e a preferência pelas AGFs, em vez do mero financiamento da comercialização privada - EGFs, foram os instrumentos utilizados pelo governo, na tentativa de solucionar problemas de abastecimento interno, instituindo-se o que LOPES (1983) chamou de "risco institucional": os preços mínimos passaram a determinar os preços de mercado com pequenas variações acima e abaixo deste, conforme mostrado na Figura 2.2 .

Já no segundo quinquênio da década de 80 , o efeito da combinação de 2 (duas) grandes safras consecutivas (1985/86 e 1986/87) com as elevadas importações permitidas no período do Plano Cruzado, e as restrições às exportações, forçaram o governo a formar estoques em níveis cada vez maiores a cada safra, os quais passaram a pressionar forternente o mercado e, sem dúvida, foram eles os maiores responsáveis pela vertiginosa derrocada dos preços mostrado na Figura 2.2 .

Os níveis crescentes das AGFs, que atingiram $27,2 \%$ da produção em 1987 (Tabela 2.5), extrapolaram em muito o objetivo de uma Política de Estoques Reguladores de estabilizar preços entre anos. Tanto assim que muitas vezes os preços, na safra, apresentaram-se superiores aos da entressafra, inviabilizando em definitivo a armazenagem privada.

O perfil do abastecimento interno de arroz ao longo das duas últimas décadas é mostrado na Tabela 2.6. No período compreendido entre as safras 1970/71 a 1979/80, ou seja, antes da reforma da PGPM (financiamentos de custeio desvinculado dos preços mínimos a partir da criação dos Valores Básicos de Custeio - VBC), a produção e consumo médios de arroz giravam em torno de 7,0 milhões de toneladas, mostrando o Brasil como esporádico importador.

Nas seis safras subsequentes, já sob a égide da nova PGPM e antes do "Plano Cruzado", para um consumo médio de 9,1 milhões de toneladas, a produção apresenta-se estagnada em torno de 8,8 milhões de toneladas, passando o país a caracterizar-se como importador de arroz.

Produção e consumo médios das safras 1985/86 a 1988/89, em torno de 10,8 e 10,4 milhões_de toneladas, já poderiam caracterizar o Brasil como exportador. Em consequência da política de contingenciamento das exportaçôes, no final da safra $88 / 89$ existia um excedente de aproximadamente 4,5 milhões de toneladas, ou seja, $45 \%$ do consumo médio anual da década. 
Tabela 2.4: ARROZ-Preços médios reais recebidos pelos produtores e preços mínimos reais, na safra (março a maio) - 1971/90

\begin{tabular}{r|r|r|r}
\hline \multirow{2}{*}{ ANO } & \multicolumn{1}{|c|}{$\begin{array}{c}\text { Preços } \\
\text { Recebidos }(1)\end{array}$} & \multicolumn{2}{|c}{$\begin{array}{r}\text { Preço Mínimo (1) } \\
(\mathrm{Cr} \$ / \mathrm{kg})\end{array}$} \\
\cline { 3 - 4 } & (Cr\$ $\$ \mathrm{~kg})$ & sequeiro & irrigado \\
\hline 1971 & 88,07 & 62,59 & nd \\
1972 & 97,67 & 70,43 & nd \\
1973 & 91,68 & 82,92 & nd \\
1974 & 105,20 & 81,08 & nd \\
1975 & 147,18 & 99,10 & 109,53 \\
1976 & 103,45 & 89,46 & 99,54 \\
1977 & 79,88 & 85,91 & 95,30 \\
1978 & 97,54 & 82,24 & 90,50 \\
1979 & 107,51 & 78,80 & 87,46 \\
1980 & 114,86 & 73,45 & 96,40 \\
1981 & 82,08 & 75,01 & 83,34 \\
1982 & 99,04 & 76,14 & 91,29 \\
1983 & 87,47 & 68,23 & 81,73 \\
1984 & 83,68 & 71,47 & 85,62 \\
1985 & 89,93 & 93,60 & 111,29 \\
1986 & 89,06 & 81,17 & 94,64 \\
1987 & 50,71 & 57,11 & 66,61 \\
1988 & 49,16 & 57,11 & 66,61 \\
1989 & 56,25 & 54,16 & 54,16 \\
1990 & 37,79 & 37,16 & 37,16 \\
\hline & & &
\end{tabular}

Fonte: Companhia Nacional de Abastecimento - CONAB

(1) Preços em cruzeiros de maio de 1991, corrigidos pelo Índice Geral de Preços - Disponibilidade Interna (IGP-DI) da Fundação Getúlio Vargas. 


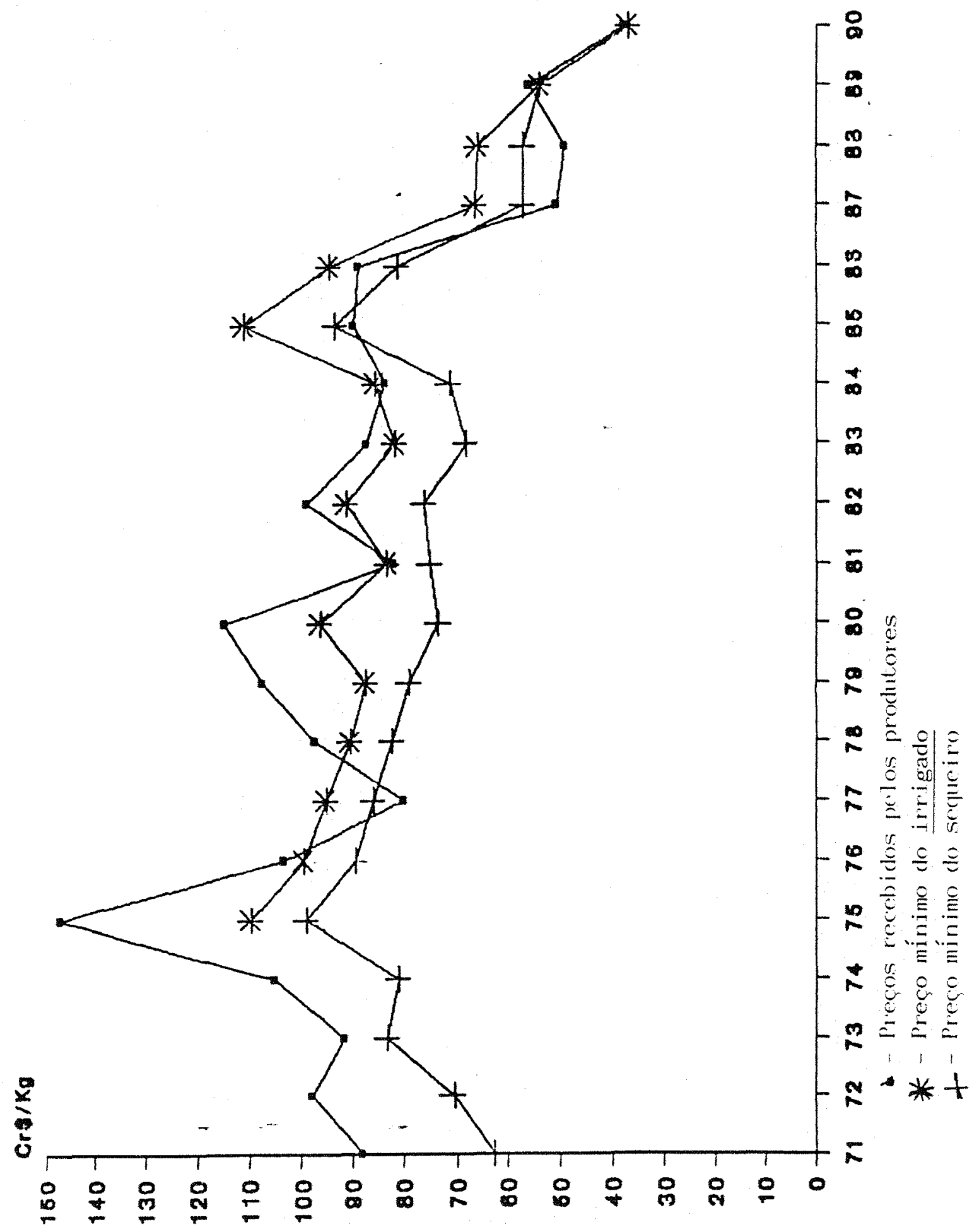


Tabela 2.5: ARROZ-Aquisições do Governo Federal (AGFs), Emprestimos do Governo Federal (EGFs) e nível de preços - 1971/90

\begin{tabular}{l|r|r|r|r|r|r|r}
\hline \multirow{2}{*}{ Ano } & Produção & \multicolumn{2}{|c|}{ AGFs } & \multicolumn{2}{|c|}{ EGFs } & \multicolumn{2}{|c}{$P_{\text {rec }} / P_{\min }$} \\
\cline { 2 - 8 } & \multicolumn{1}{c|}{$(\mathrm{t})$} & \multicolumn{1}{c|}{$(\mathrm{t})$} & \multicolumn{1}{c|}{$\%$} & \multicolumn{1}{c|}{$(\mathrm{t})$} & $\%$ & sequeiro & irrigado \\
\hline 1971 & 6.593 .179 & 14.122 & 0 & 422.069 & 6,4 & 1,41 & - \\
1972 & 7.824 .231 & - & - & 648.967 & 8,3 & 1,39 & - \\
1973 & 7.167 .145 & 12.162 & 0 & 724.967 & 10,1 & 1,11 & - \\
1974 & 6.764 .038 & 6.548 & 0 & 603.765 & 8,9 & 1,30 & - \\
1975 & 7.781 .537 & 3.115 & 0 & 806.824 & 10,4 & 1,49 & 1,34 \\
1976 & 9.757 .079 & 649.302 & 6,7 & 1.929 .500 & 19,8 & 1,16 & 1,04 \\
1977 & 8.993 .696 & 1.169 .974 & 13,0 & 1.347 .686 & 15,0 & 0,93 & 0,84 \\
1978 & 7.296 .042 & 156.076 & 2,1 & 780.930 & 10,7 & 1,19 & 1,08 \\
1979 & 7.595 .214 & 110.871 & 1,4 & 842.658 & 11,1 & 1,36 & 1,23 \\
1980 & 9.775 .920 & 221.868 & 2,3 & 1.504 .954 & 15,4 & 1,56 & 1,19 \\
1981 & 8.228 .326 & 800.040 & 9,7 & 1.370 .704 & 16,6 & 1,09 & 0,98 \\
1982 & 9.734 .552 & 733.343 & 7,5 & 1.751 .428 & 18,0 & 1,30 & 1,08 \\
1983 & 7.749 .072 & 501.142 & 6,5 & 2.009 .008 & 25,9 & 1,28 & 1,07 \\
1984 & 9.027 .363 & 664.534 & 7,4 & 940.938 & 10,4 & 1,17 & 0,98 \\
1985 & 9.024 .555 & 1.513 .822 & 16,8 & 1.850 .923 & 20,5 & 0,97 & 0,81 \\
1986 & 10.374 .030 & 1.774 .555 & 17,1 & 3.568 .291 & 34,4 & 1,13 & 0,94 \\
1987 & 10.435 .100 & 2.837 .377 & 27,2 & 3.138 .564 & 30,1 & 0,89 & 0,81 \\
1988 & 11.809 .467 & 2.231 .727 & 18,9 & 3.651 .114 & 30,9 & 0,94 & 0,78 \\
1989 & 11.043 .228 & 891.158 & 8,1 & & $\ldots$ & 1,04 & 1,04 \\
1990 & 7.425 .056 & 1.927 .070 & 26,0 & & $\ldots$ & 1,02 & 1,02 \\
\hline
\end{tabular}

Fonte: Companhia Nacional de Abastecimento - CONAB 
Tabela 2.6: ARROZ-Estimativas de Suprimento (safras 1970/71 a 1989/90)(1)

\begin{tabular}{|c|c|c|c|c|c|c|c|c|}
\hline & & & & & & & & 1000 ton \\
\hline Safra & $\begin{array}{l}\text { Estoque } \\
\text { Inicial }(2)\end{array}$ & Produção & Importação & Suprimento & Consumo & Excedente & Exportaç̃̃o & $\begin{array}{c}\text { Estoque } \\
\text { Final }\end{array}$ \\
\hline $1970 / 71$ & 523,40 & $5.129,50$ & 2,00 & - & $5.245,00$ & - & 410,10 & - \\
\hline $1971 / 72$ & 5,70 & $5.825,00$ & 1,40 & . & $5.841,50$ & - & 2,80 & - \\
\hline $1972 / 73$ & 1,10 & $6.300,00$ & 16,10 & . & $6.268,00$ & . & 49,00 & . \\
\hline $1973 / 74$ & 108,70 & $6.100,00$ & 0,5 & - & $6.126,00$ & . & 83,20 & - \\
\hline $1975 / 76$ & - & $9.500,00$ & . & $9.500,00$ & $7.900,00$ & $1.600,00$ & . & $1.600,00$ \\
\hline $1976 / 77$ & $1.600,00$ & $8.478,00$ & - & $10.078,00$ & $8.000,00$ & $2.078,00$ & 602,00 & $1.476,00$ \\
\hline $1977 / 78$ & $1.476,00$ & $7.417,00$ & 42,00 & $8.935,00$ & $8.200,00$ & 735,00 & 216,00 & 519,00 \\
\hline $1978 / 79$ & 519,00 & $7.570,00$ & $1.033,00$ & $9.122,00$ & $8.385,00$ & 737,00 & . & 737,00 \\
\hline $1983 / 84$ & 647,30 & $8.991,00$ & 91,00 & $9.729,30$ & $9.200,00$ & 529,30 & 2,0 & 527,30 \\
\hline $1984 / 85$ & 527,30 & $8.760,00$ & 500,00 & $9.787,30$ & $9.660,00$ & 127,30 & 5,0 & 122,30 \\
\hline $1985 / 86$ & 122,30 & $9.813,00$ & $2.074,00$ & $12.009,30$ & $10.240,00$ & $1.769,30$ & 6,0 & $1.763,30$ \\
\hline $1986 / 87$ & $1.763,30$ & $10.578,00$ & 235,00 & $12.576,30$ & $10.000,00$ & $2.576,30$ & 5,0 & $2.571,30$ \\
\hline $1987 / 88$ & $2.571,30$ & $11.762,20$ & 190,00 & $14.523,50$ & $10.500,00$ & $4.023,50$ & 10,00 & $4.013,50$ \\
\hline $1988 / 89$ & $4.013,50$ & $11.092,00$ & 200,00 & $15.305,50$ & $10.800,00$ & $4.505,50$ & 10,00 & $4.495,50$ \\
\hline $1989 / 90$ & $4.495,50$ & $7.967,60$ & 800,30 & $13.263,40$ & $11.000,00$ & 2. 263,40 & 10,00 & $2.253,40$ \\
\hline
\end{tabular}

Fontes:

Comissão de Financiamento da Produção-CFP.

1970/71 a 1975/76: Preços mínimos: Regiões centro-oeste,sudeste e sul. Brasilia,CFP.1975 1976/77 a 1979/80: Relatório anual da CFP (vários) 1980/81 a 1989/90: Boletim Informativo CFP . abril/91

(1) No período compreendido entre as safras de 1970/71 a 1975/76 a metodologia de apuração dos dados era outra o que explica a ausência de algumas informações.

(2) Até 1975/76 os dados referem-se à variação dos estoques. A partir daí referem-se ao estoque inicial do dia primeiro de março do ano da colheita da respectiva safra. 


\subsection{Armazenamento}

A armazenagem do arroz pode ser feita tanto em casca como beneficiado. A primeira forma é tradicionalmente mais utilizada devido às características peculiares do grão (fragilidade), não podendo ser submetido a choques e velocidades.

Neste caso, o produto é armazenado em sacaria de juta, não apresentando problemas maiores quanto à conservação, sendo comum a estocagem por 2 (dois) anos. Quando armazenado beneficiado, invariavelmente, após 6 (seis) meses necessita de novo polimento para ser comercializado (YAMAGUISHI et alli, 1984).

Antes de ser armazenado o produto tem que ser sêco, o que pode ser feito a nível de propriedade, ou na própria unidade armazenadora, o que é mais comum. $\mathrm{O}$ arroz irrigado apresenta em média, $20 \%$ de umidade e a quebra média de peso com a secagem é de 5 a $10 \%$. No caso do sequeiro, a umidade é de aproximadamente $12 \%$ (PORTO, 1986).

Para efeito desse estudo, a prestação do serviço de armazenagem é definida como envolvendo as operações de recepção/braçagem, armazenamento/conservação e expedição/braçagem. 


\section{Capítulo 3}

\section{Metodologia}

\subsection{Teoria da Armazenagem Competitiva sob Con- dições de Incerteza}

As bases, fundamentos e representações algébricas e gráficas da Teoria da Armazenagem Competitiva, desenvolvida por HELMBERGER \& WEAVER (1977) a seguir apresentadas, encontram-se fundamentalmente em BARROS (1987).

Admite -se que para um ano $t$ qualquer, o mercado de determinado produto agrícola armazenável seja representado pelas seguintes equações:

$$
\begin{gathered}
D_{t}=\alpha_{0}-\alpha_{1} P_{t}+U_{t} \\
S_{t}=\beta_{0}-\beta_{1} P_{t}^{*}+V_{t} \\
D_{t}=S_{t}-I_{t-1}+I_{t}=0
\end{gathered}
$$

Onde $D_{t}$ e $S_{t}$ săo as quantidades demandadas e ofertadas respectivamente; $P_{t}$ é o preço unitário do produto no período $t ; P_{t}^{*}$ é o preço esperado na época do plantio; $\alpha_{0}, \alpha_{1}, \beta_{0}$ e $\beta_{1}$ são parâmetros positivos e $U_{t}$ e $V_{t}$ são variáveis exógenas estocásticas, independentes entre si, com valores esperados iguais a zero (deslocadores das duas curvas).

A equação (3.3) representa a condição de equilíbrio de mercado, onde $I_{t-1}$ é o estoque no início do período "carryin" e $I_{t}$ o estoque no final do período "carryout".

Assumindo a pressuposição de expectativas racionais, conforme MUTH 
(1961), tem-se que os produtores esperam um preço $P_{t}^{*}$ igual à esperança do preço (no sentido estatístico), a se estabelecer através do equilíbrio de mercado, ou seja, $P_{t}^{*}=E\left(P_{t}\right)$. Substituindo (3.1) e (3.2) em (3.3) e tomando a esperança obtém-se:

$$
P_{t}^{*}=\frac{1}{\alpha_{1}+\beta_{1}}\left[\alpha_{0}-\beta_{0}-E\left(I_{t-1}\right)+E\left(I_{t}\right)\right]
$$

Sem armazenamento, o valor de $P_{t}^{*}$ é imediatamente determinado para todo $t$. Com armazenamento, $P_{t}^{*}, E\left(I_{t-1}\right)$ e $E\left(I_{t}\right)$ são determinados simultaneamente, mostrando que o equilíbrio competitivo no ano $t$ é afetado pela "performance" do mercado nos anos passados e pela "performance" esperada para os anos futuros.

Conhecido o estoque inicial referente ao ano $t$, a substituição de sua esperança pelo valor observado levará a duas situações distintas no que se refere a determinação de $P_{t}^{*}$, quais sejam:

CASO 1: $I_{t-1}=0$. Se não há estoque inicial, $E\left(I_{t}\right)$ é também igual a zero e através de (3.4) tem-se que:

$$
P_{t}^{*}=P^{*}=\frac{\alpha_{0}-\beta_{0}}{\alpha_{1}+\beta_{1}}
$$

A afirmativa de que se $I_{t-1}=0$, então $E\left(I_{t}\right)=0$, pode ser entendida através do seguinte raciocínio: na possibilidade de $I_{t-1}=0$ e $E\left(I_{t}\right)>0$, então, face a expectativa de retirada do produto no ano $t$, tem-se $P_{t}^{*}>P^{*}$. Por outro lado, no ano $t+1, P_{t+1}^{*}<P^{*}$, face a expectativa de aumento nas disponibilidades deste ano. Estas duas condições implicam em $P_{t+1}^{*}<P_{t}^{*}$ e não seria lucrativo transferir o produto de um ano para outro, mesmo ao custo de armazenamento zero. Assim, $I_{t-1}=0$ implica em $E\left(I_{t}\right)=0$ também. Não haverá situação potencial ou demanda de produtos para armazenamento. Neste caso, $P_{t}^{*}$ será uma constante igual ao preço que simplesmente iguala a demanda esperada, $E\left(D_{t}\right)$ à oferta esperada $E\left(S_{t}\right)$ conforme (3.5).

CASO 2: $I_{t-1}>0$. Se existe estoque inicial então:

$$
-P_{-t}^{*}=\frac{1}{\alpha_{1}+\beta_{1}^{-}}\left[\alpha_{0}-\beta_{0}-I_{t-1}+E\left(I_{t}\right)\right]
$$

Ou seja, a determinação de $P_{t}^{*}$ depende da relação entre $I_{t-1}$ e $E\left(I_{t}\right)$, isto é, entre o estoque inicial e o estoque final esperado. Mas, por sua vez, o estoque final esperado depende da relação entre oferta e demanda esperadas de produtos para armazenamento, mostrando que, neste caso, $P_{t}^{*}$ pode ser determinado através 
destas funções e não pelas tradicionais funções de produção e demanda para consumo imediato.

\subsubsection{Demanda de Produtos para Armazenamento}

Conceitua-se demanda de produtos para armazenamento no periodo 1 como a soma das quantidades de produtos demandadas para armazenamento com liberações previstas para os períodos subsequentes. Fazendo $i_{1 t}$ igual a quantidade de produtos armazenados tomada no primeiro período, com liberação prevista para o t-ésimo periodo, sendo $t>1$ e $I_{1}^{d}$ a quantidade total de produtos demandada para armazenamento no primeiro período, pela definição tem-se que:

$$
I_{1}^{d}=i_{12}+i_{13}+i_{14}+\cdots
$$

Armazenamento no primeiro período provoca queda no preço esperado para o segundo período e, possivelmente, nos preços dos períodos subsequentes e preços baixos no primeiro período viabiliza a armazenagem para liberaçăo em um número sucessivamente maior de períodos. Se não houver expectativa de armazenamento para o período 2 o preço esperado para esse período será $P^{*}$, caso dado em $(3.5)$.

Observado o preço $P_{1}$ no período 1 e sendo $\mathrm{C}$ o custo unitário constante de armazenamento por período,não será lucrativo armazenar se $P^{*}-P_{1} \leq C$, ou seja: $I_{1}^{d}=0 ; P_{1} \geq P^{*}-C$

Será lucrativo armazenar do período 1 para o período 2 , se $P^{*}-P_{1} \geq C$. A oportunidade de lucro cessa quando $P_{2}^{*}-P_{1}=C$, sendo $P_{2}^{*}$ o preço esperado para o período 2 na presença de armazenamento. Se além de $P^{*}-P_{1} \geq C$, ocorrer também $P^{*}-P_{1}<2 C$, não será lucrativo armazenar para os demais períodos, pois $P^{*}$ é também igual a $P_{3}^{*}$, quando $E\left(I_{2}\right)=E\left(I_{3}\right)=0$. Então, se $P^{*}-2 C \leq P_{1}<$ $P^{*}-C, I_{1}^{d}=i_{12}$ e $i_{1 t}=0$ para todo $t \geq 3$. Além disso se $P_{2}^{*}=P^{*}$, a oferta e demanda esperadas para o segundo período são iguais não existindo demanda de produtos para armazenamento.

É a queda nos preços esperados para o período 2 que aumenta a diferença entre quantidades de ofertas e demandas e cria uma demanda de produtos para armazenamento. Assim,

$$
I_{1}^{d}=i_{12}=E\left(D_{2}\right)-E\left(S_{2}\right)
$$




$$
=\left(\alpha_{0}-\beta_{0}\right)-\left(\alpha_{1}+\beta_{1}\right) \bar{P}_{2}^{*}
$$

No caso de $P_{2}^{*}-C=P_{1}$, não há expectativa de lucro com armazenamento para liberação além do segundo período. A demanda de produtos para armazenamento no primeiro período para liberação no segundo período é dada por:

$$
I_{1}^{d}=\left(\alpha_{0}-\beta_{0}\right)-\left(\alpha_{1}+\beta_{1}\right)\left(P_{1}+C\right) ; P^{*}-2 C \leq P_{1}<P^{*}-C
$$

Será lucrativo armazenar também para o terceiro período e não para os demais se $P^{*}-3 C \leq P_{1}<P^{*}-2 C$. Por outro lado, $P_{1}=P_{2}^{*}-C=P_{3}^{*}-2 C$ é a condição a partir da qual armazenamento para liberação nos períodos 2 e 3 passa a não ser lucrativo. A demanda de produtos para armazenamento conjunto, nos dois períodos é dado por:

$$
\begin{aligned}
I_{1}^{d}=i_{12}+i_{13} & =\left[E\left(D_{2}\right)-E\left(S_{2}\right)\right]+\left[E\left(D_{3}\right)-E\left(S_{3}\right)\right] \\
& =\left[\left(\alpha_{0}-\beta_{0}\right)-\left(\alpha_{1}+\beta_{1}\right) P_{2}^{*}\right]+\left[\left(\alpha_{0}-\beta_{0}\right)-\left(\alpha_{1}+\beta_{1}\right) P_{3}^{*}\right]
\end{aligned}
$$

$$
I_{1}^{d}=2\left(\alpha_{0}-\beta_{0}\right)-2\left(\alpha_{1}+\beta_{1}\right) P_{1}-3\left(\alpha_{1}+\beta_{1}\right) C ; P^{*}-3 C \leq P_{1} \leq P^{*}-2 C
$$

Generalizando, a demanda de produtos para armazenamento no primeiro período, para liberação em cada um dos n-1 períodos subsequentes é igual a:

$$
\begin{aligned}
I_{1}^{d} & =(n-1)\left(\alpha_{0}-\beta_{0}\right)-(n-1)\left(\alpha_{1}+\beta_{1}\right) P_{1}-\left(\alpha_{1}+\beta_{1}\right) C \sum_{t=2}^{n}(t+1) \\
P^{*}-n C & \leq P_{1}<P^{*}-(n-1) C
\end{aligned}
$$

Ou seja, a demanda de produtos para armazenamento no primeiro período é uma linha quebrada nos pontos de ordenadas $\left(P^{*}-C\right),\left(P^{*}-2 C\right),\left(P^{*}-3 C\right)$, ..., etc, consistindo em um número-finito de funçōes lineares, cada uma restrita à sua própria faixa de valores.

A derivação gráfica das funções $(3.7),(3.8)$ e (3.10) é mostrada na Figura 3.1. As curvas de oferta e demanda esperadas para o período $2-E\left(S_{2}\right)$ e $E\left(D_{2}\right)$ - aparecem invertidas a esquerda do eixo vertical, pois as quantidades são medidas 
da direita para a esquerda a partir do ponto 0 . O gráfico da função (3.7) $-R_{1}-$ é obtido subtraindo-se lateralmente $E\left(S_{2}\right)$ de $E\left(D_{2}\right)$ para preços inferiores a $P^{*} \mathrm{e}$ plotando-se as diferenças positivas à direita do eixo vertical. A função (3.8) - $D i_{12}$ - é obtida pela subtração vertical de $C$ a partir de $R_{1_{2}}$ levando-se em consideração as restrições dessa faixa de aplicabilidade. $D i_{13}$ é a representação gráfica da função (3.10) obtida por processo análogo ao da função (3.8), apenas respeitando os limites de sua faixa de valores.

Figura 3.1: Derivação gráfica da. Demanda de Produtos para Armazenamento

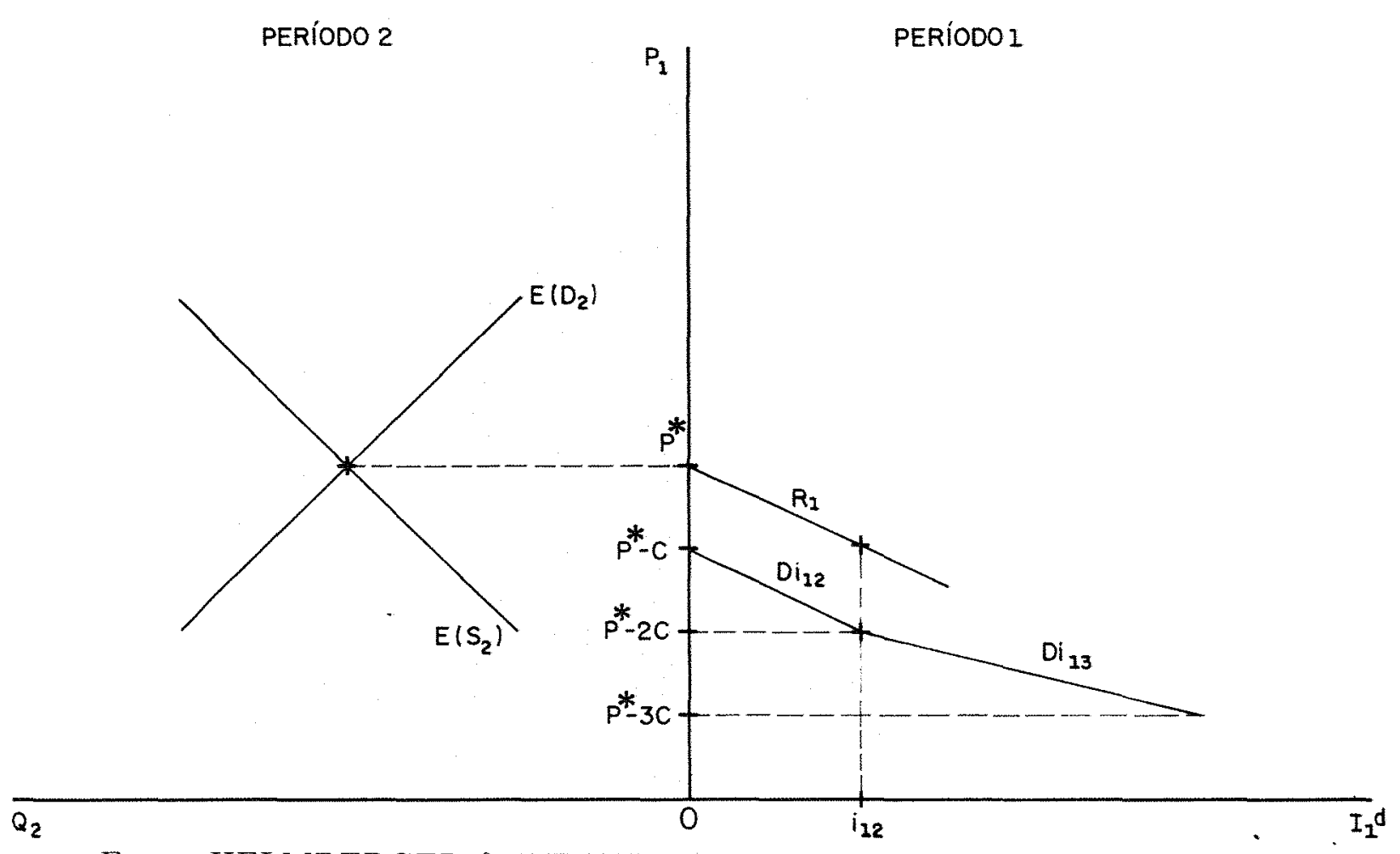

Fonte: HELMBERGER \& WEAVER (1977) 


\subsubsection{Oferta de Produtos para Armazenamento}

Por definição, a oferta de produtos para armazenamento - $I_{1}^{S}$ - relaciona as quantidades excedentes do produto a diferentes níveis alternativos de preços no primeiro período $\left(P_{1}\right)$ e é derivada da expressão:

$$
I_{1}^{S}=Q_{10}-D_{1} ; \quad P_{1} \geq P_{10} \text { e } D_{1} \geq 0
$$

onde $Q_{10}$ é a quantidade máxima a ser produzida para que não ocorra excedente e $P_{10}$ o preço ao qual toda a produção será consumida.

No CASO $1, I_{0}=E\left(I_{1}\right)=0$, o preço esperado para o período 1 é igual a $P^{*}$ conforme dado em (3.5). A substituição de (3.5) em (3.2) determina a quantidade máxima a ser produzida nesse periodo, qual seja:

$$
S_{1}=Q_{10}=\frac{\alpha_{1} \beta_{0}+\alpha_{0} \beta_{1}}{\alpha_{1}+\beta_{1}}+V_{1}
$$

Igualando (3.12) a (3.1) tem-se a expressão para o preço observado:

$$
P_{10}=\frac{\alpha_{0}-\beta_{0}}{\alpha_{1}+\beta_{1}}+\frac{\left(U_{1}-V_{1}\right)}{\alpha_{1}}
$$

Pela definição de oferta de produtos para armazenamento e dado (3.12) e (3.13) tem-se que:

$$
\begin{gathered}
I_{1}^{S}=\alpha_{1}\left(P_{1}-P_{10}\right) ; \quad P_{10} \leq P_{1}<\frac{\alpha_{0}+U_{1}}{\alpha_{1}} \\
I_{1}^{S}=Q_{10} ; \quad P_{1} \geq \frac{\alpha_{0}+U_{1}}{\alpha_{1}}
\end{gathered}
$$

onde $P_{1}<\frac{\alpha_{0}+U_{1}}{\alpha_{1}}$, corresponde ao intervalo em que $D_{1}>0$.

No CASO $2, I_{0} \geq 0$, a oferta (esperada) de produtos para armazenamento (sendo o termo esperado entre parênteses devido à presença de $P_{1}^{*}$ na fórmula), é obtida a partir de (3.3):

$$
I_{1}^{S}=\beta_{0}-\beta_{1} P_{1}^{*}+V_{1}+I_{0}-\alpha_{0}+\alpha_{1} P_{1}-U_{1} ; \quad P_{1} \leq \frac{\alpha_{0}+U_{1}}{\alpha_{1}}
$$




$$
I_{1}^{S}=\beta_{0}+\beta_{1} P_{1}^{*}+I_{0}: \quad P_{1} \geq \frac{\alpha_{0}+U_{1}}{\alpha_{1}}
$$

A derivaçào gráfica da oferta de produtos para armazenamento é mostrada na Figura 3.2 . $I_{1}^{S}$ é obtida subtraindo-se lateralmente $D_{1}$ da linha vertical pontilhada, $Q_{10}$.

Figura 3.2: Derivação gráfica da Oferta de Produtos para Armazenamento

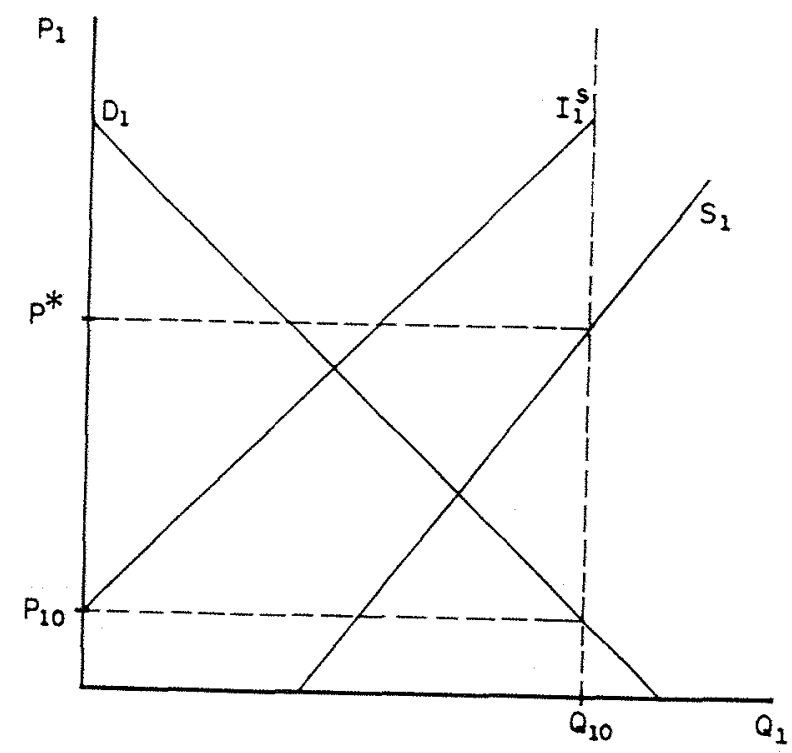

Fonte: HELMBERGER \& WEAVER - 1977 


\subsubsection{Equilíbrio Competitivo e Formação de Preços}

Se ocorre armazenamento, o equilíbrio competitivo entre oferta e demanda de produtos para armazenamento, é dado por: $I_{1}^{S}=I_{1}^{d}=I_{1}$. O equilíbrio pode ser encontrado graficamente ou pelo método de tentativa e erro.

No CASO 1 , ou seja, não há estoque inicial, dados $U_{1}$ e $V_{1}$ verifica-se a produção $Q_{10}$ que passa a ser tomada como fixa. As decisões quanto a oferecer o produto para armazenamento passam a ser tomadas com base em $P_{10}$ e nos preços esperados para os períodos seguintes. Se $I_{0}=0, P_{1}^{*}=P^{*}$, isto é, prevalecerá o preço que iguala oferta e demanda esperadas.

A Figura 3.3 mostra o equilíbrio competitivo e a formação de preços, para um horizonte de 3 períodos, quando $I_{0}=0$. Como $\bar{D}_{2}$ e $\bar{S}_{2}$ são as quantidades que se espera sejam produzidas e consumidas no período 2 , a diferença entre elas $\left(i_{12}\right)$ representa o "déficit" do período, ou seja, a quantidade a ser retirada do armazém para consumo no período 2. No período 3, o "déficit" de produção - $\left[E\left(S_{3}\right)-E\left(D_{3}\right)\right]$ - é menor que o anterior, mostrando que a interação das forças do mercado tende ao equilíbrio.

$\mathrm{Na}$ medida em que se considera níveis positivos e crescentes de $I_{0}$, passa-se a ter expectativa de "superávit" no mercado e, portanto, de preços decrescentes. Do ponto de vista da oferta de produtos para armazenamento interessa, em particular, o nivel de $I_{0}$ a partir do qual menores valores de $P_{1}^{*}$ conduzem a níveis positivos de $E\left(I_{1}\right)$. Esse ponto corresponde ao valor de $P_{1}^{*}$ que anula $I_{1}^{d}$, ou seja quando, $P_{1}^{*}=P^{*}-C$.

O nível de $I_{0}$ que faz com que $P_{1}^{*}=P^{*}-C$ e, logo, $E\left(I_{1}\right)=0$, é dado por:

$$
E\left(D_{1}\right)-E\left(S_{1}\right)-I_{0}=0
$$

Especificamente para $P_{1}^{*}=P^{*}-C$ tem-se, $\alpha_{0}-\alpha_{1}\left(P^{*}-C\right)-\beta_{0}-\beta_{1}\left(P^{*}-\right.$ C) $-I_{0}=0$, que resulta em:

$$
I_{00}=\left(\alpha_{0}-\beta_{0}\right)-\left(\alpha_{1}+\beta_{1}\right) P^{*}+\left(\alpha_{1}+\beta_{1}\right) C
$$

ou, usando (3.5).

$$
I_{00}=\left(\alpha_{1}+\beta_{1}\right) C
$$


Ou seja, $I_{00}$ representa o nivel de estoque inicial que faz com que não haja expectativa de "superávit" para o final do período.

Para valores de $I_{0}$ tais que $0<I_{0} \leq I_{00}$, oferta e demanda esperadas não se cruzam, não há expectativa de armazenamento. Um aumento (decréscimo) em $I_{0}$, desloca $E\left(S_{1}\right)+I_{0}$, e $E\left(I_{1}^{S}\right)$ para a direita (esquerda) e, desta maneira, $E\left(I_{1}^{S}\right)$ cortará o eixo vertical acima de $E\left(I_{1}^{d}\right)$. Neste caso, o equilíbrio competitivo esperado é dado pela interseç̧ão de $E\left(D_{1}\right) \operatorname{com} E\left(S_{1}\right)+I_{0}$ e o preço esperado para o período 1 será:

$$
P_{1}^{*}=\frac{\alpha_{0}-\beta_{0}-I_{0}}{\alpha_{1}+\beta_{1}}
$$

e,

$$
Q_{10}=S_{1}+I_{0}
$$

Com $S_{1}$ obtido em (3.2) usando (3.20) e $P_{10}$ obtido usando (3.1) dado $(3.21)$.

Neste caso, $\left(I_{0} \leq I_{00}\right)$, a oferta de produtos para armazenamento é dada por (3.14) e (3.15). Para tanto substituem-se (3.20) em (3.16) e (3.17)

A Figura 3.4 mostra o equilíbrio competitivo e a formação de preços para o caso de $I_{0}>0$, mas são suficientemente grande para gerar $E\left(I_{1}\right)$ pois, $I_{0} \leq I_{00}$. Note-se que $P^{*}$ cai para $P_{1}^{*}$ tornando a armazenagem lucrativa.

No caso de $I_{0}>I_{00}, P_{1}^{*}$ é determinado pelo equilíbrio entre oferta e demanda esperadas de produtos para armazenamento. $P_{1}^{*}$ é obtido por tentativa, igualando-se o valor esperado de (3.16) e (3.17) ao valor esperado de (3.11) - $E\left(I_{1}^{d}\right)$ - para diferentes valores de $n$ até que o valor encontrado para $P_{1}$ caia no intervalo desejado.

Graficamente a Figura 3.5 mostra o equilíbrio competitivo e a formação de preços para o caso de $I_{0}>I_{00}$. Neste caso o valor de $I_{0}$ é grande o suficiente para que, antecipadamente, já ocorra armazenamento para o período seguinte. A queda nos preços esperados, consequência de um efetivo "superávit" no mercado, faz com que $P_{1}^{*}$ seja menor que $\ddot{P}^{*}-C$. 


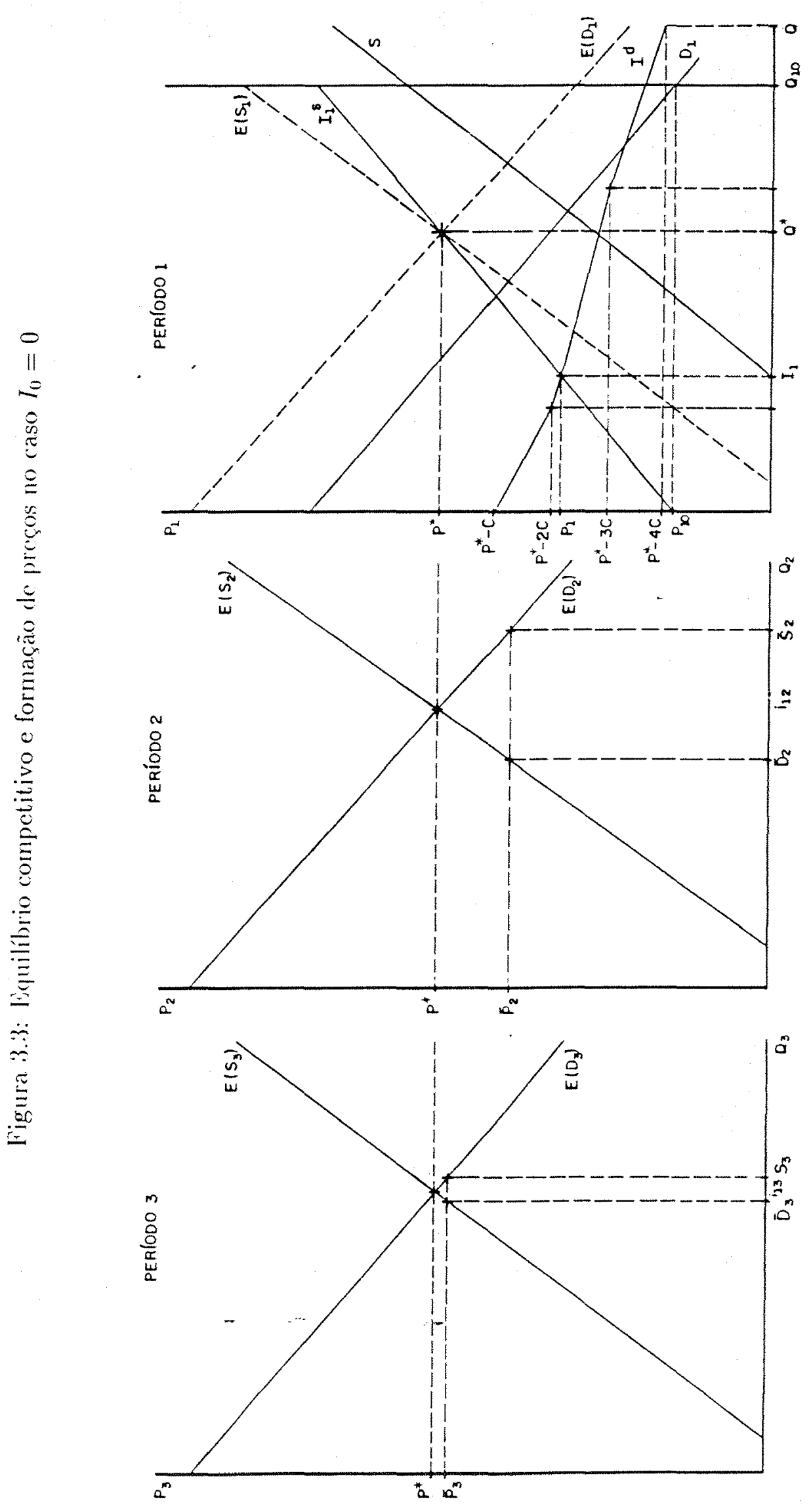




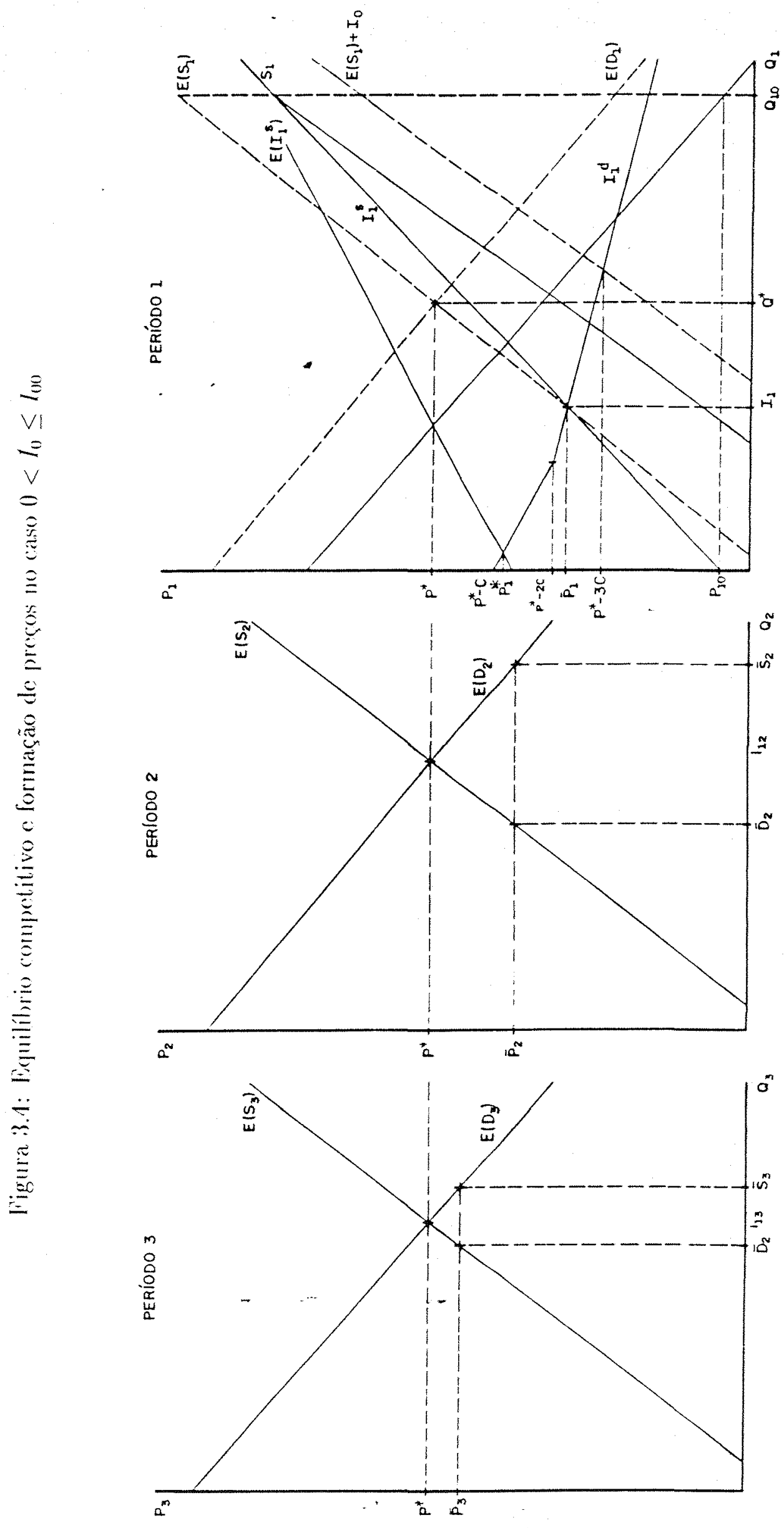




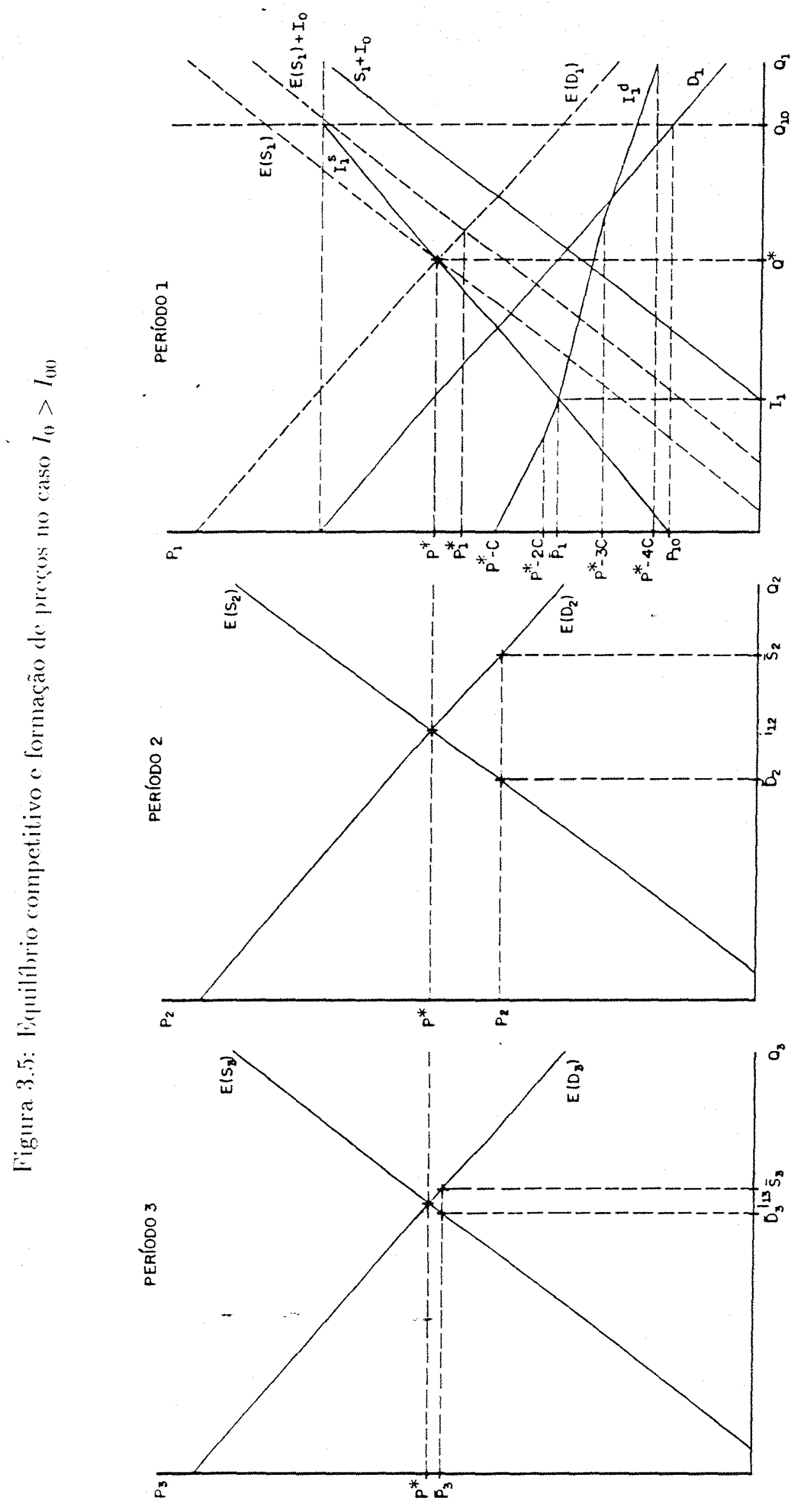




\subsubsection{Custos e Benefícios da Armazenagem Competitiva}

O armazenamento é uma das funções da comercializaçăo que, ao transferir o produto ao longo do tempo, mediante o emprego de recursos produtivos - capital e trabalho - cria utilidade de tempo, ou seja, trata-se ". . de um processo de produção e como tal pode ser analisado valendo-se dos instrumentos da Teoria Econômica." (BARROS - 1987,p.6)

Assim, benefícios e/ou custos decorrentes do armazenamento competitivo podem ser mensurados com base nos três postulados convencionais da Teoria do Bem Estar: (a) o preço competitivo pago pelos consumidores por unidade de produto mede o valor dos benefícios obtidos com seu consumo; (b) o preço competitivo de oferta, para uma determinada unidade, mede o valor daquela unidade para o produtor; (c) o princípio de Hicks-Kaldor Selowsky, da compensação potencial (HARBERGER - 1971).

Os dois primeiros postulados asseguram que podemos aferir custos e benefícios de estados econômicos alternativos, mediante o uso de curvas de oferta e demanda. O terceiro permite que benefícios e custos incorridos por cada indivíduo ou agente de produção sejam adicionados, sem maiores preocupações com equidade de distribuição de renda, favorecimento, penalização de determinados grupos, etc.

A metodologia a ser utilizada para avaliação dos benefícios da armazenagem competitiva é aquela derivada dos conceitos de excedente dos consumidores e excedente (renda) dos produtores conforme apresentado por MISHAN (1971), e que têm implícitas as concepções de que: (a) a área total sob a curva de demanda e à esquerda de dada quantidade, representa a utilidade total proporcionada por aquela quantidade e; (b) a área à direita da curva de oferta reflete os custos de oportunidade dos recursos usados na produção de cada quantidade.

O excedente dos consumidores é definido como a diferença entre o dispêndio efetivamente pago pelo fator (ou produto) e o dispêndio máximo que o consumidor estaria disposto a pagar para ter a quantidade adicional do fator (ou produto), versus a alternativa de não tê-la.

Este conceito pode ser entendido com o auxilio da Figura 3.6(a). Ao preço $P_{0}$ o consumidor (ou empresa) irá consumir (empregar) a quantidade $Q_{0}$ e logo despender o valor correspondente ao pr̄eço $P_{0}$ vezes a quantidade $Q_{0}$, ou seja, a área $O P_{0} a Q_{0}$. Ao novo preço $P_{1}$, o dispêndio será $O P_{1} b Q_{1}$. A diferença entre o dispêndio que deixou de ser feito e o atual, corresponde, por definição, ao excedente do consumidor. Assim, a área $P_{0} a b P_{1}$ representa a magnitude do ganho do consumidor com a redução do preço do bem. 
Por outro lado. o excedente (renda) do produtor pode ser entendido como a variaçào no lucro. Na Figura $3.6(\mathrm{~b})$. $S S$ representa a curva de custo marginal privado. O aumento do preço de $P_{0}$ para $P_{1}$ faz com que a receita bruta varie de $P_{0} a Q_{0}$ para $P_{1} b Q_{1}$, ou seja. o aumento da receita é de $P_{0} a Q_{0} Q_{1} b P_{1}$. Como o custo de produção aumenta em $Q_{0} a b Q_{1}$, a variação no lucro - diferença entre a variação na receita bruta e a variação no custo - é dada pela área $P_{0} a b P_{1}$, a qual corresponde ao ganho do produtor.

Figura 3.6: Representação gráfica do excedente dos consumidores e produtores
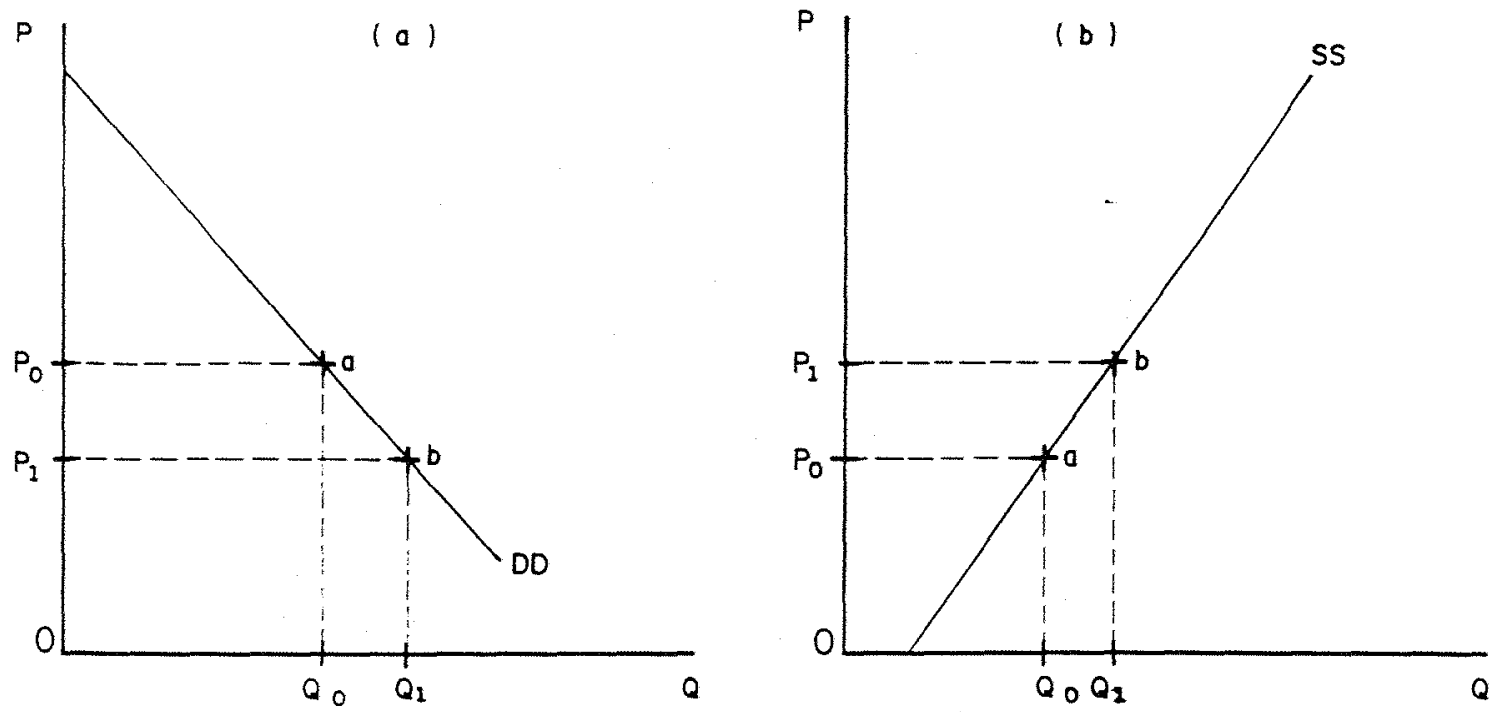

Com base nesta fundamentação teórica podemos avaliar. sob a ótica alocativa. os ganhos decorrentes do armazenamento competitivo.comparativamente ao nào armazenamento. a nivel de consumidor, produtor, e do empresário armazenador.

Supondo inexistência de estoque inicial $\left(I_{0}=0\right)$ e que ocorra armazenamento $\left(I_{1}>0\right)$ para liberação em cada um dos $n-1$ períodos futuros. as expectativas de ganhos serão modificadas pois o armazenamento fará com que o preço do primeiro período aumente e os preços esperados para os $n-1$ periodos subsequentes caiam.

Admitindo equilíbrio competitivo no primeiro período, ou seja, que todas as variáveis endógenas bem como $S_{1}, P_{1}$ e $I_{1}$ são iguais aos seus valores de equilíbrio tem-se, pelo lado da ofertä, que:

$$
P_{1}=\frac{\alpha_{0}-\beta_{0}}{\alpha_{1}+\beta_{1}}+\frac{I_{1}}{\alpha_{1}}+\frac{L_{1}-V_{1}}{\alpha_{1}}
$$


e, pelo lado da demanda:

$$
P_{1}=\frac{\alpha_{0}-\beta_{0}}{\alpha_{1}+\beta_{1}}-\frac{C \sum_{t=2}^{n}(t-1)}{(n-1)}-\frac{I_{1}}{(n-1)\left(\alpha_{1}+\beta_{1}\right)}
$$

Se o equilíbrio competitivo, no primeiro período, produz determinado valor para $i_{1 t}$, como neste período, $E\left(I_{t}\right)=i_{1(t+1)}+i_{1(t+2)} \cdots$, e $E\left(I_{t-1}\right)=i_{1 t}+E\left(I_{t}\right)$, então:

$$
\begin{gathered}
E\left(I_{t}\right)-E\left(I_{t-1}\right)=-i_{1 t} \quad \text { e, usando }(3.4) \\
P_{t}^{*}=\frac{1}{\alpha_{1}+\beta_{1}}\left(\alpha_{0}-\beta_{0}-i_{1 t}\right) ; \quad t>1
\end{gathered}
$$

Fazendo $P_{t}^{*}=P^{*}$, quando $i_{1 t}=0$ e $P_{t}^{*}=P_{t c}^{*}$ quando $i_{1 t}>0$, a Figura 3.7 mostra, graficamente, os efeitos do armazenamento competitivo nas expectativas de ganhos. A área dada por $b$ representa a perda esperada pelos produtores no $t$-ésimo período, devido à queda no preço esperado de $P^{*}$ para $P_{t c}^{*}$, provocada pelas liberações das $i_{1 t}$ quantidades armazenadas, quantidades estas suficientes para suprir o "déficit" de demanda àquele preço inferior. Consequentemente, a área $a+b$ representa, pelos mesmos motivos, o ganho esperado pelos consumidores no $t$-ésimo período.

Em resumo, os efeitos da armazenagem competitiva fazem com que o ganho dos produtores seja igual ao ganho do primeiro periodo - decorrente da redução na quantidade ofertada presente e consequente aumento do preço presente - menos o total das perdas esperadas nos $n-1$ períodos futuros, pelos motivos já mencionados. Os ganhos dos consumidores, ao contrário, serão iguais a determinada perda do primeiro período - causada pelo aumento do preço presente e consequente redução na quantidade consumida, na medida da quantidade armazenada neste periodo - mais os ganhos esperados nos $n-1$ períodos subsequentes, já que a quantidade ofertada futura aumenta com o armazenamento e, logo, reduz os preços futuros. Por fim, os empresários armazenadores não terão lucro com armazenamento zero e não esperam por lucro no equilíbrio competitivo.

\section{A - Ganho dos Produtores}

Uma vez que o produtor já tenha incorrido no custo de produção relativo ao primeiro ano, por definição, o ganho dos produtores, no primeiro período, é mensurado pela receita total. Fazendo $W_{p 1}$ igual aos ganhos do primeiro período, 
Figura 3.7: Ganhos (perdas) esperadas no t-ésimo período por consumidores (produtores) com armazenamento competitivo

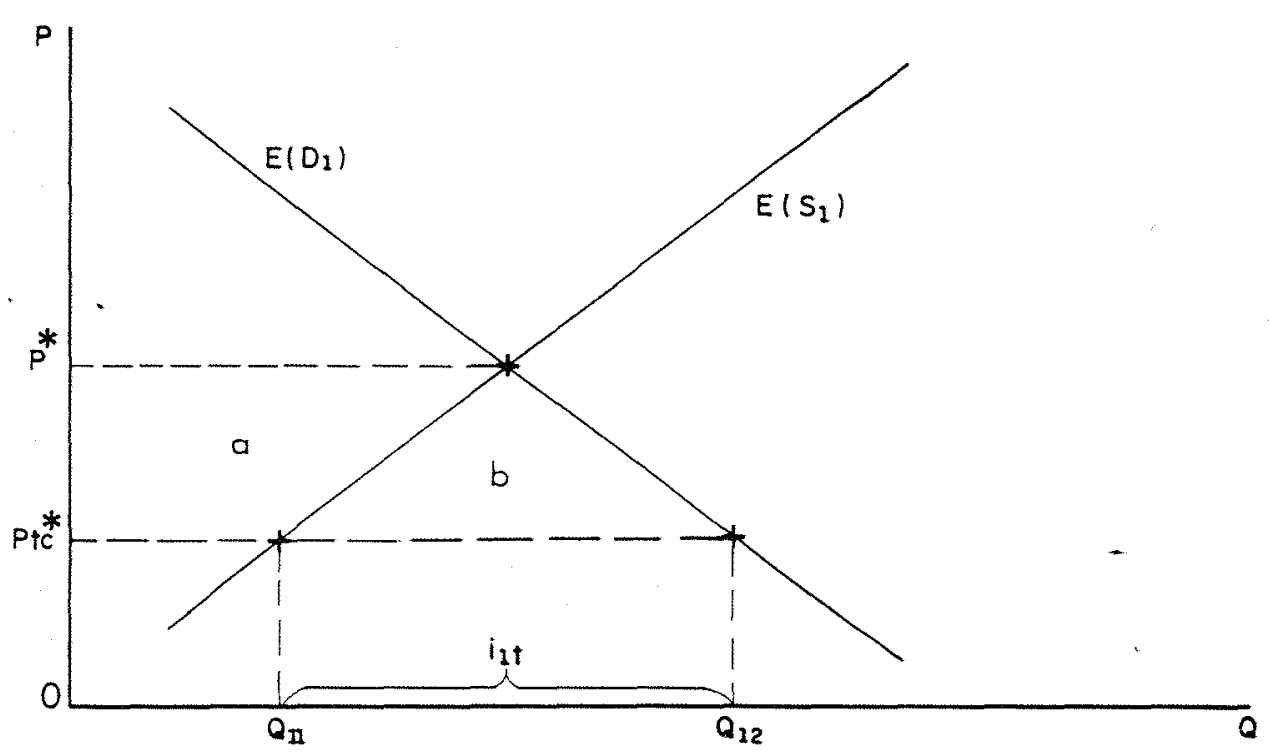

Fonte: HELMBERGER \& WEAVER - 1977

então:

$$
W_{P_{1}}=\left(P_{1}-P_{10}\right) S_{1}=\left[\frac{\beta_{0} \alpha_{1}+\beta_{1} \alpha_{0}+V_{1}\left(\alpha_{1}+\beta_{1}\right)}{\alpha_{1}\left(\alpha_{1}+\beta_{1}\right)}\right] I_{1}
$$

onde $P_{10}$ é o preço ao qual não há excedente para ser armazenado e as outras variáveis como definidas anteriormente.

Fazendo $E\left(W_{p t}\right)$ igual à perda esperada pelos produtores no t-ésimo período. então $E\left(W_{p t}\right)$ é dada pela integral definida da função de oferta esperada para o t-ésimo período. com $P_{t}^{*}=P^{*}$ e $P_{t}^{*}=P_{t c}^{*}$. sendo os limites superior e inferior respectivamente ou seja. a área $b$ da Figura 3.7. é dada por:

$$
E\left(W_{p t}\right)=\frac{\beta_{0} \alpha_{1}+\beta_{1} \alpha_{0}}{\left(\alpha_{1}+\beta_{1}\right)^{2}} i_{1 t}-\frac{\beta_{1}}{2\left(\alpha_{1}+\beta_{1}\right)^{2}} i_{1 t}^{2}
$$

E os ganhos totais esperados pelos produtores $-E\left(W_{p}\right)$ - serão iguais a: 


$$
\begin{aligned}
E\left(W_{p}\right) & =W_{p 1}-\sum_{t=2}^{n} E\left(W_{p t}\right) \\
& =\left[\frac{\beta_{1}\left(\beta_{0} \alpha_{1}+\beta_{1} \alpha_{0}\right)}{\alpha_{1}\left(\alpha_{1}+\beta_{1}\right)^{2}}+\frac{V_{1}}{\alpha_{1}}\right] I_{1}+\frac{\beta_{1}}{2\left(\alpha_{1}+\beta_{1}\right)^{2}} \sum_{t=2}^{n} i_{1 t}^{2}
\end{aligned}
$$

\section{B - Ganhos dos Consumidores}

Fazendo $W_{c 1}$ igual as perdas dos consumidores no primeiro período, então $W_{c 1}$ é dada pela integral definida da função demanda para consumo do primeiro período com $P_{1}$ e $P_{10}$ sendo os limites superior e inferior respectivamente, ou seja:

$$
W_{c 1}=\left[\frac{\beta_{0} \alpha_{1}+\beta_{1} \alpha_{0}+V_{1}\left(\alpha_{1}+\beta_{1}\right)}{\alpha_{1}\left(\alpha_{1}+\beta_{1}\right)}\right]=\frac{1}{I_{1}}-\frac{1}{2 \alpha_{1}} I_{1}^{2}
$$

e, fazendo $E\left(W_{c t}\right)$ igual ao ganho esperado pelos consumidores no t-ésimo período, então $E\left(W_{c t}\right)$ será dada pela integral definida da função demanda esperada para consumo no t-ésimo período, com $P_{t}^{*}=P_{t c}^{*}$ e $P_{t}^{*}=P^{*}$, sendo os limites superior e inferior, respectivamente. Logo, a área $a+b$ da Figura 3.7 é igual a:

$$
E\left(W_{c t}\right)=\frac{\beta_{0} \alpha_{1}+\beta_{1} \alpha_{0}}{\left(\alpha_{1}+\beta_{1}\right)^{2}} i_{1 t}+\frac{\alpha_{1}}{2\left(\alpha_{1}+\beta_{1}\right)^{2}} i_{1 t}^{2}
$$

Finalmente, os ganhos dos consumidores, $E\left(W_{C}\right)$ serão iguais a:

$$
\begin{aligned}
E\left(W_{C}\right)= & \sum_{t=2}^{n} E\left(W_{c t}\right)-W_{c 1} \\
= & -\left[\frac{\beta_{1}\left(\beta_{0} \alpha_{1}+\beta_{1} \alpha_{0}\right)+\left(\alpha_{1}+\beta_{1}\right)}{\alpha_{1}\left(\alpha_{1}+\beta_{1}\right)^{2}}+\frac{V_{1}}{\alpha_{1}}\right] I_{1}+ \\
& -\frac{1}{2 \alpha_{1}} I_{1}^{2}+\frac{\alpha_{1}}{2\left(\alpha_{1}+\beta_{1}\right)^{2}} \sum_{t=2}^{n} i_{1 t}^{2}
\end{aligned}
$$

\section{C - Ganhos dos Empresários Armazenadores}

Apesar de não existirem expectativas nem de ganhos nem de perdas por parte dos empresários armazenadores, no equilíbrio competitivo, eles podem esperar 
ganhos ou perdas a partir de níveis alternativos de armazenamento, isto é, fora do equilíbrio.

Abolindo a pressuposição de que todas as variáveis endógenas estão em equilíbrio, por definição, os ganhos dos empresários, $W_{A}$, serão iguais a:

$$
W_{A}=\sum_{t=2}^{n}\left[P_{t}-P_{1}-(t-1) C\right] i_{1 t}
$$

Fazendo as substituições e tomando a esperança:

$$
E\left(W_{A}\right)=\frac{\alpha_{0}-\beta_{0}}{\alpha_{1}+\beta_{1}} I_{1}-\frac{1}{\alpha_{1}+\beta_{1}} \sum_{t=2}^{n} i_{1 t}^{2}-\frac{I_{1}^{2}}{\alpha_{1}}-\sum_{t=2}^{n}(t-1) C i_{1 t}
$$

\subsubsection{Eficiência Econômica da Armazenagem Competitiva}

Critérios de eficiência econômica são especificados em função dos propósitos ou objetivos da unidade econômica em consideração. Em se tratando de ganhos de bem-estar, a maximização da função de ganhos líquidos da sociedade é o critério de natureza econômica usado para determinar as condições necessárias para se atingir a máxima eficiência alocativa dos fatores.

Pressupondo ausência de externalidades os ganhos esperados por produtores, consumidores e empresários armazenadores serão iguais a:

$$
\begin{aligned}
E\left(W_{S}\right) & =E\left(W_{P}\right)+E\left(W_{C}\right)+E\left(W_{A}\right) \\
& =\frac{\alpha_{0}-\beta_{0}}{\alpha_{1}+\beta_{1}} I_{1}-\frac{I_{1}^{2}}{2 \alpha_{1}}-\frac{1}{2\left(\alpha_{1}+\beta_{1}\right)} \sum_{t=2}^{n} i_{1 t}^{2}-\sum_{t=2}^{n}(t-1) C i_{1 t}
\end{aligned}
$$

Maximizando $E\left(W_{S}\right)$ com respeito a $i_{1 t}$, sujeito à restrição de que $I_{1}=$ $i_{12}+i_{13}+\cdots+i_{1 t}$, obtém-se:

$$
i_{12}=i_{1 t}+(t-2)\left(\alpha_{1}+\beta_{1}\right) C ; \quad 3<t<n
$$

Usando as $n-2$ relações dadas em (3.34) mais a restrição, o sistema fornece uma solução para $i_{1 t}$ em termos de $I_{1} \operatorname{com} 2<t<n$. Por exemplo: 


$$
i_{12}=\frac{I_{1}}{n-1}-\frac{C\left(\alpha_{1}+\beta_{1}\right)}{n-1} \sum_{t=1}^{n-2} t
$$

Expressando-se $i_{1 t}$ em termos de $I_{1}$, podemos escrever $E\left(W_{S}\right)$ em função de $I_{1}$ apenas. Maximizando $E\left(W_{S}\right)$ tem-se uma expressão algébrica para $I_{1}$ e assim para $P_{1}$, análoga à obtida pela solução do equilíbrio competitivo dada em (3.22).

Por outro lado, usando as $(n-2)$ relaçóes dadas em (3.34) mais a (3.24) tem-se que :

$$
P_{t}^{*}-P^{*}=(t-2) C ; \quad 3<t<n
$$

E, por fim, dado que $I_{1}$ e $P_{1}$ igualam os valores do equilíbrio competitivo, através de manipulações algébricas das equaçǒes (3.11), (3.24) e (3.28) é possivel demonstrar que $P_{2}^{*}=P_{1}+C$ ou $P_{2}^{*}-P_{1}=C$

Ou seja, a armazenagem competitiva - nos moldes da teoria desenvolvida por HELMBERGER \& WEAVER (1977) - é um estado particular da economia que envolve uma alocação eficiente de recursos.

\subsubsection{Efeitos Distributivos de Políticas de Preços}

O objetivo aqui é analisar e quantificar, sob o ponto de vista da teoria do bem-estar, os efeitos de políticas de preços agrícolas em comparação à armazenagem competitiva. Duas políticas governamentais serão analisadas: estabilizaçào completa de preços ao nível de $P^{*}$, e estabilização parcial de preços, que consiste da fixação de limites, superior e inferior, para a livre variação dos preços. Assume-se que o governo não tenha estoques do(s) produto(s) em questão.

\section{A - Política de Estabilização Completa de Preços}

Dada a pressuposição de que o governo não possui estoques e admitindose restrição total às importações, o nível dó preço $P^{*}$ a ser estabilizado pelo governo deverá, obrigatoriamente, ser supecior ao preço competitivo, dado pela interaçào entre oferta e demanda de produtos para armazenamento $\left(P_{1}\right)$.

Assim, supõe-se um período de supersafra, cujo excesso de oferta permite ao governo formar estoques suficientes para forçar o preço ao nível de $P^{*}$, isto é, ao nível do preço que vigoraria se não houvesse produtos armazenados. 
Graficamente a Figura 3.8, onde os preços específicos e as dadas quantidades nào têm relaçào com os das Figuras anteriores, mostra os efeitos da politica de completa estabilização de preços, em comparação à armazenagem competitiva.

Figura 3.8: Efeitos de políticas governamentais de estabilização de preços. comparativamente à armazenagem competitiva

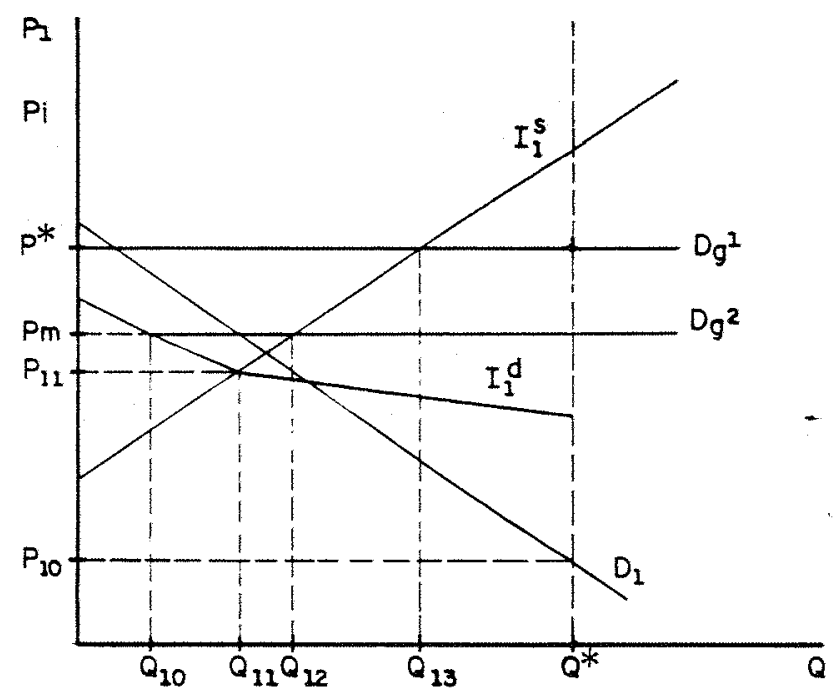

Fonte: Helmberguer \& Weaver (1977).

A demanda de produtos para armazenamento por parte do governo $\left(D_{g 1}\right)$ torna-se perfeitamente elástica a partir de $P^{*}$. O nível de armazenamento governamental é igual a $Q_{13}$ dado pela intersecçào de $D_{g 1}$ e a oferta de produtos para armazenamento $I_{1}^{S}$. A quantidade demandada de produtos para armazenamento por parte da iniciativa privada $\left(I_{1}^{d}\right)$ não é grande o suficiente para explicar este nivel de armazenagem. Para a iniciativa privada só será lucrativo armazenar se o preço esperado para o segundo período for igual ou maior que $P_{11}+C$.

Para análise dessa política, é importante considerar que nào existindo restriçòes orçamentárias. o governo poderá garantir que os preços não sejam menores do que $P^{*}$ pois. através da formaçâo e manipulação de estoques têm como forçar o preço ao nivel desej̃ado. Ao contrárió. com estoques limitados, no caso de frustação de safra, por exemplo. não tem como manter os preços ao nivel de $P^{*}$ e. logo, que os preços esperados para os n-1 períodos futuros nào sejam superiores a $P^{*}$.

Esta assimetria. conforme HELMBERGER \& WEAVER (197i). impòe 
sérias limitações teóricas à análise do bem-estar da política. No entanto, o problema foi contornado pelos pesquisadores a partir da pressuposiçào de que o preço esperado nos $n-1$ períodos futuros é igual ao preço $P^{*}$ que se quer estabilizar. Assim, pelas expressões desenvolvidas tem-se o que chamaram, comparativamente à armazenagem competitiva, de "ganhos mínimos dos produtores" e "máxima perda dos consumidores".

Na Figura 3.8, o preço competitivo é $P_{11}$ dado pela intersecção entre oferta e demanda de produtos para armazenamento. No primeiro período, o ganho dos produtores com a completa estabilização de preços será aumentado na proporção em que o total de recebimentos excede aos do equilíbrio competitivo, ou seja, em $\left(P^{*}-P_{11}\right) S_{1}$. As perdas esperadas pelos produtores nos $n-1$ períodos futuros com armazenamento competitivo, não serão concretizadas em consequência da manutenção do preço $P^{*}$ que vigoraria se não houvesse estoques armazenados.

Fazendo $E\left(W_{c p}\right)$ igual aos ganhos mínimos esperados por produtores comparativamente à armazenagem competitiva - a partir da completa estabilização de preços, então:

$$
E\left(W_{c p}\right)=\left(P^{*}-P_{11}\right) S_{1}+\frac{\beta_{0} \alpha_{1}+\beta_{1} \alpha_{0}}{\left(\alpha_{1}+\beta_{1}\right)^{2}} I_{1}-\frac{\beta_{1}}{2\left(\alpha_{1}+\beta_{1}\right)^{2}} \sum_{t=2}^{n} i_{1 t}^{2}
$$

onde os dois últimos termos do lado direito, vêm da soma da equação (3.23) para todo $t$, pois, o que se deixa de perder é ganho.

Quanto aos consumidores, a formação de estoques governamentais, no primeiro período, superior ao nivel competitivo, eleva ainda mais os preços e, logo, aumenta a perda de excedente (renda) dos consumidores nesse período. Além disso, os ganhos esperados para os n-1 períodos futuros não são concretizados: os efeitos da armazenagem competitiva - queda dos preços esperados para os n-1 períodos futuros - são destruídos pela política de estabilização de preços.

Fazendo $E\left(W_{c c}\right)$ igual a máxima perda esperada pelos consumidores com uma política governamental de completa estabilização de preços, em comparação à armazenagem competitiva, então, $E\left(W_{\mathfrak{c c}}\right)$ será igual ao incremento de perda de excedente no primeiro período, dado pela integral definida da função de demanda do primeiro período com $\tilde{P^{*}}$ e $P_{11}$ sendo os limites superior e inferior, respectivamente, mais os ganhos não concretizados, dos $n-1$ períodos futuros ou seja,

$$
E\left(W_{c c}\right)=\left(\alpha_{0}+U_{1}\right)\left(P^{*}-P_{11}\right)-\frac{\alpha_{1}}{2}\left(P^{*^{2}}-P_{11}^{2}\right)+
$$




$$
\frac{\beta_{0} \alpha_{1}+\beta_{1} \alpha_{0}}{\left(\alpha_{1}+\beta_{1}\right)^{2}} I_{1}+\frac{\beta_{1}}{2\left(\alpha_{1}+\beta_{1}\right)^{2}} \sum_{t=2}^{n} i_{1 t}^{2}
$$

onde os dois últimos termos da direita vêm da soma da equação (3.26) para todo t.

\section{B - Política de Estabilização Parcial de Preços}

Os efeitos desta política estão diretamente relacionados aos limites dos intervalos permitidos à livre variação dos preços dos produtos.

Na Figura 3.8, $P_{i}$ e $P_{m}$ são, respectivamente, os limites superior e inferior fixados para a livre variação dos preços. A demanda de produtos para armazenamento $D_{g 2}$ é igual a $I_{1}^{d}$, para preços superiores a $P_{m}$ e torna-se perfeitamente elástica a partir de $P_{m}$. Esta política de preços, que implica na formação de estoques reguladores por parte do governo, normalmente, quando o prèço mínimo é fixado acima do preço competitivo, leva os preços à níveis superiores a $P_{m}$, reduzindo a armazenagem privada, no mínimo, de $Q_{11}$ para $Q_{10}$.

Neste caso, relativamente ao armazenamento competitivo, o preço esperado para o segundo período e possivelmente para os períodos futuros será superior. Ceteribus-paribus, a quantidade consumida diminui, a produção aumenta e o governo terá mais e mais que adquirir excedentes e formar estoques para garantir a política de preço. $\mathrm{O}$ setor privado afasta-se gradativamente da atividade armazenadora. Novamente produtores ganham, consumidores perdem e a eficiência econômica decresce.

A compatibilização da análise de benefícios e custos da armazenagem competitiva com a da política de estabilização completa de preços leva à derivação direta das equações dos "ganhos mínimos esperados por produtores" e "máxima perda esperada por consumidores", decorrentes da política de estabilização parcial de preços, em relação ao armazenamento competitivo. Para tanto, considera-se apenas o limite inferior fixado para a variação dos preços $\left(P_{m}\right)$. Então, comparativamente à armazenagem competitiva os ganhos mínimos esperados pelos produtores com uma política de estabilização parcial de preços, $E\left(W_{p p}\right)$-são dados por:

$$
E\left(W_{p p}\right)=\left(P_{m}-P_{11}\right) S_{1}+\frac{\beta_{0} \alpha_{1}+\beta_{1} \alpha_{0}}{\left(\alpha_{1}+\beta_{1}\right)^{2}} I_{1}-\frac{\beta_{1}}{2\left(\alpha_{1}+\beta_{1}\right)^{2}} \sum_{t=2}^{n} i_{1 t}^{2}
$$

e a perda mínima esperada pelos consumidores nessa mesma situação igual 


$$
\begin{aligned}
E\left(W_{p c}\right)= & \left(\alpha_{0}+U_{1}\right)\left(P_{m}-P_{11}\right)-\frac{\alpha_{1}}{2}\left(P_{m}^{2}-P_{11}^{2}\right)+\frac{\beta_{0} \alpha_{1}+\beta_{1} \alpha_{0}}{\left(\alpha_{1}+\beta_{1}\right)^{2}} I_{1}+ \\
& \frac{\beta_{1}}{2\left(\alpha_{1}+\beta_{1}\right)^{2}} \sum_{t=2}^{n} i_{1 t}^{2}
\end{aligned}
$$

Pelas equações (3.39) e (3.40), observa-se que à medida em que o limite inferior do intervalo $\left(P_{m}\right)$ aproxima-se do preço competitivo $\left.\left(P_{11}\right)\right)$, os efeitos da - política são anulados. No caso de $P_{m}$ ser fixado abaixo de $P_{11}$, os efeitos distributivos da política no primeiro ano são opostos ao do caso exemplificado na Figura 3.8: o primeiro termo de cada equação terá sinal negativo.

\subsection{Descrição dos dados}

Conhecidas as elasticidades preço da oferta e da demanda de arroz ao nível de Brasil, e os valores médios do consumo aparente $(\bar{Q})$ e do preço recebido pelos produtores $(\bar{P})$, a parametrização das funções $(3.1)$ e $(3.2)$ pode ser feita por aproximação linear no ponto $(\bar{Q}, \bar{P})$, a partir da pressuposição de modelo de elasticidade constante.

Assim, os dados básicos necessários ao presente estudo são: preços recebidos pelos produtores, consumo aparente total (humano, animal e para semente), custo de armazenagem, estoque inicial e definição das situaçòes de estabilidade/instabilidade da oferta e/ou da demanda que se quer simular (definição das variáveis estocásticas).

a) Elasticidades

A pesquisa bibliográfica efetuada mostrou que dispõe-se de poucas estimativas empíricas atualizadas das elasticidades preço da oferta $\left(\eta_{s}\right)$ e da demanda $\left(\eta_{d}\right)$ de arroz ao nível de Brasil.

O estudo sobre produção e consumo de alimentos básicos efetuado por BOS (1986) estimou em 0,21 a elasticidade preço da oferta (produção) de arroz no Brasil (dados do período de 1966/83). A estimativa da elasticidade preço da demanda foi prejudicada pela não significância da variável preço na função consumo aparente.

SANTI et alii (1978), com base em dados do período de 1953/76, estimou em 0,30 a elasticidade preço da oferta (área plantada) e em - 0,31 a elasticidade preço 
da demanda (consumo per-capita) de arroz no Brasil.

Como essas estimativas não são representativas de nenhum período específico, optou-se por utilizá-las para simulações referentes tanto à década de 70 (valores médios das observações do período 1971/80), quanto à década de 80 (valores médios das observações do período 1981/90).

Por outro lado, para dar maior profundidade quantitativa à teoria da armazenagem competitiva, far-se-á uma análise de sensibilidade com base em combinações de diferentes elasticidades preço de oferta e de demanda aleatoriamente escolhidas, e nos valores médios do consumo aparente e do preço recebido pelos produtores de arroz, observados no período 1981/90. As elasticidades preço da oferta consideradas são: 0,$2 ; 0,3 ; 0,4$ e 0,5 . E as elasticidades preço da demanda: - 0,2; $-0,3 ;-0,4$ e $-0,5$.

\section{b) Consumo aparente}

A extinta Companhia de Financiamento da Produção - CFP, hoje, CO$\mathrm{NAB}$, faz e atualiza sistematicamente, safra a safra, a situação do abastecimento interno dos produtos que integram a Política de Garantia de Preços Mínimos - PGPM, dentre os quais o arroz, conforme apresentado na Tabela 2.6. Os dados da coluna intitulada "consumo", referem-se ao consumo aparente total (humano, não humano e para sementes) de arroz em casca e serão estas as informações usadas para estimar o consumo aparente médio dos dois períodos a serem analisados (1971/80 e 1981/90).

\section{c) Preços}

A Tabela 3.1 apresenta as séries históricas dos preços recebidos e dos preços mínimos para o arroz em casca, em $\mathrm{Cr} \$ / \mathrm{kg}$, referente ao periodo de 1971 a 1990.

Os dados sobre preço anual médio recebido pelos produtores têm como fonte primária a Fundação Getúlio Vargas - FGV e os dados sobre preços mínimos médios anuais, a Companhia Nacional de Abastecimento - CONAB.

O preço mínimo é o único dado que faz distinção entre os sistemas de cultivo: irrigado e sequeiro. Assim, a última coluna da Tabela 3.1 apresenta a média anual do preço mínimo dos dois cultivos, tornando o dado comparável aos outros.

Todos os preços foram corrigidos (cruzeiros de maio de 1991) pelo Índice Geral de Preços - Disponibilidade Interna (IGP-DI) da Fundação Getúlio Vargas FGV. 
Tabela 3.1: ARROZ - Preços médios reais anuais: preços recebidos pelos produtores, preços mínimos do sequeiro, preços mínimos do irrigado e preços mínimos médios Brasil 1971/90

\begin{tabular}{r|r|r|r|r}
\hline \multicolumn{3}{|c}{ Cr $\$ / \mathrm{kg}(1)$} \\
\hline ANO & Preço & \multicolumn{3}{|c}{ Preços Mínimos } \\
\cline { 3 - 5 } & Recebido & sequeiro & irrigado & Médio \\
\hline 1971 & 96,26 & 59,83 & nd & 59,83 \\
1972 & 103,35 & 67,05 & nd & 67,05 \\
1973 & 97,59 & 77,15 & nd & 77,15 \\
1974 & 119,50 & 77,12 & nd & 77,12 \\
1975 & 148,87 & 90,72 & 102,56 & 99,64 \\
1976 & 98,29 & 81,63 & 90,78 & 86,20 \\
1977 & 82,72 & 77,31 & 88,32 & 82,81 \\
1978 & 99,81 & 73,45 & 83,24 & 78,34 \\
1979 & 111,75 & 66,95 & 76,58 & 71,76 \\
1980 & 111,97 & 60,65 & 78,77 & 69,71 \\
1981 & 84,38 & 63,23 & 70,95 & 67,09 \\
1982 & 96,20 & 63,60 & 75,84 & 69,72 \\
1983 & 97,02 & 51,71 & 61,95 & 56,83 \\
1984 & 80,68 & 53,60 & 64,20 & 58,90 \\
1985 & 92,47 & 70,39 & 83,71 & 77,05 \\
1986 & 87,47 & 74,79 & 87,27 & 81,03 \\
1987 & 51,46 & 46,89 & 54,66 & 50,77 \\
1988 & 51,85 & 39,92 & 46,51 & 43,21 \\
1989 & 45,28 & 34,25 & 44,51 & 39,38 \\
\hline 1990 & 45,17 & 23,15 & 30,20 & 26,67 \\
\hline & & & &
\end{tabular}

FONTE: Companhia Nacional de Abastecimento - CONAB.

(1) Preços em cruzeiros de maio de 1991, corrigidos pelo Índice Geral de Preços- Disponibilidade Interna (IGP-DI) da Fundação Getulio Vargas (FGV). 


\section{d) Custo de Armazenamento}

A "Tabela de Tarifas para Produtos vinculados à PGPM - Ambiente Natural", fornecida pela Diretoria de Operações - DIROP, da Companhia Nacional de Armazenamento - CONAB, que vigorava em maio de 1991, serviu de base para estimar o custo de armazenamento.

Considerou-se o arroz:

- como produto destinado exclusivamente a processamento/beneficiamento, logo com acréscimo de $30 \%$ na respectiva tarifa conforme determinado no ítem 5 das observações da referida tabela;

- no estado limpo e seco;

- armazenado e conservado ensacado; e,

- um período de armazenamento de 1 (hum) ano.

Assim, o custo de armazenagem para a década de 70 foi estimado em $\mathrm{Cr} \$$ $6.600,00 / t$ e para a década de 80, em $\mathrm{Cr} \$ 5.810,00 / t$. A diferença (queda) do custo tem explicação na queda do preço mínimo real sobre o qual é calculado o ad valorem $(15 \%)$.

e) Estoque inicial

Para as possíveis combinações das elasticidades estimadas por BOS, A. M. (1986) e por SANTI (1978) et alii, bem como para as combinações das elasticidades utilizadas na análise de sensibilidade, definiu-se três níveis de estoques iniciais de forma a simular os três casos da teoria da armazenagem sob condições de incerteza.

Conforme 3.19, $I_{00}=\left(\alpha_{1}+\beta_{1}\right) C$. Assim os estoques iniciais mínimos que implicam (em qualquer caso simulado) em $I_{0} \leq I_{00}$ e $I_{0}>I_{00}$, é dado pelos parâmetros das funções de demanda $\left(\alpha_{1}\right)$ e de oferta $\left(\beta_{1}\right)$ de arroz com $\left|\eta_{D}\right|=\eta_{S}=$ 0,2 e $\left|\eta_{D}\right|=\eta_{S}=0,5$ respectivamente, e pelos custos de armazenagem.

\section{f) Variáveis estocásticas}

Os valores das variáveis estocásticas foram definidos de forma a simular-se dois casos distintos em cada período estudado.

Um caso extremo com aumento de produção $\left(V_{1}=20 \%\right.$ da produção média) e redução da demanda ( $U_{1}=-20 \%$ do consumo aparente médio) e outro, com a mesma oferta mas com demanda estável $\left(U_{1}=0\right)$. 


\section{Capítulo 4}

\section{Resultados}

Os resultados das simulaçoos da armazenagem competitiva serão apresentados em dois itens: o primeiro referente às simulações feitas com base nas elasticidades empiricamente estimadas por BOS (1986) e SANTI et alii (1978) e o segundo referente à análise de sensibilidade, baseada em elasticidades aleatoriamente escolhidas (sem fundamentação empírica).

\subsection{Resultados das simulações da armazenagem competitiva (elasticidades estimadas empiri- camente)}

Como as elasticidades preço da demanda e da oferta disponiveis não representam um período em particular (foram estimadas por diferentes métodos e para períodos distintos), optou-se por realizar simulações com base na produção e consumo médios observados na década de $70(1971 / 80)$ e na década de $80(1981 / 90)$.

As simulações foram feitas considerando-se três níveis de estoque inicial para cada período, de forma a se ter os três casos apresentados na metodologia. Admitiu-se, para cada um dos três casos, uma mesma oferta com $v_{1}=+20 \%$ do consumo aparente médio do período em questão, e fez-se variar a demanda: um caso de demanda instável ( $u_{1}=-20 \%$ do consumo aparente médio) e um caso de demanda estável $\left(u_{1}=0\right)$.

\subsubsection{Década de $70(1971 / 80)$}

Para este período as aproximações lineares das funções de oferta e de demanda foram feitas no ponto $(\bar{P}=\operatorname{Cr} \$ 107.000,00 / t, \bar{Q}=7.200,00$ mil $t)$, onde $\bar{P}$ e $\bar{Q}$ são os valores médios do consumo aparente e do preço recebido pelos produtores, 
obtidos a partir dos valores observados no período $1971 / 80$. Ou seja, além de $\vec{P}$ $=\operatorname{Cr} \$ 107.000,00 / t$ ser o preço esperado (esperança matemática) é também o preço esperado que iguala oferta esperada à demanda esperada, simbolizado por $P^{*}$ na Teoria da Armazenagem.

Os valores dos parâmetros das funções de demanda (consumo) esperada e da oferta (produção) esperada, assim encontrados, foram:

$-\operatorname{para} \eta_{D}=-0,31, \alpha_{1}=0,020860$ e $\alpha_{0}=9.432$

- para $\eta_{S}=0,21, \beta_{1}=0,014131$ e $\beta_{0}=5.688 ; \mathrm{e}$,

- para $\eta_{S}=0,30, \beta_{1}=0,020187$ e $\beta_{0}=5.040$.

Com base nestes parâmetros e no custo de armazenagem $(C=\mathrm{Cr} \$ 6.600,00 / t)$ quantificou-se, conforme dado em (3.19) os estoques críticos $\left(I_{00}\right)$ quais sejam:

- quando $\eta_{D}=-0,31$ e $\eta_{S}=0,21, I_{00}=230,934 \mathrm{mil} t ; \mathrm{e}$,

- quando $\eta_{D}=-0,31$ e $\eta_{S}=0,30, I_{00}=270,910$ mil $t$.

Assim, os três níveis de estoques iniciais admitidos, $I_{0}=0, I_{0}=230,934$ mil $t$ e $I_{0}=314,309$ mil $t$, implicam em se ter para as duas possíveis combinações de elasticidades, os três casos de formação de preços apresentado na Teoria de Armazenagem sob Condições de Incerteza.

Além disso, considerou-se um caso de demanda instável denotada por $u_{1} \neq 0$, significando assumir $u_{1}=-1.440,0$ mil $t$ e outro com demanda estável, denotada e valorizada por $u_{1}=0$. Em todos os casos simulados admitiu-se uma mesma oferta com $v_{1}=1.440,0$ mil $t$.

As Tabelas 4.1, 4.2 e 4.3 apresentam as estimativas dos valores de equilíbrio da armazenagem competitiva referente às simulações com demanda instável $\left(u_{1} \neq 0\right)$, e as Tabelas $4.4,4.5$ e 4.6 mostram essas mesmas estimativas para o caso de demanda estável $\left(u_{1}=0\right)$.

As estimativas das variáveis apresentadas nas referidas Tabelas foram endogenamente determinadas conforme apresentado na teoria da armazenagem competitiva ou seja, através da derivação das funções de oferta e demanda de produtos para armazenagem. $I_{1}$ é a quantidade-a ser armazenada no primeiro ano; $i_{12}, i_{13}$, $\ldots, i_{1 n}$, os volumes a serem liberados; $P_{1}, P_{2}, \ldots, P_{n}$, os preços esperados; $D_{1}$, $D_{2}, \ldots, D_{n}$, as quantidades que se espera sejam consumidas; e, $S_{1}, S_{2}, \ldots, S_{n}$, as quantidades que se espera sejam produzidas.

O horizonte temporal - período esperado de armazenamento - do modelo de equilíbrio intertemporal da armazenagem competitiva foi também endogenamente determinado.

Observa-se que, quando a demanda é instável $\left(u_{1} \neq 0\right)$, o periodo de armazenamento é de 4 anos nos casos de $I_{0}=0$, passando para 5 anos nos casos de 
$I_{0} \leq I_{00}$ e $I_{0}>I_{00}$. Quando a demanda é estável, o período de armazenamento é de 4 anos em todos os casos.

As quantidades a serem armazenadas $\left(I_{1}\right)$, mostram-se sensiveis aos níveis dos estoques iniciais e às elasticidades. Comparativamente às estimativas dos casos de $I_{0}=0$, quando a demanda é instável, a quantidade a ser armazenada aumenta de $7,1 \%\left(\eta_{D}=-0,31\right.$ e $\left.\eta_{S}=0,21\right)$ e de $5,7 \%\left(\eta_{D}=-0,31\right.$ e $\left.\eta_{S}=0,30\right)$, com $I_{0} \leq-I_{00} ;$ e, na mesma ordem, de $8,3 \%$ e de $7,8 \%$ quando $I_{0}>I_{00}$.

Quando a demanda é estável, as quantidades a serem armazenadas apresentam-se mais sensiveis aos níveis de estoque inicial e às elasticidades preço da oferta. Comparativamente a $I_{0}=0, I_{1}$ aumenta de $11,8 \%\left(\eta_{D}=-0,31\right.$ e $\left.\eta_{S}=0,21\right)$, e de $10,1 \%$ com $\eta_{S}=0,30$, quando $I_{0} \leq I_{00}$; e, na mesma ordem, de $15,3 \%$ e de $14,6 \%$ quando $I_{0}>I_{00}$.

Como era de se esperar, as variações nas quantidades a serem armazenadas em situações de instabilidade ou estabilidade da demananda, são bastante significativas: $I_{1}$ diminui de aproximadamente $55,5 \%$ nas duas simulações com $I_{0}=0$; de $53,5 \%$ nas simulações com $I_{0} \leq I_{00}$; e de $52,4 \%$ nas simulações com $I_{0}>I_{00}$.

As estimativas dos preços mostram que a armazenagem competitiva é compatível com grandes flutuações de preços. Quando a demanda é instável e $I_{0}=0$, o preço do primeiro ano soma $68,3 \%$ do preço esperado (Cr\$107.000,00/t) com $\eta_{D}=-0,31$ e $\eta_{S}=0,21$. Se $\eta_{S}=0,30$, passa a somar $69,8 \%$ do esperado. No caso de demanda estável e $I_{0}=0$, a estimativa do preço para o primeiro ano soma $79,0 \%$ do preço esperado $\left(\eta_{D}=-0,31\right.$ e $\left.\eta_{S}=0,21\right)$, e 80,1\% quando $\eta_{S}=0,30$.

Quanto às quantidades que se espera sejam consumidas $\left(D_{1}, D_{2}, \ldots, D_{n}\right)$ e produzidas $\left(S_{1}, S_{2}, \ldots, S_{n}\right)$, as estimativas destas confirmam os efeitos da armazenagem competitiva, apresentadas na metodologia. Por exemplo, no caso de $I_{0}=0, u_{1} \neq 0, \eta_{D}=0,31$ e $\eta_{S}=0,21$, as estimativas das quantidades a serem consumidas no primeiro ano diminui de $11,3 \%$ em relação à esperada, enquanto a produção aumenta de $20 \%$, determinando assim, o quantum a ser armazenado. Nos anos seguintes as quantidades que se espera sejam consumidas (produzidas) aumentam (diminuem), tendendo à igualação ao nível da demanda esperada $(7.200,000$ mil toneladas).

Os efeitos distributivos da armazenagem competitiva comparativamente ao não armazenamento são mostrados na Tabela 4.7. No caso de $I_{0}=0$ os ganhos esperados pelos consumidores $E\left(W_{C}\right)$, pelos produtores $E\left(W_{P}\right)$ e os ganhos esperados pela sociedade $E\left(W_{S}\right)$ foram estimados conforme dado nas equages $3.27,3.30$ e 3.33 . Nos outros casos $\left(I_{0} \leq I_{00}\right.$ e $\left.I_{0}>I_{00}\right)$, estimou-se ganhos (perdas) de produtores (consumidores) em cada periodo do horizonte temporal do armazenamento. 
Os ganhos esperados pelos empresários armazenadores não foram explicitados na referida Tabela porque estes são nulos no equilíbrio competitivo.

Os dados mostram que produtores ganham e consumidores perdem com armazenagem competitiva. As magnitudes das transferências de ganhos de consumidores para produtores mostram-se bastante sensiveis aos niveis dos estoques iniciais e à estabilidade da demanda. 
Tabela 4.1: Estimativas de estoques, preços, oferta e demanda de arroz para o caso $I_{0}=0$ e $u_{1} \neq 0-$ Brasil 1971/80.

\begin{tabular}{|c|c|c|}
\hline \multirow{2}{*}{$\begin{array}{c}\text { Elasticidade Preço } \\
\text { da Demanda }\end{array}$} & \multicolumn{2}{|c|}{ Elasticidade Preço da Oferta } \\
\hline & $0,21^{(1)}$ & $0,30^{(2)}$ \\
\hline$\eta_{D}=-0,31^{(2)}$ & & \\
\hline$\tilde{I}_{1}(1000 \mathrm{t})$ & $2.172,863$ & $2.227,341$ \\
\hline$i_{12}(1000 t)$ & 955,231 & $1.013,358$ \\
\hline$i_{13}(1000 \mathrm{t})$ & 724,294 & 742,450 \\
\hline$i_{14}(1000 t)$ & 493,356 & $-\quad 471,541$ \\
\hline $\bar{P}_{1}(\mathrm{Cr} \$ / t)$ & $73.100,50$ & $74.712,14$ \\
\hline $\bar{P}_{2}(\mathrm{Cr} \$ / t)$ & $79.700,50$ & $82.312,17$ \\
\hline $\bar{P}_{3}(\mathrm{Cr} \$ / \mathrm{t})$ & $86.300,50$ & $88.912,14$ \\
\hline $\bar{P}_{4}(\mathrm{Cr} \$ / \mathrm{t})$ & $92.900,50$ & $95.512,14$ \\
\hline $\bar{S}_{1}(1000 \mathrm{t})$ & $8.640,000$ & $8.640,000$ \\
\hline $\bar{S}_{2}(1000 \mathrm{t})$ & $6.814,232$ & $6.701,627$ \\
\hline $\bar{S}_{3}(1000 t)$ & $6.907,000$ & $6.834,860$ \\
\hline $\bar{S}_{4}(1000 \mathrm{t})$ & $7.000,758$ & $6.968,094$ \\
\hline $\bar{D}_{1}(1000 t)$ & $6.467,138$ & $6.412,660$ \\
\hline $\bar{D}_{2}(1000 t)$ & $7.769,463$ & $7.714,985$ \\
\hline $\bar{D}_{3}(1000 \mathrm{t})$ & $7.631,789$ & $7.577,310$ \\
\hline $\bar{D}_{4}(1000 t)$ & $7.494,114$ & $7.439,636$ \\
\hline
\end{tabular}

Fonte: Dados da simulação
(1) BOS (1986)
(2) SANTI et alii (1978) 
Tabela 4.2: Estimativas de estoques, preços, oferta e demanda de arroz para o caso $I_{0} \leq I_{00}$ e $u_{1} \neq 0-$ Brasil 1971/80.

\begin{tabular}{|c|c|c|}
\hline \multirow{2}{*}{$\begin{array}{c}\text { Elasticidade Preço } \\
\text { da Demanda }\end{array}$} & \multicolumn{2}{|c|}{ Elasticidade Preço da Oferta } \\
\hline & $0,21^{(1)}$ & $0,30^{(2)}$ \\
\hline$\eta_{D}=-0,31^{(2)}$ & & \\
\hline $\bar{I}_{1}(1000 t)$ & $2.327,169$ & $2.354,098$ \\
\hline$i_{12}(1000 t)$ & 927,305 & 994,861 \\
\hline$i_{13}(1000 t)$ & 696,371 & 723,951 \\
\hline$i_{14}(1000 t)$ & 465,437 & 453,041 \\
\hline$i_{15}(1000 t)$ & 236,503 & 182,131 \\
\hline $\bar{P}_{1}(\mathrm{Cr} \$ / t)$ & $73.900,00$ & $76.162,17$ \\
\hline $\bar{P}_{2}(\mathrm{Cr} \$ / t)$ & $80.500,00$ & $82.762,17$ \\
\hline $\bar{P}_{3}(\mathrm{Cr} \$ / t)$ & $87.100,00$ & $89.362,17$ \\
\hline $\bar{P}_{4}(\mathrm{Cr} \$ / t)$ & $93.700,00$ & $95.962,17$ \\
\hline $\bar{P}_{5}(\mathrm{Cr} \$ / t)$ & $100.300,00$ & $102.562,17$ \\
\hline $\bar{S}_{1}(1000 t)$ & $8.546,680$ & $8.526,421$ \\
\hline $\bar{S}_{2}(1000 t)$ & $6.825,465$ & $6.710,720$ \\
\hline $\bar{S}_{3}(1000 t)$ & $6.918,723$ & $6.843,954$ \\
\hline $\bar{S}_{4}(1000 t)$ & $7.011,981$ & $6.977,188$ \\
\hline $\bar{S}_{5}(1000 t)$ & $7.105,239$ & $7.110,422$ \\
\hline $\bar{D}_{1}(1000 t)$ & $6.450,446$ & $6.403,257$ \\
\hline$\widetilde{D}_{2}(1000 t)$ & $7.752,770$ & $7.705,581$ \\
\hline$-\bar{D}_{3}(1000 t)$ & $7.615,094$ & $7.567,905$ \\
\hline $\bar{D}_{4}(1000 t)$ & $7.477,418$ & $7.430,229$ \\
\hline $\bar{D}_{5}(1000 t)$ & $7.339,742$ & $7.292,553$ \\
\hline
\end{tabular}

Fonte: Dados da simulação

(1) BOS (1986)

(2) SANTI et alii (1978) 
Tabela 4.3: Estimativas de estoques, preços, oferta e demanda de arroz para o caso $I_{0}>I_{00}$ e $u_{1} \neq 0-$ Brasil $1971 / 80$.

\begin{tabular}{|c|c|c|}
\hline \multirow{2}{*}{$\begin{array}{c}\text { Elasticidade Preço } \\
\text { da Demanda }\end{array}$} & \multicolumn{2}{|c|}{ Elasticidade Preço da Oferta } \\
\hline & $0,21^{(1)}$ & $0,30^{(2)}$ \\
\hline$\eta_{D}=-0,31^{(2)}$ & & \\
\hline $\bar{I}_{1}(1000 t)$ & $2.354,022$ & $2.401,152$ \\
\hline$i_{12}(1000 t)$ & 934,672 & 1006,650 \\
\hline$i_{13}(1000 t)$ & 703,739 & 735,742 \\
\hline$i_{14}(1000 t)$ & 472,809 & 464,339 \\
\hline$i_{15}(1000 t)$ & 241,870 & 193,926 \\
\hline$\tilde{P}_{1}(\mathrm{Cr} \$ / t)$ & $73.689,44$ & $75.875,56$ \\
\hline $\bar{P}_{2}(\mathrm{Cr} \$ / t)$ & $80.289,44$ & $82.475,56$ \\
\hline$\vec{P}_{3}(\mathrm{Cr} \$ / t)$ & $86.889,44$ & $89.075,56$ \\
\hline $\bar{P}_{4}(\mathrm{Cr} \$ / t)$ & $93.489,44$ & $95.675,56$ \\
\hline $\bar{P}_{5}(\mathrm{Cr} \$ / t)$ & $100.089,44$ & $102.275,56$ \\
\hline $\bar{S}_{1}(1000 t)$ & $8.504,375$ & $8.496,094$ \\
\hline $\bar{S}_{2}(1000 t)$ & $6.822,490$ & $6.704,926$ \\
\hline $\bar{S}_{3}(1000 t)$ & $6.915,747$ & $6.838,159$ \\
\hline $\bar{S}_{4}(1000 t)$ & $7.009,006$ & $6.971,393$ \\
\hline$\tilde{S}_{5}(1000 t)$ & $7.102,264$ & $7.104,626$ \\
\hline $\bar{D}_{1}(1000 t)$ & $6.454,838$ & $6.409,251$ \\
\hline $\bar{D}_{2}(1000 t)$ & $7.757,162$ & $7.711,576$ \\
\hline$-\bar{D}_{3}(1000 t)$ & $7.619,486$ & $7.573,900$ \\
\hline $\bar{D}_{4}(1000 t)$ & $7.481,810$ & $7.436,227$ \\
\hline $\bar{D}_{5}(1000 t)$ & $7.344,134$ & $7.298,558$ \\
\hline
\end{tabular}

Fonte: Dados da simulação

(1) BOS (1986)

(2) SANTI et alii (1978) 
Tabela 4.4: Estimativas de estoques, preços, oferta e demanda de arroz para o caso $I_{0}=0$ e $u_{1}=0-$ Brasil $1971 / 80$.

\begin{tabular}{l|r|r}
\hline Elasticidade Preço & \multicolumn{2}{|c}{ Elasticidade Preço da Oferta } \\
\cline { 2 - 3 } \multicolumn{1}{c}{ da Demanda } & \multicolumn{1}{c}{$0,21^{(1)}$} & \multicolumn{1}{c}{$0,30^{(2)}$} \\
\hline$\eta_{D}=-0,31^{(2)}$ & & \\
$\bar{I}_{1}(1000 t)$ & 995,935 & 971,580 \\
$i_{12}(1000 t)$ & 553,947 & 602,852 \\
$i_{13}(1000 t)$ & 323,944 & 331,942 \\
$i_{14}(1000 t)$ & 93,408 & 61,032 \\
& & \\
$\bar{P}_{1}(\mathrm{Cr} \$ / t)$ & $84.544,37$ & $85.712,42$ \\
$\bar{P}_{2}(\mathrm{Cr} \$ / t)$ & $91.144,37$ & $92.312,42$ \\
$\bar{P}_{3}(\mathrm{Cr} \$ / t)$ & $97.744,37$ & $98.912,42$ \\
$\bar{P}_{4}(\mathrm{Cr} \$ / t)$ & $104.344,37$ & $105.512,42$ \\
& & \\
$\bar{S}_{1}(1000 t)$ & $8.640,000$ & $8.640,000$ \\
$\bar{S}_{2}(1000 t)$ & $6.975,870$ & $6.903,510$ \\
$\bar{S}_{3}(1000 t)$ & $7.069,128$ & $7.036,745$ \\
$\bar{S}_{4}(1000 t)$ & $7.162,386$ & $7.169,975$ \\
$\bar{D}_{1}(1000 t)$ & & \\
$\bar{D}_{2}(1000 t)$ & $7.667,559$ & $7.644,045$ \\
$\bar{D}_{3}(1000 t)$ & $7.393,072$ & $7.506,363$ \\
$\bar{D}_{4}(1000 t)$ & $7.255,793$ & $7.231,011$ \\
\hline $\bar{y}_{2}$ &
\end{tabular}

Fonte: Dados da simulação

(1) BOS (1986)

(2) SANTI et alii (1978) 
Tabela 4.5: Estimativas de estoques, preços, oferta e demanda de arroz para o caso $I_{0} \leq I_{00}$ e $u_{1}=0-$ Brasil $1971 / 80$.

\begin{tabular}{l|r|r}
\hline Elasticidade Preço & \multicolumn{2}{|c}{ Elasticidade Preço da Oferta } \\
\cline { 2 - 3 } \multicolumn{1}{c}{ da Demanda } & \multicolumn{1}{|c}{$0,21^{(1)}$} & \multicolumn{1}{c}{$0,30^{(2)}$} \\
\hline$\eta_{D}=-0,31^{(2)}$ & & \\
$\bar{I}_{1}(1000 t)$ & $1.086,426$ & $1.096,296$ \\
$i_{12}(1000 t)$ & 593,074 & 636,341 \\
$i_{13}(1000 t)$ & 362,141 & 365,432 \\
$i_{14}(1000 t)$ & 131,207 & 94,522 \\
& & \\
$\bar{P}_{1}(\mathrm{Cr} \$ / t)$ & $83.452,16$ & $84.896,52$ \\
$\bar{P}_{2}(\mathrm{Cr} \$ / t)$ & $90.052,16$ & $91.496,52$ \\
$\bar{P}_{3}(\mathrm{Cr} \$ / t)$ & $96.652,16$ & $98.096,52$ \\
$\bar{P}_{4}(\mathrm{Cr} \$ / t)$ & $103.252,16$ & $104.696,52$ \\
& & \\
$\bar{S}_{1}(1000 t)$ & $8.546,680$ & $8.526,421$ \\
$\bar{S}_{2}(1000 t)$ & $6.960,437$ & $6.887,040$ \\
$\bar{S}_{3}(1000 t)$ & $7.053,695$ & $7.090,274$ \\
$\bar{S}_{4}(1000 t)$ & $7.146,953$ & $7.153,509$ \\
& & \\
$\bar{D}_{1}(1000 t)$ & $7.691,188$ & $7.661,058$ \\
$\bar{D}_{2}(1000 t)$ & $7.553,512$ & $7.523,382$ \\
$\bar{D}_{3}(1000 t)$ & $7.415,835$ & $7.385,706$ \\
$\bar{D}_{4}(1000 t)$ & $7.278,160$ & $7.248,030$ \\
\hline & &
\end{tabular}

Fonte: Dados da simulação

(1) BOS (1986)

(2) SANTI et alii (1978) 
Tabela 4.6: Estimativas de estoques, preços, oferta e demanda de arroz para o caso $I_{0}>I_{00}$ e $u_{1}=0-$ Brasil 1971/80.

\begin{tabular}{l|r|r}
\hline \multirow{2}{*}{$\begin{array}{c}\text { Elasticidade Preço } \\
\text { da Demanda }\end{array}$} & \multicolumn{2}{|c}{ Elasticidade Preço da Oferta } \\
\cline { 2 - 3 }$\eta_{D}=-0,31^{(2)}$ & & \multicolumn{1}{c}{$0,30^{(2)}$} \\
$\bar{I}_{1}(1000 t)$ & $1.120,683$ & \\
$i_{12}(1000 t)$ & 604,495 & $1.141,660$ \\
$i_{13}(1000 t)$ & 373,540 & 351,463 \\
$i_{14}(1000 t)$ & 142,627 & 380,554 \\
& & 109,643 \\
$\bar{P}_{1}(\mathrm{Cr} \$ / t)$ & $83.125,77$ & \\
$\bar{P}_{2}(\mathrm{Cr} \$ / t)$ & $89.725,77$ & $84.528,13$ \\
$\bar{P}_{3}(\mathrm{Cr} \$ / t)$ & $96.325,77$ & $91.128,13$ \\
$\bar{P}_{4}(\mathrm{Cr} \$ / t)$ & $102.925,77$ & $104.328,13$ \\
& & \\
$\bar{S}_{1}(1000 t)$ & $8.504,371$ & $8.496,094$ \\
$\bar{S}_{2}(1000 t)$ & $6.955,825$ & $6.879,604$ \\
$\bar{S}_{3}(1000 t)$ & $7.049,083$ & $7.012,837$ \\
$\bar{S}_{4}(1000 t)$ & $7.142,341$ & $7.146,072$ \\
& & \\
$\bar{D}_{1}(1000 t)$ & $7.697,996$ & $7.668,743$ \\
$\bar{D}_{2}(1000 t)$ & $7.560,320$ & $7.531,067$ \\
$\bar{D}_{3}(1000 t)$ & $7.422,623$ & $7.393,391$ \\
$\bar{D}_{4}(1000 t)$ & $7.284,968$ & $7.255,719$ \\
\hline $\bar{S}_{-}$ &
\end{tabular}

Fonte: Dados da simulação

(1) BOS (1986)

(2) SANTI et alii (1978) 
Tabela 4.7: Efeitos distributivos da armazenagem competitiva no mercado de arroz comparativamente ao năo armazenamento - Brasil 1971/80.

\begin{tabular}{|c|c|c|}
\hline \multirow{2}{*}{$\begin{array}{c}\text { Elasticidade Preço } \\
\text { da Demanda }\end{array}$} & \multicolumn{2}{|c|}{ Elasticidade Preço da Oferta } \\
\hline & $0,21^{(1)}$ & $0,30^{(2)}$ \\
\hline$\eta_{D}=-0,31^{(2)}$ & \multicolumn{2}{|c|}{$I_{0}=0 ; u_{1} \neq 0$} \\
\hline$E\left(W_{P}\right)$ & 462,280 & 542,676 \\
\hline$E\left(W_{C}\right)$ & $-325,395$ & $-401,794$ \\
\hline \multirow[t]{2}{*}{$E\left(W_{S}\right)$} & 136,885 & 140,882 \\
\hline & \multicolumn{2}{|c|}{$I_{0}=0 ; u_{1}=\overline{0}$} \\
\hline$E\left(W_{P}\right)$ & 204,932 & 242,575 \\
\hline$E\left(W_{C}\right)$ & $-176,282$ & $-211,164$ \\
\hline \multirow[t]{2}{*}{$E\left(W_{S}\right)$} & 28,650 & 31,411 \\
\hline & \multicolumn{2}{|c|}{$I_{0} \leq I_{00} ; u_{1} \neq 0$} \\
\hline$E\left(W_{P}\right)$ & 484,731 & 595,794 \\
\hline$E\left(W_{C}\right)$ & $-342,497$ & $-431,678$ \\
\hline \multirow[t]{2}{*}{$E\left(W_{S}\right)$} & 142,234 & 164,116 \\
\hline & \multicolumn{2}{|c|}{$I_{0} \leq I_{00} ; u_{1}=0$} \\
\hline$E\left(W_{P}\right)$ & 224,558 & 259,190 \\
\hline$E\left(W_{C}\right)$ & $-201,091$ & $-235,731$ \\
\hline \multirow[t]{2}{*}{$E\left(W_{S}\right)$} & 23,467 & 23,459 \\
\hline & \multicolumn{2}{|c|}{$I_{0}>I_{00} ; u_{1} \neq 0$} \\
\hline$E\left(W_{P}\right)$ & 474,613 & 567,666 \\
\hline$E\left(W_{C}\right)$ & $-367,188$ & $-443,583$ \\
\hline \multirow[t]{2}{*}{$E\left(W_{S}\right)$} & 107,425 & 124,083 \\
\hline & \multicolumn{2}{|c|}{$I_{0}>I_{00} ; u_{1}=0$} \\
\hline$E\left(W_{P}\right)$ & 229,359 & 254,876 \\
\hline$E\left(W_{C}\right)$ & $-208,635$ & $-233,078$ \\
\hline$E\left(W_{S}\right)$ & 20,724 & 21,798 \\
\hline
\end{tabular}

Fonte: Dados da simulação

(1) BOS (1986)

(2) SANTI et alii (1978) 


\subsubsection{Década de $80(1980 / 90)$}

Para esta década as aproximações lineares das funções de oferta e de demanda foram feitas no ponto $(\vec{P}=\operatorname{Cr} \$ 73.200,00 / t, \bar{Q}=9.900,0$ mil $t)$, com $\bar{P}$ e $\bar{Q}$ sendo os valores médios do preço recebido pelos produtores e do consumo aparente, obtidos a partir das observações do período 1981/90. Ou seja, $\bar{P}$ e $\bar{Q}$. são ao mesmo tempo os valores esperados (esperança matemática) e também os valores esperados $\left(P^{*}\right.$ e $\left.Q^{*}\right)$ dados pela intersecção entre oferta e demanda esperadas.

Os valores dos parâmetros das funções de demanda (consumo) e da oferta (produção) esperada encontrados, foram:

$-\operatorname{para} \eta_{D}=-0,31, \alpha_{1}=0,041926$ e $\alpha_{0}=12.969$

- para $\eta_{S}=0,21, \beta_{1}=0,028402$ e $\beta_{0}=7.821 ; \mathrm{e}$,

- para $\eta_{S}=0,30, \beta_{1}=0,040570$ e $\beta_{0}=6.930$.

Conforme (3.19) e lembrando que para este-período $C=\operatorname{Cr} \$ 5.810,00 / t$, tem-se os estoques críticos $\left(I_{00}\right)$, quais sejam:

- quando $\eta_{D}=-0,31$ e $\eta_{S}=0,21, I_{00}=408,605$ mil $t$; e,

- quando $\eta_{D}=-0,31$ e $\eta_{S}=0,30, I_{00}=479,302 \mathrm{mil} t$.

Logo, admitindo três níveis de estoque inicial, $I_{0}=0, I_{0}=314,309 \mathrm{mil}$ $t$ e $I_{0}=785,768$ mil $t$, tem-se para cada uma das duas possíveis combinações de elasticidades os três casos de formação de preços.

Em todos os casos simulados admitiu-se $v_{1}=1.980,0$ mil $t$, ou seja não se fez variar a oferta. Por outro lado, simulou-se um caso de demanda instável simbolizada por $u_{1} \neq 0$ significando assumir $u_{1}=-1980,0$ mil $t$, e um caso de demanda estável simbolizada e valorizada por $u_{1}=0$.

As Tabelas $4.8,4.9$ e 4.10 apresentam as estimativas dos valores de equilíbrio da simulação da armazenagem competitiva para o caso de demanda instável $\left(u_{1} \neq 0\right)$, e as Tabelas $4.11,4.12$ e 4.13 mostram as estimativas para o caso de demanda estável $\left(u_{1}=0\right)$.

Nos casos de $u_{1} \neq 0$ o período esperado para armazenamento é de 4 anos quando $I_{0}=0$, aumentando para 5 anos nos casos de $I_{0} \leq I_{00}$ e $I_{0}>I_{00}$. Se a demanda é estável $\left(u_{1}=0\right)$, o período esperado de armazenamento é de 4 anos quando $I_{0}=0$ ou $I_{0} \leq I_{00}$ com $\eta_{D}=-0,31$ e $\eta_{S}=0,21$, bem como nos casos de $I_{0}>I_{00}$. Quando $I_{0}=\tilde{0}$ ou $I_{0} \leq I_{00}$ e $\eta_{D}=-0,31$ e $\eta_{S}=0,30$, o período esperado de armazenamento é de 3 anos.

O sentido da sensibilidade das estimativas das quantidades a serem armazenadas com relação aos níveis do estoque inicial e às elasticidades preço da oferta é o mesmo apresentado pelas estimativas da década de 70. Comparativamente às 
estimativas dos casos $I_{0}=0$, maiores elasticidades preço da oferta provocam aumentos menores nas quantidades a serem armazenadas, tanto nos casos de demanda instável quanto nos casos de demanda estável.

No caso de $I_{0} \leq I_{00}$ e $u_{1} \neq 0$, a quantidade armazenada aumenta de $6,3 \%$ se $\eta_{D}=-0,31$ e $\eta_{S}=0,21$. Se $\eta_{S}=0,30$, o aumento da quantidade armazenada é de apenas $4,9 \%$. Para o mesmo caso de demanda, mas com $I_{0}>I_{00}$, o aumento em $I_{1}$ é de $17,0 \%$ na primeira situação e de $14,3 \%$ na segunda.

Quando a demanda é estável o sentido da sensibilidade é o mesmo, mudando apenas a intensidade. Se $I_{0} \leq I_{00}, \eta_{D}=-0,31$ e $\eta_{S}=0,21$, comparativamente às simulações de $I_{0}=0$, as estimativas das quantidades a serem armazenadas aumentam de $9,4 \%$ e de $7,8 \%$ se $\eta_{S}=0,30$. Se $I_{0}>I_{00}$ o aumento é de $32,7 \%$ no primeiro caso e de $28,1 \%$ no segundo.

As simulações mostram que a estabilidade de demanda provoca queda nas quantidades estimadas para armazenamento de aproximadamente $55,8 \%$ quando $I_{0}=0 ;$ de $54,6 \%$ quando $I_{0} \leq I_{00} ;$ e, de $50,2 \%$ quando $I_{0}>I_{00}$.

As estimativas dos preços esperados confirmam a compatibilidade da armazenagem competitiva com grandes flutuações de preços.Observa-se que as flutuações são maiores na medida em que o período de armazenamento é maior. Em um extremo, quando $I_{0}>I_{00}, u_{1}=0, \eta_{D}=-0,31$ e $\eta_{S}=0,21$, o preço do primeiro ano soma $63,7 \%$ do esperado $(\mathrm{Cr} \$ 73.200,00 / t)$ e o período de armazenamento é de 5 anos; no outro extremo, para um período de armazenamento de 3 anos, no caso de $I_{0}=0, u_{1}=0, \eta_{D}=-0,31$ e $\eta_{S}=0,30$, o preço do primeiro ano $\left(P_{1}\right)$ soma $77,2 \%$ do esperado.

Com relação as estimativas das quantidades que se espera sejam consumidas $\left(D_{1}, D_{2}, \ldots, D_{n}\right)$ e produzidas $\left(S_{1}, S_{2}, \ldots, S_{n}\right)$, estas apresentam a mesma tendência observada nas estimativas da década anterior, ou seja, coerentes com os pressupostos da teoria da armazenagem competitiva.

Dentro do horizonte temporal de cada caso específico, preços e quantidades que se espera sejam consumidas e produzidas tendem aos valores esperados. Produção e consumo tendem a igualarem-se ao nível do consumo aparente esperado $(9.900,000 \mathrm{mil} t / \mathrm{ano})$ e o preço, ao nível do preço esperado (Cr\$73.200,00/t).

Os efeitos distributivos da armazenagem competitiva, ganhos esperados dos produtores $E\left(W_{P}\right)$, ganhos esperados dos consumidores, ganhos esperados dos empresários armazenadores $E\left(W_{A}\right)$ e ganhos esperados da sociedade $E\left(W_{S}\right)$, apresentados na Tabela 4.4 foram estimados em relação ao não armazenamento conforme apresentado na metodologia.

Mais uma vez fica constatado que, de um modo geral, os produtores ga- 
nham e os consumidores perdem com a armazenagem competitiva. Os empresários armazenadores não tềm lucro no equilíbrio competitivo.

As transferências de ganhos de consumidores para produtores apresentamse bastante sensíveis aos níveis dos estoques iniciais e à estabilidade da demanda. A magnitude das transferência é maior quando aumenta o nível de $I_{0}$ com $u_{1} \neq 0 \mathrm{e}$ menor se $u_{1}=0$. 
Tabela 4.8: Estimativas de estoques, preços, oferta e demanda de arroz para o caso $I_{0}=0$ e $u_{1} \neq 0-$ Brasil 1981/90.

\begin{tabular}{|c|c|c|}
\hline \multirow{2}{*}{$\begin{array}{c}\text { Elasticidade Preço } \\
\text { da Demanda }\end{array}$} & \multicolumn{2}{|c|}{ Elasticidade Preço da Oferta } \\
\hline & $0,21^{(1)}$ & $0,30^{(2)}$ \\
\hline$\eta_{D}=-0,31^{(2)}$ & & \\
\hline$\widetilde{I}_{1}(1000 t)$ & $2.897,095$ & $2.969,132$ \\
\hline$i_{12}(1000 t)$ & $1.374,407$ & $1.469,291$ \\
\hline$i_{13}(1000 t)$ & 965,813 & 989,972 \\
\hline$i_{14}(1000 t)$ & 557,218 & 510,652 \\
\hline $\bar{P}_{1}(\mathrm{Cr} \$ / t)$ & $47.848,58$ & $49.581,08$ \\
\hline $\bar{P}_{2}(\mathrm{Cr} \$ / t)$ & $53.658,58$ & $55.391,08$ \\
\hline $\bar{P}_{3}(\mathrm{Cr} S / t)$ & $59.468,58$ & $61.201,08$ \\
\hline $\bar{P}_{4}(\mathrm{Cr} \$ / t)$ & $65.278,58$ & $67.011,08$ \\
\hline $\bar{S}_{1}(1000 t)$ & $11.880,000$ & $11.880,000$ \\
\hline $\bar{S}_{2}(1000 t)$ & $9.344,903$ & 9.177 .382 \\
\hline $\bar{S}_{3}(1000 t)$ & 9.509 .907 & $9.413,111$ \\
\hline $\bar{S}_{4}(1000 t)$ & $9.674,912$ & $9.648,841$ \\
\hline $\bar{D}_{1}(1000 t)$ & $8.982,100$ & $8.910,152$ \\
\hline $\bar{D}_{2}(1000 t)$ & $10.719,310$ & $10.646,673$ \\
\hline $\bar{D}_{3}(1000 t)$ & $10.475,720$ & $10.403,083$ \\
\hline $\bar{D}_{4}(1000 t)$ & $10.232,130$ & $10.159,493$ \\
\hline
\end{tabular}

Fonte: Dados da simulação

(1) BOS (1986)

(2) SANTI et alii (1978) 
Tabela 4.9: Estimativas de estoques, preços, oferta e demanda de arroz para o caso $I_{0} \leq I_{00}$ e $u_{1} \neq 0-$ Brasil $1981 / 90$.

\begin{tabular}{|c|c|c|}
\hline \multirow{2}{*}{$\begin{array}{l}\text { Elasticidade Preço } \\
\text { da Demanda }\end{array}$} & \multicolumn{2}{|c|}{ Elasticidade Preço da Oferta } \\
\hline & $0,21^{(1)}$ & $0,30^{(2)}$ \\
\hline \multicolumn{3}{|l|}{$\eta_{D}=-0,31^{(2)}$} \\
\hline $\bar{I}_{1}(1000 t)$ & $3.079,446$ & $3.114,989$ \\
\hline$i_{12}(1000 t)$ & $1.382,767$ & $1.497,700$ \\
\hline$i_{13}(1000 t)$ & 974,164 & $1.018,398$ \\
\hline$i_{14}(1000 t)$ & 565,560 & 539,097 \\
\hline$i_{15}(1000 t)$ & 156,956 & $\begin{array}{r}59,795 \\
-\quad 5\end{array}$ \\
\hline $\bar{P}_{1}(\mathrm{Cr} \$ / t)$ & $47.728,45$ & $49.238,73$ \\
\hline $\bar{P}_{2}(\mathrm{Cr} \$ / t)$ & $53.538,45$ & $55.048,73$ \\
\hline $\bar{P}_{3}(\operatorname{Cr} \$ / t)$ & $59.348,45$ & $60.858,73$ \\
\hline $\bar{P}_{4}(\mathrm{Cr} \$ / t)$ & $65.158,45$ & $66.668,73$ \\
\hline$\tilde{P}_{5}(\mathrm{Cr} \$ / t)$ & $70.968,45$ & $72.478,73$ \\
\hline $\bar{S}_{1}(1000 t)$ & $11.753,070$ & $11.725,297$ \\
\hline $\bar{S}_{2}(1000 t)$ & $9.341,580$ & 9.163 .327 \\
\hline $\bar{S}_{3}(1000 t)$ & 9.506 .593 & $9.399,039$ \\
\hline $\bar{S}_{4}(1000 t)$ & $9.671,607$ & $9.634,750$ \\
\hline $\bar{S}_{5}(1000 t)$ & $9.836,620$ & $9.870,462$ \\
\hline & & \\
\hline $\bar{D}_{1}(1000 t)$ & $8.987,937$ & $8.924,617$ \\
\hline $\bar{D}_{2}(1000 t)$ & $10.724,347$ & $10.661,027$ \\
\hline $\bar{D}_{3}(1000 t)$ & $10.480,757$ & $10.417,437$ \\
\hline $\bar{D}_{4}(1000 t)$ & $10.237,167$ & $10.173,847$ \\
\hline $\bar{D}_{5}(1000 t)$ & $9.993,576$ & $9.930,257$ \\
\hline
\end{tabular}

Fonte: Dados da simulação

(1) BOS (1986)

(2) SANTI et alii (1978) 
Tabela 4.10: Estimativas de estoques, preços, oferta e demanda de arroz para o caso $I_{0}>I_{00}$ e $u_{1} \neq 0-$ Brasil 1981/90.

\begin{tabular}{|c|c|c|}
\hline \multirow{2}{*}{$\begin{array}{c}\text { Elasticidade Preço } \\
\text { da Demanda }\end{array}$} & \multicolumn{2}{|c|}{ Elasticidade Preço da Oferta } \\
\hline & $0,21^{(1)}$ & $0,30^{(2)}$ \\
\hline$\eta_{D}=-0,31^{(2)}$ & & \\
\hline $\bar{I}_{1}(1000 t)$ & $3.390,332$ & $3.394,436$ \\
\hline$i_{12}(1000 t)$ & $1.459,768$ & $1.567,564$ \\
\hline$i_{13}(1000 t)$ & $1.051,885$ & $1.088,262$ \\
\hline$i_{14}(1000 t)$ & 643,781 & 608,960 \\
\hline$i_{15}(1000 t)$ & 234,778 & - $\quad 129,659$ \\
\hline $\bar{P}_{1}(\mathrm{Cr} \$ / t)$ & $46.623,35$ & $48.391,85$ \\
\hline$\vec{P}_{2}(\mathrm{Cr} \$ / t)$ & $52.433,35$ & $54.201,85$ \\
\hline $\bar{P}_{3}(\mathrm{Cr} \$ / t)$ & $58.243,35$ & $60.011,85$ \\
\hline $\bar{P}_{4}(\mathrm{Cr} \$ / t)$ & $64.053,35$ & $65.821,85$ \\
\hline $\bar{P}_{5}(\mathrm{Cr} \$ / t)$ & $69.863,35$ & $71.631,85$ \\
\hline $\bar{S}_{1}(1000 t)$ & $11.638,833$ & $11.568,799$ \\
\hline $\bar{S}_{2}(1000 t)$ & $9.310,191$ & 9.128 .969 \\
\hline $\bar{S}_{3}(1000 t)$ & 9.475 .204 & $9.364,681$ \\
\hline$\tilde{S}_{4}(1000 t)$ & $9.640,218$ & $9.600,392$ \\
\hline $\bar{S}_{5}(1000 t)$ & $9.805,231$ & $9.836,104$ \\
\hline $\bar{D}_{1}(1000 t)$ & $9.034,269$ & $8.960,123$ \\
\hline $\bar{D}_{2}(1000 t)$ & $10.770,679$ & $10.696,533$ \\
\hline $\bar{D}_{3}(1-000 t)$ & $10.770,679$ & $10.452,942$ \\
\hline $\bar{D}_{4}(1000 t)$ & $10.283,499$ & $10.209,353$ \\
\hline $\bar{D}_{5}(1000 t)$ & $10.039,909$ & $9.965,763$ \\
\hline
\end{tabular}

Fonte: Dados da simulação

(1) BOS (1986)

(2) SANTI et alii (1978) 
Tabela 4.11: Estimativas de estoques, preços, oferta e demanda de arroz para o caso $I_{0}=0$ e $u_{1}=0-$ Brasil $1981 / 90$.

\begin{tabular}{|c|c|c|}
\hline \multirow{2}{*}{$\begin{array}{l}\text { Elasticidade Preço } \\
\text { da Demanda }\end{array}$} & \multicolumn{2}{|c|}{ Elasticidade Preço da Oferta } \\
\hline & $0,21^{(1)}$ & $0,30^{(2)}$ \\
\hline$\eta_{D}=-0,31^{(2)}$ & & \\
\hline $\bar{I}_{1}(1000 t)$ & $1.281,022$ & $1.312,838$ \\
\hline$i_{12}(1000 t)$ & 835,628 & 896,363 \\
\hline$i_{13}(1000 t)$ & 427,027 & 413,061 \\
\hline$i_{14}(1000 t)$ & 18,724 & - \\
\hline $\bar{P}_{1}(\operatorname{Cr} \$ / t)$ & $55.508,31$ & $56.528,02$ \\
\hline $\bar{P}_{2}(\mathrm{Cr} \$ / t)$ & $61.318,31$ & $62.338,02$ \\
\hline $\bar{P}_{3}(\mathrm{Cr} \$ / t)$ & $67.128,31$ & $68.148,02$ \\
\hline $\bar{P}_{4}(\mathrm{Cr} \$ / t)$ & $72.938,31$ & - \\
\hline $\bar{S}_{1}(1000 t)$ & $11.880,000$ & $11.879,868$ \\
\hline $\bar{S}_{2}(1000 t)$ & $9.563,540$ & 9.459 .053 \\
\hline $\bar{S}_{3}(1000 t)$ & 9.727 .551 & $9.694,765$ \\
\hline $\bar{S}_{4}(1000 t)$ & $9.892,264$ & - \\
\hline $\bar{D}_{1}(1000 t)$ & $10.641,758$ & $10.559,006$ \\
\hline$\vec{D}_{2}(1000 t)$ & $10.398,168$ & $10.355,416$ \\
\hline $\bar{D}_{3}(1000 t)$ & $10.154,578$ & $10.111,826$ \\
\hline $\bar{D}_{4}(1000 t)$ & $9.910,988$ & - \\
\hline
\end{tabular}

Fonte: Dados da simulação

(1) BOS (1986)

(2) SANTI et alii (1978) 
Tabela 4.12: Estimativas de estoques, preços, oferta e demanda de arroz para o caso $I_{0} \leq I_{00}$ e $u_{1}=0-$ Brasil 1981/90.

\begin{tabular}{l|r|r}
\hline Elasticidade Preço & \multicolumn{2}{|c}{ Elasticidade Preço da Oferta } \\
\cline { 2 - 3 } da Demanda & \multicolumn{1}{|c}{$0,21^{(1)}$} & \multicolumn{1}{|c}{$0,30^{(2)}$} \\
\hline$\eta_{D}=-0,31^{(2)}$ & & \\
$\bar{I}_{1}(1000 t)$ & $1.401,660$ & $1.414,831$ \\
$i_{12}(1000 t)$ & 874,921 & 947,067 \\
$i_{13}(1000 t)$ & 467,327 & 466,926 \\
$i_{14}(1000 t)$ & 58,732 & \\
& & \\
$\bar{P}_{1}(\mathrm{Cr} \$ / t)$ & $54.936,80$ & $55.913,40$ \\
$\bar{P}_{2}(\mathrm{Cr} \$ / t)$ & $60.746,80$ & $61.723,40$ \\
$\bar{P}_{3}(\mathrm{Cr} \$ / t)$ & $66.556,80$ & $67.553,40$ \\
$\bar{P}_{4}(\mathrm{Cr} \$ / t)$ & $72.366,80$ & \\
& & \\
$\bar{S}_{1}(1000 t)$ & $11.753,074$ & $11.725,297$ \\
$\bar{S}_{2}(1000 t)$ & $9.546,209$ & 9.434 .118 \\
$\bar{S}_{3}(1000 t)$ & 9.711 .213 & $9.669,830$ \\
$\bar{S}_{4}(1000 t)$ & $9.876,217$ & \\
& & \\
$\bar{D}_{1}(1000 t)$ & $10.665,720$ & $10.624,774$ \\
$\bar{D}_{2}(1000 t)$ & $10.422,130$ & $10.381,185$ \\
$\bar{D}_{3}(1000 t)$ & $10.178,539$ & $10.136,756$ \\
$\bar{D}_{4}(1000 t)$ & $9.934,949$ & \\
\hline
\end{tabular}

Fonte: Dados da simulação
(1) BOS (1986)
(2) SANTI et alii (1978) 
Tabela 4.13: Estimativas de estoques, preços, oferta e demanda de arroz para o caso $I_{0}>I_{00}$ e $u_{1}=0-$ Brasil 1981/90.

\begin{tabular}{l|r|r}
\hline Elasticidade Preço & \multicolumn{2}{|c}{ Elasticidade Preço da Oferta } \\
\cline { 2 - 3 } \multicolumn{1}{c}{ da Demanda } & \multicolumn{1}{c}{$0,21^{(1)}$} & \multicolumn{1}{c}{$0,30^{(2)}$} \\
\hline$\eta_{D}=-0,31^{(2)}$ & & \\
$\bar{I}_{1}(1000 t)$ & $1.699,663$ & $1.682,494$ \\
$i_{12}(1000 t)$ & 975,253 & $1.040,133$ \\
$i_{13}(1000 t)$ & 566,659 & 560,832 \\
$i_{14}(1000 t)$ & 158,065 & 81,529 \\
& & \\
$\bar{P}_{1}(\mathrm{Cr} \$ / t)$ & $53.524,35$ & $54.785,26$ \\
$\bar{P}_{2}(\mathrm{Cr} \$ / t)$ & $59.334,35$ & $60.595,26$ \\
$\bar{P}_{3}(\mathrm{Cr} \$ / t)$ & $65.144,35$ & $66.405,26$ \\
$\bar{P}_{4}(\mathrm{Cr} \$ / t)$ & $70.954,35$ & $72.215,26$ \\
& & \\
$\bar{S}_{1}(1000 t)$ & $11.683,833$ & $11.568,799$ \\
$\bar{S}_{2}(1000 t)$ & $9.506,095$ & 9.388 .350 \\
$\bar{S}_{3}(1000 t)$ & 9.671 .099 & $9.624,061$ \\
$\bar{S}_{4}(1000 t)$ & $9.836,103$ & $9.859,773$ \\
$\bar{D}_{1}(1000 t)$ & $10.724,938$ & $10.672,073$ \\
$\bar{D}_{2}(1000 t)$ & $10.481,348$ & $10.428,483$ \\
$\bar{D}_{3}(1000 t)$ & $10.237,758$ & $10.184,893$ \\
$\bar{D}_{4}(1000 t)$ & $9.994,168$ & $9.941,303$ \\
\hline
\end{tabular}

Fonte: Dados da simulação

(1) BOS (1986)

(2) SANTI et alii (1978) 
Tabela 4.14: Efeitos distributivos da armazenagem competitiva no mercado de arroz comparativamente ao não armazenamento - Brasil 1981/90.

\begin{tabular}{|c|c|c|}
\hline \multirow{2}{*}{$\begin{array}{c}\text { Elasticidade Preço } \\
\text { da Demanda }\end{array}$} & \multicolumn{2}{|c|}{ Elasticidade Preço da Oferta } \\
\hline & $0,21^{(1)}$ & $0,30^{(2)}$ \\
\hline \multirow{2}{*}{$\begin{array}{c}\eta_{D}=-0,31^{(2)} \\
E\left(W_{P}\right)\end{array}$} & \multicolumn{2}{|c|}{$I_{0}=0 ; u_{1} \neq 0$} \\
\hline & 412,897 & 495,270 \\
\hline$E\left(W_{C}\right)$ & $-299,717$ & $-369,480$ \\
\hline \multirow[t]{2}{*}{$E\left(W_{S}\right)$} & 113,180 & 125,790 \\
\hline & \multicolumn{2}{|c|}{$I_{0}=0 ; u_{1}=0$} \\
\hline$E\left(W_{P}\right)$ & 173,070 & - 208,334 \\
\hline$E\left(W_{C}\right)$ & $-148,520$ & $-182,856$ \\
\hline \multirow[t]{2}{*}{$E\left(W_{S}\right)$} & 24,550 & 25,478 \\
\hline & \multicolumn{2}{|c|}{$I_{0} \leq I_{00} ; u_{1} \neq 0$} \\
\hline$E\left(W_{P}\right)$ & 438,966 & 508,140 \\
\hline$E\left(W_{C}\right)$ & $-326,163$ & $-394,085$ \\
\hline \multirow[t]{2}{*}{$E\left(W_{S}\right)$} & 112,803 & 114,055 \\
\hline & \multicolumn{2}{|c|}{$I_{0} \leq I_{00} ; u_{1}=0$} \\
\hline$E\left(W_{P}\right)$ & 194,410 & 229,472 \\
\hline$E\left(W_{C}\right)$ & $-178,410$ & $-209,465$ \\
\hline \multirow[t]{2}{*}{$E\left(W_{S}\right)$} & 16,000 & 20,007 \\
\hline & \multicolumn{2}{|c|}{$I_{0}>I_{00} ; u_{1} \neq 0$} \\
\hline$E\left(W_{P}\right)$ & 451,288 & 541,427 \\
\hline$E\left(W_{C}\right)$ & $-349,888$ & $-433,212$ \\
\hline \multirow[t]{2}{*}{$E\left(W_{S}\right)$} & 101,400 & 108,200 \\
\hline & \multicolumn{2}{|c|}{$I_{0}>I_{00} ; u_{1}=0$} \\
\hline$E\left(W_{P}\right)$ & 236,306 & 264,754 \\
\hline \multirow{2}{*}{$E\left(W_{S}\right)$} & $-224,486$ & $-255,913$ \\
\hline & 11,820 & 8,841 \\
\hline
\end{tabular}

Fonte: Dados da simulação

(1) BOS (1986)

(2) SANTI et alii (1978) 


\subsubsection{Efeitos de uma Política de Completa Estabilização de Preços}

Pelas presuposições do modelo, o nível do preço que se consegue estabilizar através da manipulação de estoques é $P^{*}$, dado pela interação entre oferta e demanda esperadas ou seja, o preço que vigoraria se não houvesse armazenamento (estoques): Cr $\$ 107.000,00 / t$ para os anos 70 e $\operatorname{Cr} \$ 73.200,00 / t$ para os anos 80 .

Os efeitos distributivos da política de completa estabilização de preços, comparativamente à armazenagem competitiva foram estimados sob a ótica da Te-

- oria do Bem-Estar. Nos casos de $I_{0}=0$, conforme dado nas equaçòes 3.37 e 3.38 e, nos outros casos, estimados os valores do equilíbrio competitivo, quantificou-se ganhos (perdas) incorridos por produtores (consumidores) no primeiro ano de estabilização (aumento do preço de $P_{11}$ para $P^{*}$ conforme mostrado na Figura 3.7 ), e somou-se (deduziu-se) as perdas (ganhos) esperados para os outros anos em situação competitiva pois o que se deixa de perder é ganho e o que se deixa de ganhar é perda.

As Tabelas 4.15 e 4.16 apresentam as estimativas dos ganhos (perdas) máximas (mínimas) de produtores (consumidores), nas situações simuladas para as décadas de 70 e de 80 respectivamente.

Observa-se que a implementação dessa política implica em tranferências substanciais de renda de consumidores para produtores. As estimativas são de transferências mínimas de $\operatorname{Cr} \$ 20,9$ bilhões na década de 70 e de $\operatorname{Cr} \$ 50,9$ bilhões na década de 80. O nível das transferências varia significativamente em relação à estabilidade da demanda: em média a estabilização reduz de mais de $50 \%$ as transferências.

Como os níveis dos preços estabilizados são superiores aos pontos de intersecção da demanda de produtos para armazenamento com o eixo dos preços, a demanda de produtos para armazenamento por parte do governo é perfeitamente elástica.

Os dados apresentados nas Tabelas 4.17 e 4.18 mostram as quantidades totais que se esperam sejam armazenadas $\left(I_{1}\right)$, por parte do governo $\left(I_{1 G}\right)$ e por parte da iniciativa privada $\left(I_{1 A}\right)$. Ou seja, mostram o Estado assumindo a função armazenagem e os armazenadores sendo alijados da atividade.

Comparätivamenente à armázenagem competitiva as estimativas das quantidades que se espera sejam armazenadas (décadas de 70 e de 80 ), agora pelo governo, aumentam em média de $30 \%$ quando $U_{1} \neq 0$ e de $55 \%$ com estabilização da demanda $\left(u_{1}=0\right)$. 
Tabela 4.15: Efeitos da política de estabilização de preços no mercado de arroz: "Ganhos Mínimos dos Produtores" e "Perdas Máximas dos Consumidores" - Brasil $1971 / 80$.

\begin{tabular}{|c|c|c|}
\hline \multirow{2}{*}{$\begin{array}{c}\text { Elasticidade Preço } \\
\text { da Demanda }\end{array}$} & \multicolumn{2}{|c|}{ Elasticidade Preço da Oferta } \\
\hline & $0,21^{(1)}$ & $0,30^{(2)}$ \\
\hline$\eta_{D}=-0,31^{(2)}$ & \multicolumn{2}{|c|}{$I_{0}=0 ; u_{1} \neq 0$} \\
\hline Produtores & 665,503 & 607,971 \\
\hline \multirow[t]{2}{*}{ Consumidores } & $-620,756$ & $-561,175$ \\
\hline & \multicolumn{2}{|c|}{$I_{0}=0 ; u_{1}=0$} \\
\hline Produtores & 425,583 & 398,083 \\
\hline \multirow[t]{2}{*}{ Consumidores } & $-400,860$ & $-374,920$ \\
\hline & \multicolumn{2}{|c|}{$I_{0} \leq I_{00} ; u_{1} \neq 0$} \\
\hline Produtores & 713,612 & 683,380 \\
\hline \multirow[t]{2}{*}{ Consumidores } & $-657,536$ & $-625,214$ \\
\hline & \multicolumn{2}{|c|}{$I_{0} \leq I_{00} ; u_{1}=0$} \\
\hline Produtores & 446,200 & 414,013 \\
\hline \multirow[t]{2}{*}{ Consumidores } & $-425,120$ & $-393,052$ \\
\hline & \multicolumn{2}{|c|}{$I_{0}>I_{00} ; u_{1} \neq 0$} \\
\hline Produtores & 750,788 & 690,682 \\
\hline \multirow[t]{2}{*}{ Consumidores } & $-693,384$ & $-633,815$ \\
\hline & \multicolumn{2}{|c|}{$I_{0}>I_{00} ; u_{1}=0$} \\
\hline Produtores & 461,045 & 432,218 \\
\hline Consumidores & $-432,385$ & $-401,219$ \\
\hline
\end{tabular}

Fonte: Dados da simulação

(1) BOS (1986)

(2) SANTI et alii (1978) 
Tabela 4.16: Efeitos da política de estabilizaçăo de preços no mercado de arroz: "Ganhos Mínimos" e "Perdas Máximas" - Brasil 1981/90.

\begin{tabular}{|c|c|c|}
\hline \multirow{2}{*}{$\begin{array}{c}\text { Elasticidade Preço } \\
\text { da Demanda }\end{array}$} & \multicolumn{2}{|c|}{ Elasticidade Preço da Oferta } \\
\hline & $0,21^{(1)}$ & $0,30^{(2)}$ \\
\hline$\eta_{D}=-0,31^{(2)}$ & \multicolumn{2}{|c|}{$I_{0}=0 ; u_{1} \neq 0$} \\
\hline Produtores & 675,113 & 622,320 \\
\hline \multirow[t]{2}{*}{ Consumidores } & $-616,479$ & $-562,162$ \\
\hline & \multicolumn{2}{|c|}{$I_{0}=0 ; u_{1}=0$} \\
\hline Produtores & 453,889 & 430,735 \\
\hline \multirow[t]{2}{*}{ Consumidores } & $-379,446$ & 355,939 \\
\hline & \multicolumn{2}{|c|}{$I_{0} \leq I_{00} ; u_{1} \neq 0$} \\
\hline Produtores & 697,433 & 635,513 \\
\hline \multirow[t]{2}{*}{ Consumidores } & $-642,472$ & $-580,089$ \\
\hline & \multicolumn{2}{|c|}{$I_{0} \leq I_{00} ; u_{1}=0$} \\
\hline Produtores & 471,655 & 438,704 \\
\hline \multirow[t]{2}{*}{ Consumidores } & $-396,877$ & $-368,332$ \\
\hline & \multicolumn{2}{|c|}{$I_{0}>I_{00} ; u_{1} \neq 0$} \\
\hline Produtores & 737,090 & 665,924 \\
\hline \multirow[t]{2}{*}{ Consumidores } & $-688,365$ & $-615,018$ \\
\hline & \multicolumn{2}{|c|}{$I_{0}>I_{00} ; u_{1}=0$} \\
\hline Produtores & 506,613 & 468,361 \\
\hline Consumidores & $-440,132$ & $-403,389$ \\
\hline
\end{tabular}

Fonte: Dados da simulação

(1) BOS (1986)

(2) SANTI et alii (1978) 
Tabela 4.17: Efeitos da política de estabilização de preços: quantidade total de arroz a ser armazenada $\left(I_{1}\right)$, pelos empresários armazenadores $\left(I_{1 \mathrm{~A}}\right)$ e pelo governo $\left(I_{1 G}\right)$ - Brasil 1971/80.

\begin{tabular}{|c|c|c|c|}
\hline \multirow{2}{*}{$\begin{array}{c}\text { Elasticidade Preço } \\
\text { da Demanda }\end{array}$} & \multicolumn{3}{|c|}{ Elasticidade Preço da Oferta } \\
\hline & $0,21^{(1)}$ & \multicolumn{2}{|c|}{$0,30^{(2)}$} \\
\hline$\eta_{D}=-0,31^{(2)}$ & \multicolumn{3}{|c|}{$I_{0}=0 ; u_{1} \neq 0$} \\
\hline$I_{1}$ & $2.880,000$ & & $2.880,000$ \\
\hline$I_{1 A}$ & 0,000 & & 0,000 \\
\hline \multirow[t]{2}{*}{$I_{1 G}$} & $2.800,000$ & - & $2.800,000$ \\
\hline & \multicolumn{3}{|c|}{$I_{0}=0 ; u_{1}=0$} \\
\hline$I_{1}$ & $1.440,000$ & . & $1.440,000$ \\
\hline$I_{1 A}$ & 0,000 & & 0,000 \\
\hline \multirow[t]{2}{*}{$I_{1 G}$} & $1.440,000$ & & $1.440,000$ \\
\hline & \multicolumn{3}{|c|}{$I_{0} \leq I_{00} ; u_{1} \neq 0$} \\
\hline$I_{1}$ & $3.017,634$ & & $2.997,375$ \\
\hline$I_{1, A}$ & 0,000 & & 0,000 \\
\hline \multirow[t]{2}{*}{$I_{1 G}$} & $3.017,634$ & & $2.997,375$ \\
\hline & \multicolumn{3}{|c|}{$I_{0} \leq I_{00} ; u_{1}=0$} \\
\hline$I_{1}$ & $1.577,634$ & & $1.557,375$ \\
\hline$I_{1 A}$ & 0,000 & & 0,000 \\
\hline \multirow[t]{2}{*}{$I_{1 G}$} & $1.577,634$ & & $1.557,375$ \\
\hline & \multicolumn{3}{|c|}{$I_{0}>I_{00} ; u_{1} \neq 0$} \\
\hline$I_{1}$ & $3.058,700$ & & $3.050,423$ \\
\hline$I_{1.4}$ & 0,000 & & 0,000 \\
\hline \multirow[t]{2}{*}{$I_{1 G}$} & $3.058,700$ & & $3.050,423$ \\
\hline & \multicolumn{3}{|c|}{$I_{0}>I_{00} ; u_{1}=0$} \\
\hline$I_{1}$ & $1.618,700$ & & $1.610,423$ \\
\hline$I_{1 \mathrm{~A}}$ & 0,000 & & 0,000 \\
\hline$I_{1 G}$ & $1.618,700$ & & $1.610,423$ \\
\hline
\end{tabular}

Fonte: Dados da simulação

(1) BOS (1986)

(2) SANTI et alii (1978) 
Tabela 4.18: Efeitos da política de estabilização de preços: quantidade total de arroz a ser armazenada $\left(I_{1}\right)$, pelos empresários armazenadores $\left(I_{1 A}\right)$ e pelo governo $\left(\dot{I}_{1 G}\right)$ - Brasil 1981/90)

\begin{tabular}{|c|c|c|c|}
\hline \multirow{2}{*}{$\begin{array}{c}\text { Elasticidade Preço } \\
\text { da Demanda }\end{array}$} & \multicolumn{3}{|c|}{ Elasticidade Preço da Oferta } \\
\hline & 0,21 & \multicolumn{2}{|c|}{$0,30^{(2)}$} \\
\hline \multirow{2}{*}{$\begin{array}{c}\eta_{D}=-0,31^{(2)} \\
I_{1}\end{array}$} & \multicolumn{3}{|c|}{$I_{0}=0 ; u_{1} \neq 0$} \\
\hline & $3.960,000$ & & $3.960,000$ \\
\hline$I_{1 A}$ & 0,000 & & 0,000 \\
\hline \multirow[t]{2}{*}{$I_{1 G}$} & $3.960,000$ & - & $3.960,000$ \\
\hline & \multicolumn{3}{|c|}{$I_{0}=0 ; u_{1}=0$} \\
\hline$I_{1}$ & $1.980,000$ & . & $1.980,000$ \\
\hline$I_{1 \mathrm{~A}}$ & 0,000 & & 0,000 \\
\hline \multirow[t]{2}{*}{$I_{1 G}$} & $1.980,000$ & & $1.980,000$ \\
\hline & \multicolumn{3}{|c|}{$I_{0} \leq I_{00} ; u_{1} \neq 0$} \\
\hline$I_{1}$ & $4.147,366$ & & $4.119,588$ \\
\hline$I_{1 \mathrm{~A}}$ & 0,000 & & 0,000 \\
\hline \multirow[t]{2}{*}{$I_{1 G}$} & $4.147,366$ & & $4.119,588$ \\
\hline & \multicolumn{3}{|c|}{$I_{0} \leq I_{00} ; u_{1}=0$} \\
\hline$I_{1}$ & $2.167,363$ & & $2.139,589$ \\
\hline$I_{1 \mathrm{~A}}$ & 0,000 & & 0,000 \\
\hline \multirow[t]{2}{*}{$I_{1 G}$} & $2.167,363$ & & $2.139,589$ \\
\hline & \multicolumn{3}{|c|}{$I_{0}>I_{00} ; u_{1} \neq 0$} \\
\hline$I_{1}$ & $4.504,584$ & & $4.434,550$ \\
\hline$I_{1 A}$ & 0,000 & & 0,000 \\
\hline \multirow[t]{2}{*}{$I_{1 G}$} & $4.504,584$ & & $4.434,550$ \\
\hline & \multicolumn{3}{|c|}{$I_{0}>I_{00} ; u_{1}=0$} \\
\hline$I_{1}$ & $2.524,584$ & & $2.454,550$ \\
\hline$I_{1 A}$ & 0,000 & & 0,000 \\
\hline$I_{1 G}$ & $2.524,584$ & & $2.454,550$ \\
\hline
\end{tabular}

Fonte: Dados da simulação

(1) BOS (1986)

(2) SANTI et alii (1978) 


\subsubsection{Efeitos de uma Política de Estabilização Parcial de Preços}

Uma política de estabilização parcial de preços consiste na determinação de limites mínimos e máximos para a livre variação dos preços. Permite-se interferência no mercado do produto apenas quando os preços ultrapassarem os definidos limites.

No Brasil, com o objetivo de disciplinar as interferências governamentais nos mercados dos produtos integrantes da PGPM, dentre os quais o arroz faz parte,

" foi criado em 1977 o "preço de intervenção", que junto com o preço mínimo passaram a delimitar a faixa admitida para livre variação dos preços.

Dentro do mesmo raciocínio utilizado na análise da política de completa estabilização de preços, quantificou-se os efeitos da política de estabilização parcial de preços comparativamente à armazenagem competitiva, considerando apenas o limite inferior da faixa de variação dos preços.

Assim, estimativas de ganhos (perdas) mínimas (máximas) de produtores (consumidores), a partir dessa política são apresentadas nas Tabelas 4.19 e 4.20 . Os preços mínimos médios considerados foram: Cr $\$ 77.000,00 / t$ para a década de 70 e $\operatorname{Cr} \$ 57.100,00 / t$ para a década de 80 . As Tabelas 4.21 e 4.22 apresentam as estimativas das quantidades totais que se esperam sejam armazenadas $\left(I_{1}\right)$, por empresários armazenadores $\left(I_{1 A}\right)$ e pelo governo $\left(I_{1 G}\right)$.

Observa-se que no caso da década de 70, apesar de bem próximas, as "perdas máximas dos consumidores" apresentaram-se superiores aos "ganhos mínimos dos produtores".

Comparativamente à armazenagem competitiva, os efeitos da política de estabilização parcial de preços sobre as quantidades esperadas para armazenamento, apresentaram-se insignificantes quando $U_{1} \neq 0$. Nos casos com demanda estável, as quantidades que se espera sejam armazenadas diminuem de 22,3 a $12,8 \%$.

Estas constatações são explicadas pelo fato do nível do preço mínimo ter-se apresentado inferior às estimativas dos preços competitivos dados pela interação entre oferta e demanda de produtos para armazenamento, em todos os casos simulados para os anos 70 .

Conforme obsēervado por MOLLO (1980), ao analisar a PPM no periodo 1970/82, os preços mínimos do arroz se colocaram, muitas vezes, abaixo do custo de produção e os diferenciais entre o preço tendência e o preço mínimo foram os maiores dentre os seis produtos por ela analisados. A pesquisadora concluiu que na fixação do preço mínimo, a diretriz de controle imediatista de inflação teria predominado 
sobre a de apoio efetivo ao setor agrícola, e que o resultado daquele comportamento, salvo situações excepcionaimente favoráveis de clima, é de inflação por escassez.

Corroborando, os resultados das simulações da armazenagem competitiva e da política de estabilização parcial de preços, levam a inferir que a Política de Preços Mínimos, nos moldes implementados nos anos 70 é ineficiente pois não consegue contribuir positivamente no sentido de melhorar o funcionamento do sistema de preços, aumentar a capacidade de previsão dos produtores e influenciar a formação das expectativas no momento do produtor tomar as decisões de produção.

Quanto à década de 80 , ao contrário da de 70 , as estimativas dos efeitos de uma política de estabilização parcial de preços (Tabelas 4.20 e 4.22), comparativamente à armazenagem competitiva mostram, nada mais, que os efeitos de se fixar um preço mínimo acima do preço competitivo.

Nos casos simulados com demanda instável $\left(U_{1}=-1980,0\right.$ mil $\left.t\right)$, os preços mínimos apresentaram-se superiores aos preços competitivos o suficiente para inviabilizar, por completo, a armazenagem privada. Naquelas dadas situaçóes o governo teria que assumir a armazenagem retirando do mercado, em média, $32 \%$ da produção esperada. Comparativamente à armazenagem competitiva, os volumes a serem armazenados aumentam de $37 \%$ a $10 \%$.

Já nos casos de demanda estável, representativa para o arroz que tem baixa elasticidade renda, os preços mínimos apresentaram-se superiores aos preços competitivos, mas não suficientemente maiores para anular a demanda de produtos para armazenamento por parte da iniciativa privada. O nível do preço mínimo leva o governo a ter que participar, conjuntamente, da funçăo de armazenamento. Em média as quantidades estimadas para armazenamento aumentam de $8 \%$ em relação à armazenagem competitiva ( $12 \%$ da produção esperada).

Resta saber se, relativamente à armazenagem competitiva, os efeitos dos aumentos de preços são suficientes para compensar os custos sociais de se ter que assumir e/ou participar da função de armazenador e da administração dos estoques governamentais. Ressalta-se que em termos de bem-estar, ganhos (perdas) mínimos (máximos) de produtores (consumidores), praticamente se igualam (Tabelas $4.19 \mathrm{e}$ $4.20)$. 
Tabela 4.19: Efeitos da política de estabilização parcial de preços no mercado de arroz: "Ganhos Mínimos dos Produtores" e "Perdas Máximas dos Consumidores" Brasil 1971/80.

\begin{tabular}{|c|c|c|}
\hline \multirow{2}{*}{$\begin{array}{l}\text { Elasticidade Preço } \\
\text { da Demanda }\end{array}$} & \multicolumn{2}{|c|}{ Elasticidade Preço da Oferta } \\
\hline & 0,21 & $0,30^{(2)}$ \\
\hline$\eta_{D}=-0,31^{(2)}$ & \multicolumn{2}{|c|}{$I_{0}=0 ; u_{1} \neq 0$} \\
\hline Produtores & 471,098 & 391,002 \\
\hline \multirow[t]{2}{*}{ Consumidores } & $-503,660$ & $-415,827$ \\
\hline & \multicolumn{2}{|c|}{$I_{0}=0 ; u_{1}=0$} \\
\hline Produtores & 132,304 & 94,668 \\
\hline \multirow[t]{2}{*}{ Consumidores } & $-131,758$ & $-94,607$ \\
\hline & \multicolumn{2}{|c|}{$I_{0} \leq I_{00} ; u_{1} \neq 0$} \\
\hline Produtores & 447,320 & 409,576 \\
\hline \multirow[t]{2}{*}{ Consumidores } & $-525,449$ & $-432,878$ \\
\hline & \multicolumn{2}{|c|}{$I_{0} \leq I_{00} ; u_{1}=0$} \\
\hline Produtores & 165,424 & 121,586 \\
\hline \multirow[t]{2}{*}{ Consumidores } & $-166,481$ & $-120,573$ \\
\hline & \multicolumn{2}{|c|}{$I_{0}>I_{00} ; u_{1} \neq 0$} \\
\hline Produtores & 502,767 & 419,864 \\
\hline \multirow[t]{2}{*}{ Consumidores } & $-534,082$ & $-444,588$ \\
\hline & \multicolumn{2}{|c|}{$I_{0}>I_{00} ; u_{1}=0$} \\
\hline Produtores & 175,434 & 144,674 \\
\hline Consumidores & $-176,867$ & $-132,273$ \\
\hline
\end{tabular}

Fonte: Dados da simulação

(1) $\operatorname{BOS}(1986)$

(2) SANTI et alii (1978) 
Tabela 4.20: Efeitos da política de estabilização parcial de preços no mercado de arroz: "Ganhos Mínimos dos Produtores" e "Perdas Máximas dos Consumidores" Brasil 1981/90.

\begin{tabular}{|c|c|c|}
\hline \multirow{2}{*}{$\begin{array}{c}\text { Elasticidade Preço } \\
\text { da Demanda }\end{array}$} & \multicolumn{2}{|c|}{ Elasticidade Preço da Oferta } \\
\hline & $0,21^{(1)}$ & $0,30^{(2)}$ \\
\hline$\eta_{D}=-0,31^{(2)}$ & \multicolumn{2}{|c|}{$I_{0}=0 ; u_{1} \neq 0$} \\
\hline Produtores & 251,676 & 196,663 \\
\hline \multirow[t]{2}{*}{ Consumidores } & $-270,829$ & $-209,366$ \\
\hline & \multicolumn{2}{|c|}{$I_{0}=0 ; u_{1}=0$} \\
\hline Produtores & 161,439 & 196,707 \\
\hline \multirow[t]{2}{*}{ Consumidores } & $-167,967$ & $-204,653$ \\
\hline & \multicolumn{2}{|c|}{$I_{0} \leq I_{00} ; u_{1} \neq 0$} \\
\hline Produtores & 534,436 & 455,193 \\
\hline \multirow[t]{2}{*}{ Consumidores } & $-585,343$ & $-500,929$ \\
\hline & \multicolumn{2}{|c|}{$I_{0} \leq I_{00} ; u_{1}=0$} \\
\hline Produtores & 223,940 & 180,121 \\
\hline \multirow[t]{2}{*}{ Consumidores } & $-229,450$ & $-188,309$ \\
\hline & \multicolumn{2}{|c|}{$I_{0}>I_{00} ; u_{1} \neq 0$} \\
\hline Produtores & 588,540 & 495,958 \\
\hline \multirow[t]{2}{*}{ Consumidores } & $-647,292$ & $-548,223$ \\
\hline & \multicolumn{2}{|c|}{$I_{0}>I_{00} ; u_{1}=0$} \\
\hline Produtores & 277,143 & 226,281 \\
\hline Consumidores & $-290,854$ & $-237,914$ \\
\hline
\end{tabular}

Fonte: Dados da simulação

(1) BOS (1986)

(2) SANTI et alii (1978) 
Tabela 4.21: Efeitos da política de estabilização parcial de preços: quantidades total de arroz a ser armazenada $\left(I_{1}\right)$ pelos empresários $\left(I_{1 A}\right)$ e pelo governo $\left(I_{1 G}-\right.$ Brasil $1971 / 80$.

\begin{tabular}{|c|c|c|}
\hline \multirow{2}{*}{$\begin{array}{c}\text { Elasticidade Preço } \\
\text { da Demanda }\end{array}$} & \multicolumn{2}{|c|}{ Elasticidade Preço da Oferta } \\
\hline & $0,21^{(1)}$ & $0,30^{(2)}$ \\
\hline$\eta_{D}=-0,31^{(2)}$ & \multicolumn{2}{|c|}{$I_{0}=0 ; u_{1} \neq 0$} \\
\hline$I_{1}$ & $2.254,205$ & $2.254,205$ \\
\hline$I_{1 A}$ & $2.254,205$ & $2.254,205$ \\
\hline \multirow[t]{2}{*}{$I_{1 G}$} & 0,000 & 0,000 \\
\hline & \multicolumn{2}{|c|}{$I_{0}=0 ; u_{1}=0$} \\
\hline$I_{1}$ & 814,214 & 814,214 \\
\hline$I_{1 A}$ & 814,214 & 814,214 \\
\hline \multirow[t]{2}{*}{$I_{1 G}$} & 0,000 & 0,000 \\
\hline & \multicolumn{2}{|c|}{$I_{0} \leq I_{00} ; u_{1} \neq 0$} \\
\hline$I_{1}$ & $2.391,834$ & $2.371,575$ \\
\hline$I_{1 A}$ & $2.391,834$ & $2.371,575$ \\
\hline \multirow[t]{2}{*}{$I_{1 G}$} & 0,000 & 0,000 \\
\hline & \multicolumn{2}{|c|}{$I_{0} \leq I_{00} ; u_{1}=0$} \\
\hline$I_{1}$ & 951,834 & 931,575 \\
\hline$I_{1 \mathrm{~A}}$ & 951,834 & 931,575 \\
\hline \multirow[t]{2}{*}{$I_{1 G}$} & 0,000 & 0,000 \\
\hline & \multicolumn{2}{|c|}{$I_{0}>I_{00} ; u_{1} \neq 0$} \\
\hline$I_{1}$ & $2.433,080$ & $2.424,607$ \\
\hline$I_{1 A}$ & $2.433,080$ & $2.424,607$ \\
\hline \multirow[t]{2}{*}{$I_{1 G}$} & 0,000 & 0,000 \\
\hline & \multicolumn{2}{|c|}{$I_{0}>I_{00} ; u_{1}=0$} \\
\hline$I_{1}$ & 992,900 & 984,623 \\
\hline$I_{1 \mathrm{~A}}$ & 992,900 & 984,623 \\
\hline$I_{1 G}$ & 0,000 & 0,000 \\
\hline
\end{tabular}

Fonte: Dados da simulação

(1) BOS (1986)

(2) SANTI et alii (1978) 
Tabela 4.22: Efeitos da política de estabilização parcial de preços: quantidades total de arroz a ser armazenada $\left(I_{1}\right)$ pelos empresários $\left(I_{1 A}\right)$ e pelo governo $\left(I_{1 G}-\right.$ Brasil $1981 / 90$.

$1000 t$

\begin{tabular}{|c|c|c|}
\hline \multirow{2}{*}{$\begin{array}{c}\text { Elasticidade Preço } \\
\text { da Demanda }\end{array}$} & \multicolumn{2}{|c|}{ Elasticidade Preço da Oferta } \\
\hline & $0,21^{(1)}$ & $0,30^{(2)}$ \\
\hline$\eta_{D}=-0,31^{(2)}$ & \multicolumn{2}{|c|}{$I_{0}=0 ; u_{1} \neq 0$} \\
\hline$I_{1}$ & $3.969,389$ & $3.696,389$ \\
\hline$\Gamma_{1 \mathrm{~A}}$ & 0,000 & 0,000 \\
\hline \multirow[t]{2}{*}{$I_{1 G}$} & $3.969,389$ & $3.696,389$ \\
\hline & \multicolumn{2}{|c|}{$I_{0}=0: u_{1}=0$} \\
\hline$I_{1}$ & $1.304,991$ & $1.304,991$ \\
\hline$I_{1 A}$ & 945,592 & $1.109,625$ \\
\hline \multirow[t]{2}{*}{$I_{1 G}$} & 359,399 & 195,366 \\
\hline & \multicolumn{2}{|c|}{$I_{0} \leq I_{00} ; u_{1} \neq 0$} \\
\hline$I_{1}$ & $3.472,357$ & $3.444,574$ \\
\hline$r_{1 A}$ & 0,000 & 0,000 \\
\hline \multirow[t]{2}{*}{$I_{1 G}$} & $3.472,357$ & $3.444,574$ \\
\hline & \multicolumn{2}{|c|}{$I_{0} \leq I_{00} ; u_{1}=0$} \\
\hline$I_{1}$ & $1.492,354$ & $1.464,581$ \\
\hline$I_{1 \mathrm{~A}}$ & 945,262 & $1.219,052$ \\
\hline \multirow[t]{2}{*}{$I_{1 G}$} & 547,092 & 245,529 \\
\hline & \multicolumn{2}{|c|}{$I_{0}>I_{00} ; u_{1} \neq 0$} \\
\hline$I_{1}$ & $3.829,575$ & $3.759,542$ \\
\hline$I_{1 \mathrm{~A}}$ & 0,000 & 0,000 \\
\hline \multirow[t]{2}{*}{$I_{1 G}$} & $3.829,575$ & $3.759,542$ \\
\hline & \multicolumn{2}{|c|}{$I_{0}>I_{00} ; u_{1}=0$} \\
\hline$I_{1}$ & $1.849,576$ & $1.775,542$ \\
\hline$I_{1 \mathrm{~A}}$ & 945,262 & $1.109,625$ \\
\hline$I_{1 G}$ & 904,314 & 669,916 \\
\hline
\end{tabular}

Fonte: Dados da simulaçąo
(1) BOS (1986)
(2) SANTI et alii (1978) 


\subsection{Análise de Sensibilidade}

Considerando-se que o objetivo da análise de sensibilidade é dar maior profundidade ao aspecto quantitativo da Teoria da Armazenagem, com ênfase à sensibilidade do quantum a ser armazenado em uma economia de mercado, as simulações com base em elasticidades aleatoriamente escolhidas, foram feitas apenas para os valores esperados da década de 80 ou seja, no ponto $(\bar{P}=\mathrm{CR} \$ 73.200,00, \bar{Q}$ $=9.900,0$ mil $t$ ).

Os valores dos parâmetros das funções de demanda (consumo) esperada encontrados foram:

$$
\begin{aligned}
& \text { - para } \eta_{D}=-0,2, \alpha_{1}=0,027049 \text { e } \alpha_{0}=11.880 ; \\
& \text { - para } \eta_{D}=-0,3, \alpha_{1}=0,04057 \text { e } \alpha_{0}=12.870 ; \\
& \text { - para } \eta_{D}=-0,4, \alpha_{1}=0,05410 \text { e } \alpha_{0}=13.860 ; \mathrm{e}, \\
& \text { - para } \eta_{D}=-0,5, \alpha_{1}=0,06762 \text { e } \alpha_{0}=14.850 .
\end{aligned}
$$

E das funções de oferta (produção) esperadas:

- para $\eta_{S}=0,2, \beta_{1}=0,027049$ e $\beta_{0}=7.920$;

- para $\eta_{S}=0,3, \beta_{1}=0,04057$ e $\beta_{0}=6.930$

- para $\eta_{S}=0,4, \beta_{1}=0,05410$ e $\beta_{0}=5.940 ; \mathrm{e}$,

- para $\eta_{S}=0,5, \beta_{1}=0,06762$ e $\beta_{0}=4.950$.

Admitiu-se três níveis de estoques iniciais: um igual a zero; outro igual ao estoque crítico $\left(I_{00}\right)$ encontrado no caso de $\eta_{S}=\left|\eta_{D}\right|=0,2$, que soma 314,309 mil $t$; e um terceiro igual ao estoque crítico do caso de $\eta_{S}=\left|\eta_{D}\right|=0,5$ que soma 785,768 mil $t$.

Assim, simulou-se para cada um das 16 (dezesseis) possíveis combinações de elasticidades preço da oferta e da demanda, os três distintos casos de formação de preços conforme apresentados na Teoria.

Fez-se também variar a demanda: um caso de demanda instável denotada nas tabelas por $u_{1} \neq 0$ e valorizada em $u_{1}=-1.980,0$ mil $t$; e um caso de demanda estável denotada e valorizada por $u_{1}=0$. Não se fez variar a oferta. Em todos os casos simulados assumiu-se $v_{1}=1.980,0$ mil $t$

As Tabelas do Apêndice $\mathrm{A}$ apresentam as estimativas das quantidades a serem armazenadas $\left(I_{1}\right)$ e dos volumes a serem liberados $\left(i_{12}, i_{13}, \ldots, i_{1 n}\right)$ para três níveis de estoques iniciais com demanda instável $\left(u_{1} \neq 0\right)$ e com demanda estável $\left(u_{1}=0\right)$.

Em geral, aumentos de $\eta_{S}$ com $\eta_{D}$ constante, resultam em maiores quantidades disponíveis para armazenamento. Aumentos em $\eta_{D}$ com $\eta_{S}$ constante implicam em menores quantidades disponíveis para armazenagem. A sensibilidade do 
quantum a ser armazenado às variações em $\eta_{D}$ são maiores: a magnitude da redução na quantidade armazenada é maior do que a magnitude do aumento decorrente de maiores niveis de $\eta_{S}$.

Tanto nos casos de demanda instável quanto nos casos de demanda estável, quanto maiores as elasticidades preço da oferta e da demanda e maiores os níveis dos estoques iniciais, maiores serão as quantidades disponiveis para armazenamento. A estabilidade da demanda provoca queda acentuada nas quantidades a serem armazenadas e no periodo esperado de armazenamento.

As Tabelas do Apêndice B mostram as estimativas dos preços esperados as quais confirmam a compatibilidade da armazenagem competitiva com grandes flutuações de preços. Quando $\left|\eta_{D}\right|=\eta_{S}=0,2, I_{0}=0$ e $u_{1} \neq 0$, o preço do primeiro ano representa apenas $57,8 \%$ do valor esperado (Cr $\$ 73.200,00 / t$ ). Se $\left|\eta_{D}\right|=\eta_{S}=0,5, I_{0}=0$ e $u_{1}=0$, o preço do primeiro ano passa a representar $82,5 \%$ do esperado.

Dos casos simulados, as menores flutuações de preços foram verificadas nos casos de $I_{0}=0$ e $u_{1}=0$. Quanto menor o nível do estoque inicial e maiores os valores de $\left|\eta_{D}\right|$ e de $\eta_{S}$, com demanda estável, menores são as flutuações nos preços.

$\mathrm{O}$ Apêndice $\mathrm{C}$ apresenta as Tabelas das estimativas das quantidades que se espera sejam consumidas $\left(D_{1}, D_{2}, \ldots, D_{n}\right)$, e o Apêndice $D$ as Tabelas das estimativas das quantidades que se espera sejam produzidas $\left(S_{1}, S_{2}, \ldots, S_{n}\right)$.

Nos diversos casos de combinações de diferentes elasticidades preço da oferta e da demanda, de níveis de estoque inicial, e de estabilidade da demanda observa-se em comum, a tendência das estimativas dos preços esperados e das quantidades que se espera sejam consumidas e produzidas aos valores esperados do período em análise.

As tabelas do Apêndice $E$ apresentam os efeitos distributivos da armazenagem competitiva. Produtores ganham, consumidores perdem e os empresários armazenadores não tem lucro no equilíbrio da armazenagem competitiva.

Como esperado, quanto maior $\eta_{D}$, menor a perda dos consumidores e quanto maior $\eta_{S}$ maior o ganho dos produtores. Observa-se ser grande a sensibilidade dos efeitos distributivos quanto à estabilidade da demanda.

Por outco lado, as magnitudes das transferências de ganhos de consumidores para produtores apresentam-se bastante sensíveis aos níveis dos estoques iniciais. Quando $u_{1} \neq 0,\left|\eta_{D}\right|=\eta_{S}=0,5$ e $I_{0}=0$ a transferência de ganhos de consumidores para produtores é superior a $\operatorname{Cr} \$ 68,5$ bilhões; reduz-se para $\operatorname{Cr} \$ 61,6$ bilhões quando $I_{0} \leq I_{00}$; e para $\operatorname{Cr} \$ 49,7$ bilhões quando $I_{0}>I_{00}$. Quando $u_{1}=0$ estas transferências somam, aproximadamente, $\operatorname{Cr} \$ 12,5$ bilhões, $\operatorname{Cr} \$ 11,9$ bilhões e $\operatorname{Cr} \$$ 
3,4 bilhões, respectivamente.

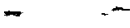




\section{Capítulo 5}

\section{Resumo e Conclusões}

Pressupondo-se que as expectativas sejam racionais, ou seja, que os agentes de mercado façam suas previsões com base nos valores esperados de equilíbrio, a Teoria da Armazenagem sob Condições de Incerteza - incerteza porque as decisões de produção têm que ser tomadas antes que os preços de mercado sejam conhecidos - apresentada neste estudo, mostrou como preços, estoques, quantidades consumidas e produzidas são determinadas para um horizonte temporal $(t, t+1, \ldots, t+n)$, onde, $t+n$ é o período esperado de armazenamento.

A partir da postulação de que a atividade de armazenagem tem um custo constante, foram derivadas as funções de oferta de produtos para armazenamento $\left(I_{1}^{S}\right)$, que relaciona as quantidades excedentes de produto a diferente níveis alternativos de preços e de demanda de produtos para armazenamento no primeiro ano $\left(I_{1}^{D}\right)$, definida como a soma das quantidades demandadas para armazenamento com liberações previstas para os anos futuros.

Mostrou-se que a armazenagem competitiva decorre da interação destas funções. Em equilíbrio, $I_{1}^{S}=I_{1}^{D}=I_{1}$, onde $I_{1}$ representa o excedente, o quantum a ser armazenado.

Pelo desenvolvimento teórico apresentado, conclui-se que a teoria da armazenagem competitiva é conclusiva pois, pelo conhecimento dos parâmetros do sistema representativo do mercado de um produto agrícola armazenavel, deduz-se os valores esperados de todas as variáveis endógenas para o período esperado de armazenamento, $t_{-}+n$.

Foi também demonstrado que a eficiência econômica é otimizada a partir da armazenagem competitiva. A maximização da função de ganhos esperados pela sociedade fornece uma solução análoga à do equilíbrio competitivo.

A avaliação quantitativa da teoria foi feita para o caso do arroz no Brasil. Pressupondo-se um modelo de elasticidade constante para o mercado do arroz ou 
seja, que as funções de oferta e demanda de arroz são da forma $Q=a P^{b}$, e dadas as elasticidades preço da oferta e da demanda, a parametrizaçăo das funçoos foi feita por aproximação linear em dois pontos $\left(\bar{P}_{70}, \bar{Q}_{70}\right.$ e $\left.\bar{P}_{80}, \bar{Q}_{80}\right)$ onde $\bar{P}_{70}$ e $\bar{P}_{80}$ são os preços médios recebidos pelos produtores nas décadas de 70 e de 80 e $\bar{Q}_{70}$ e $\bar{Q}_{80}$ os consumos aparentes médios das mesmas décadas, obtidos a partir dos valores observados nos períodos de 1971/80 e de 1981/90, respectivamente. Ou seja, são os valores esperados (esperança matemática) é, nestes casos iguais aos valores esperados simbolizados por $P^{*}$ e $Q^{*}$ na Teoria da Armazenagem, dados pela interação entre ofertas e demandas esperadas.

Foram realizadas simulações de armazenagem competitiva para as possíveis combinações das elasticidades estimadas por BOS (1986) e por SANTI et alii (1978), nos pontos $\left(\bar{P}_{70}, \bar{Q}_{70}\right)$ e $\left(\bar{P}_{80}, \bar{Q}_{80}\right)$. A análise de sensibilidade foi feita com base nas observações da década de 80 para elasticidades aleatórias, sem fundamento empírico.

Nos casos simulados com demanda estável $\left(U_{1}=0\right)$, representativo do caso do arroz, as quantidades estimadas para armazenamento no primeiro ano $\left(I_{1}\right)$ apresentam-se inferiores à média dos estoques finais/iniciais observados nos últimos cinco anos da década de $70(1.270,600 \mathrm{mil} t)$. No entanto, enquanto as quantidades estimadas variam de 995,935 a 1.141,660 mil $t$, as observadas variam de 519,000 a $2.021,00 \mathrm{mil} t$.

Para a década de 80 , as estimativas do quantum esperado para armazenamento $\left(I_{1}\right)$ variam de $1.281,022$ a $1.682,949$ mil $t$. Ressalta-se a discrepância entre estas e os níveis dos estoques observados (Tabela 2.6), em particular, os dos últimos quatro anos da década que, no caso da safra 1989/90 suplantou em $167,2 \%$ a maior estimativa.

A análise de sensibilidade mostrou que de modo geral, as quantidades disponíveis para armazenamento são bastante sensíveis aos níveis dos estoques iniciais e às elasticidades preço da oferta e da demanda. No entanto, das diversas situações simuladas $\%$ variação na demanda é que implica em maiores oscilações no quantum a ser armazenado.

As estimativas dos preços esperados mostram que a armazenagem -competitiva é perfeitamente compatível com grandes flutuações de preço. Em geral, quanto maiores as elasticidades preço da demanda e da oferta e menor o estoque inicial, menor a diferença entre preço atual e preço esperado.

Nos casos simulados com demanda instável, atípica para o caso do arroz, a menor estimativa de preço para o primeiro ano, décadas de 70 e 80 respectivamente, somam $68 \%$ e $80 \%$ do valor esperado. No entanto a queda dos preşos estimados 
para os $n-1$ anos de armazenamento (década de 70) consegue, no máximo, iguala-lo ao preço observado da década posterior.

Os níveis dos preços estimados para o primeiro ano com armazenagem competitiva (década de 80), apresentam-se baixos mas não o suficiente para igualaremse ao nível do preço observado no final da década.

Confrontando-se a "performance" do mercado arrozeiro nacional (Tabelas 2.4, 2.6 e 3.1 e Figura 2.2), com as simuladas situações de armazenagem competitiva, conclui-se que as políticas governamentais - estabilizantes e intervencionistas implementadas nestes últimos vinte anos não favoreceram o setor rizícola.

Por outro lado as estimativas dos efeitos distributivos de um política de armazenagem competitiva comparativamente ao não armazenamento, mostram que a política é socialmente recomendavel, os ganhos dela decorrentes são suficientes para compensar os indivíduos que perdem com ela e ainda resulta em ganhos líquidos para a sociedade.

Os efeitos de políticas de estabilização de preços comparativamente à armazenagem competitiva foram mensurados de acordo com os pressupostos da Teoria do Bem-Estar.

As simulações mostraram que a implementação de uma política de completa estabilização de preços envolve transferências substanciais de renda de consumidores para produtores e alijamento da iniciativa privada do setor armazenador. O governo teria que assumir a função de armazenador para garantir a política, armazenando volumes superiores aos da situação competitiva.

A mensuração dos efeitos de uma política de estabilização parcial de preços, comparativamente à armazenagem competitiva, serviu para demonstrar os efeitos de se fixar um preço mínimo fora do nível competitivo.

$\mathrm{Na}$ década de 70 o preço mínimo esteve sempre muito abaixo do competitivo. Os resultados das simulações levam a concluir que a política de preços mínimos nestes anos foi ineficiente.

Quanto à década de 80, o preço mínimo manteve-se superior aos preços competitivos. Em alguns casos simulados, superior o suficiente para levar o Estado a assumir por completo a armazenagem e em outros, a ter que dele participar junto com a iniciativa privadạ

Neste contexto é oportuno lembrar que, para que um política de preços mínimos seja efetiva, há que fornecer uma informação relevante ao processo de formação de expectativas de preços ao produtor. Como o preço competitivo dado pela interação das funções de oferta e demanda de produtos para armazenamento tem embutida a pressuposição de expectativas racionais, se o preço mínimo for fixado 
neste nível ter-se-á uma situação de "equivalência de certeza", ou seja, os produtores agiriam como se não existisse risco.

Assim, de forma a que a Teoria da Armazenagem sob Condições de Incerteza possa servir de suporte a inferências e definições de políticas de preço/armazenagem e para o próprio planejamento do setor agrícola é essencial a correta e precisa parametrização das funções de oferta e demanda de cada um dos produtos armazenáveis.

As simulações feitas neste estudo para o caso do arroz, têm caráter exemplificativo. Objetivaram fornecer uma dimensão quantitativa à teoria e indicativos da sensibilidade das variáveis endógenas às variações exógenas, ou seja, do grau de complexidade da função armazenagem.

Consequentemente, para maior aplicabilidade da Teoria, aqui apresentada, é necessário que o aspecto quantitativo seja aprofundado. Destacam-se as indicativas empíricas da sensibilidade dos preços esperados e do quantum a ser armazenado, às variáveis estocásticas e aos níveis dos estoques iniciais, evidenciadas neste estudo para o caso do arroz no Brasil. 


\section{Bibliografia}

[1] BRASIL. Ministério da Agricultura e Reforma Agrária. Plano Nacional Agrícola. Brasília, 1991.

[2] BRASIL. Ministério da Agricultura e Reforma Agrária. Plano Nacional Agrícola: medidas complementares. Brasília, 1991.

[3] BARRERA, J.V. Estudo das Vantagens comparativas dos sistemas de produção de arroz no Brasil. Viçosa, 1990. 215p. (Doutorado - Universidade Federal de Viçosa).

[4] BARROS, G.S.A.C.Economia da comercializaçăo agrícola. FEALQ, 1987. 306p.

[5] BOS, A.M. A produção e o consumo de alimentos básicos no Brasil. Análise Econômica. UFRGS. 4(6): 73-87, março/1986.

[6] COELHO, C. N. A. A política de preços mínimos dentro de uma perspectiva de desenvolvimento econômico. Coleção análise e pesquisa rit-12. Brasília, Comissão de Financiamento da Produção, 1979. 140 p.

[7] COMPANHIA BRASILEIRA DE ARMAZENAMENTO. Plano de racionalização de ativos. Brasília, 1990.

[8] COMPANHIA DE FINANCIAMENTO DA PRODUÇÃO. Relatório anual da CFP. Brasília, (vários).

[9] COMPANHIA DE FINANCIAMENTO DA PRODUÇÃo. Preços Mínimos: regióes centrō oesté, sudeste è sul. Brasília, 1975.

[10] CONTADOR, C.R. O cálculo dos benefícios e custos sociais. In: CONTADOR, C.R. Avaliação social de projetos, 2 ed. São Paulo, Atlas, 1988, cap. 4. 
[11] EMPRESA BRASILEIRA DE PLANEJAMENTO DE TRANSPORTES. Transporte e Armazenagem. Vol. 2, Brasília, 1982.

[12] FERGUSON, E.C. Microeconomia. 8 ed. Rio de Janeiro. Forense - Universitária; 1985, 610p.

[13] FRIEDMAn, M.Teoria dos Preços. Rio de Janeiro. Apec Editora S/A, 1975.

[14] FUNDAÇÃO

INSTITUTO BRASILEIRO DE GEOGRAFIA E ESTATÍSTICA. Anuário Estatístico do Brasil (vários).

[15] FUNDAÇÃO GETÚlIO VARGAS. Agroanalysis (vários)

[16] HARBERGER, H.C. Tree basic postulates for applied welfare economics: an interpretative essay. Journal of Economic Literatüre. Pensylvania, 2(3): 785-97, 1971.

[17] HELMBERGER, P. \& WEAVER, R. Welfare implications of commodity storage under uncertainty. American Journal of Agricultural Economics. 54(4): 639-651, 1977.

[18] LOPES, M.R. Formação e estabilização dos preços agrícolas: a especulação nos mercados agrícolas e formação da renda do produtor. Coleção Análise e Pesquisa. Vol. 28, Brasília, CFP, 1983.

[19] LOPES, M.R. A intervenção do governo nos mercados agrícolas no Brasil: o sistema de regras de interferência no mecanismo de preços. Coleção Análise e Pesquisa, Vol. 53. Brasília, CFP, 1986.

[20] LOPES, M.R. As razões para a mudança na política do arroz. Carta Mensal da SUPEC. 3(1). Brasília, 26 de janeiro de 1988.

[21] MENDES, J. T. G. Economia agrícola: princípios básicos e aplicações. Curitiba Scientia et Labor, 1989. 399 p.

[22] MILLER, L.R.Mičroeconomiá. São Paulo, McGraw-Hill do Brasil, 1981, 507p.

[23] MISHAN, V.E. Análise de custos-benefícios. Rio de Janeiro, Zahar Editores, 1976, 488p. 
[24] MOLLO, M. L. R. Política de garantia de preços mínimos: uma avaliação. Coleçã análise e pesquisa n-29. Brasília, Companhia de Financiamento da Produção, 1983. 45 p.

[25] MUTH, F.V. Rational expectations and the theory of price movements. Econometrica, 29(3): 315-335. July/1961.

[26] PORTO, R.O. coord. Estudo sobre métodos e processos de produção, beneficiamento e comercialização de arroz. Coleção Estudos Especiais, 18 Brasília, C.F.P., 1980, 129p.

[27] PUZZI, O. Abastecimento e armazenagem de grãos. Campinas. Instituto Campineiro de Ensino Agrícola. 12986 ed. 603p.

[28] REZENDE, G.C. Controvérsia de economia agrícola: uma revisão crítica. Textos para Discussão Interna n. (84). Rio de Janeiro, INPES/IPEA, dez. 1989

[29] SANTANA, A. C.; RUfinO, J. L. S.; VALE, S. M. L. R.; TEIXEIRA, E. C. e GARCIA, S. A. Efeitos da política de preços mínimos na produção de algodão e arroz no Nordeste. In: Congresso Brasileiro de Economia e Sociologia Rural. Campinas, 1991. Anais. Campinas, SOBER, 1991.

[30] SANTI, W.V.; ROCHA, D.S.; BARBOSA, T. e PANIAGO, E. Avaliação das políticas de preço mínimo e de subsídios a fertilizantes, para o caso do arroz no Brasil.Revista de Economia Rural, 16(2): 44-76. abr/jun. 1978.

[31] YAMAGUISHI, C.T.; TOSCANA, G.; ANJOS, N. M. e JUNQUEIRA, P.C. Aprimoramento do sistema de comercialização de grãos e derivados. IPEA/FEALQ, dez. 84/Relatório de Pesquisa. 
Apêndice A 
Tabela A.1: Estimativas das quantidades de arroz a serem armazenadas $\left(I_{1}\right)$ e dos volumes a serem liberados $\left(i_{12}, i_{13}, \ldots, i_{1 n}\right)$ no caso $I_{0}=0$ e $u_{1} \neq 0-$ Brasil $1981 / 90$.

$1000 t$

\begin{tabular}{|c|c|c|c|c|}
\hline \multirow{2}{*}{$\begin{array}{c}\text { Elasticidade Preço } \\
\text { da Demanda }\end{array}$} & \multicolumn{4}{|c|}{ Elasticidade Preço da Oferta (1) } \\
\hline & 0,2 & 0,3 & 0,4 & 0,5 \\
\hline \multicolumn{5}{|l|}{$\eta_{D}=-0,2$} \\
\hline $\bar{I}_{1}$ & $3.124,876$ & $3.216,784$ & 3.281 .120 & $3.328,670$ \\
\hline$i_{12}$ & $1.355,937$ & $1.465,151$ & $1.565,174$ & $1.659,614$ \\
\hline$i_{13}$ & $1.041,626$ & $1.072,282$ & $1.093,707$ & $1.109,631$ \\
\hline$i_{14}$ & 727,313 & 679,351 & $.622,239$ & 559,425 \\
\hline \multicolumn{5}{|l|}{$\eta_{D}=-0,3$} \\
\hline $\bar{I}_{1}$ & $2.907,111$ & $2.990,171$ & 3.052 .467 & $3.100,918$ \\
\hline$i_{12}$ & $1.361,927$ & $1.468,190$ & $1.567,534$ & $1.662,261$ \\
\hline$i_{13}$ & 969,037 & 996,724 & $1.017,488$ & $1.033,640$ \\
\hline$i_{14}$ & 576,147 & 525,257 & 467,445 & 405,017 \\
\hline \multicolumn{5}{|l|}{$\eta_{D}=-0,4$} \\
\hline $\bar{I}_{1}$ & $2.725,762$ & $2.798,357$ & 2.855 .466 & $2.901,522$ \\
\hline$i_{12}$ & $1.380,055$ & $1.482,831$ & $1.580,445$ & $1.674,374$ \\
\hline$i_{13}$ & 908,580 & 932,785 & 951,822 & 967,174 \\
\hline$i_{14}$ & 437,127 & 382,741 & 323,199 & 259,974 \\
\hline \multicolumn{5}{|l|}{$\eta_{D}=-0,5$} \\
\hline $\bar{I}_{1}$ & $2.563,795$ & $2.626,942$ & 2.678 .249 & $2.720,761$ \\
\hline$i_{12} \quad-\quad \cdots$ & $1.404 ; 643$ & $1.504,270$ & $1.599,950$ & $1.692,699$ \\
\hline$i_{13}$ & 854,598 & 875,647 & 892,750 & 906,920 \\
\hline$i_{14}$ & 304,554 & 247,025 & 185,549 & 121,142 \\
\hline
\end{tabular}

Fonte: Dados da simulação

(1) Aleatoriamente escolhidas . 
Tabela A.2: Estimativas das quantidades de arroz a serem armazenadas $\left(I_{1}\right)$ e dos volumes a serem liberados $\left(i_{12}, i_{13}, \ldots, i_{1 n}\right)$ no caso $I_{0} \leq I_{00}$ e $u_{1} \neq 0$ - Brasil 1981/90.

$1000 t$

\begin{tabular}{|c|c|c|c|c|}
\hline \multirow{2}{*}{$\begin{array}{c}\text { Elasticidade Preço } \\
\text { da Demanda }{ }^{(1)}\end{array}$} & \multicolumn{4}{|c|}{ Elasticidade Preço da Oferta (1) } \\
\hline & 0,2 & 0,3 & 0,4 & 0,5 \\
\hline \multicolumn{5}{|l|}{$\eta_{D}=-0,2$} \\
\hline $\bar{I}_{1}$ & $3.314,264$ & $3.357,115$ & 3.389 .430 & $3.413,120$ \\
\hline$i_{12}$ & $1.291,472$ & $1.428,578$ & $1.554,553$ & $1.678,338$ \\
\hline$i_{13}$ & 977,162 & $1.035,712$ & $1.083,090$ & $1.128,299$ \\
\hline$i_{14}$ & 662,852 & 642,846 & 611,626 & 578,261 \\
\hline$i_{15}$ & 348,544 & 249,979 & 140,161 & 28,222 \\
\hline \multicolumn{5}{|l|}{$\eta_{D}=-0,3$} \\
\hline $\bar{I}_{1}$ & $3.094,057$ & $3.135,889$ & 3.170 .384 & $3.205,738$ \\
\hline$i_{12}$ & $1.363,063$ & $1.491,108$ & $1.606,816$ & $1.697,175$ \\
\hline$i_{13}$ & 970,198 & $1.019,684$ & $1.056,794$ & $1.068,580$ \\
\hline$i_{14}$ & 577,331 & 548,261 & 506,773 & 439,984 \\
\hline$i_{15}$ & 184,465 & 76,837 & & \\
\hline \multicolumn{5}{|l|}{$\eta_{D}=-0,4$} \\
\hline $\bar{I}_{1}$ & $2.897,116$ & $2.949,216$ & 2.990 .173 & $3.023,192$ \\
\hline$i_{12}$ & $1.437,170$ & $1.533,093$ & $1.625,344$ & $1.714,924$ \\
\hline$i_{13}$ & 965,706 & 983,072 & 996,724 & $1.007,731$ \\
\hline$i_{14}$ & 494,241 & 433,051 & 368,106 & 300,537 \\
\hline \multicolumn{5}{|l|}{$\eta_{D}=-0,5$} \\
\hline$\tilde{I}_{1}$ & $2.745,136$ & $2.783,515$ & 2.774 .577 & $2.822,263$ \\
\hline$i_{12}-\ldots$ & $1.465,083$ & $1.558,434$ & $1.740,885$ & $1.804,016$ \\
\hline$i_{13}$ & 915,046 & 929,839 & $1.033,692$ & $1.018,248$ \\
\hline$i_{14}$ & 365,007 & 301,243 & & \\
\hline
\end{tabular}

Fonte: Dados da simulação

(1) Aleatoriamente escolhidas 
Tabela A.3: Estimativas das quantidades de arroz a serem armazenadas $\left(I_{1}\right)$ e dos volumes a serem liberados $\left(i_{12}, i_{13}, \ldots, i_{1 n}\right)$ no caso $I_{0}>I_{00}$ e $u_{1} \neq 0$ - Brasil $1981 / 90$.

\begin{tabular}{|c|c|c|c|c|}
\hline \multirow{2}{*}{$\begin{array}{c}\text { Elasticidade Preço } \\
\text { da Demanda }{ }^{(1)}\end{array}$} & \multicolumn{4}{|c|}{ Elasticidade Preço da Oferta ${ }^{(1)}$} \\
\hline & 0,2 & 0,3 & 0,4 & 0,5 \\
\hline \multicolumn{5}{|l|}{$\eta_{D}=-0,2$} \\
\hline $\bar{I}_{1}$ & $3.635,713$ & $3.635,713$ & $3.631,205$ & $3.617,928$ \\
\hline$i_{12}$ & $1.355,762$ & $1.498,228$ & $1.614,997$ & $1.726,037$ \\
\hline$i_{13}$ & $1.041,452$ & $1.105,362$ & $1.143,534$ & $1.178,333$ \\
\hline$i_{14}$ & 727,143 & 712,495 & 672,070 & 630,630 \\
\hline$i_{15}$ & 413,058 & 319,628 & 200,605 & 82,928 \\
\hline \multicolumn{5}{|l|}{$\eta_{D}=-0,3$} \\
\hline $\bar{I}_{1}$ & $3.419,048$ & $3.415,281$ & $3.409,531$ & $3.406,546$ \\
\hline$i_{12}$ & $1.444,061$ & $1.560,956$ & $1.677,415$ & $1.764,111$ \\
\hline$i_{13}$ & $1.051,958$ & $1.089,532$ & $1.127,394$ & $1.135,516$ \\
\hline$i_{14}$ & 658,329 & 618,108 & 577,372 & 506,920 \\
\hline$i_{15}$ & 265,462 & 146,685 & 27,352 & \\
\hline \multicolumn{5}{|l|}{$\eta_{D}=-0,4$} \\
\hline $\bar{I}_{1}$ & $3.214,676$ & $3.217,956$ & $3.225,902$ & $3.224,704$ \\
\hline$i_{12}$ & $1.510,865$ & $1.622,674$ & $1.703,919$ & $1.782,079$ \\
\hline$i_{13}$ & $1.039,401$ & $1.072,652$ & $1.075,301$ & $1.074,885$ \\
\hline$i_{14}$ & 567,936 & 522,261 & 445,958 & 367,692 \\
\hline$i_{15}$ & 96,473 & & & \\
\hline$\eta_{D}=-0,5$ & & . & & \\
\hline $\bar{I}_{1} \quad-$ & $3.044,331$ & $3.057,768$ & $3.061,321$ & $3.057,528$ \\
\hline$i_{12}$ & $1.564,815$ & $1.647,850$ & $1.727,633$ & $1.804,944$ \\
\hline$i_{13}$ & $1.014,777$ & $1.019,254$ & $1.020,440$ & $1.019,176$ \\
\hline$i_{14}$ & 464,739 & 390,660 & 313,247 & 233,408 \\
\hline
\end{tabular}

Fonte: Dados da simulação

(1) Aleatoriamente escolhidas 
Tabela A.4: Estimativas das quantidades de arroz a serem armazenadas $\left(I_{1}\right)$ e dos volumes a serem liberados $\left(i_{12}, i_{13}, \ldots, i_{1 n}\right)$ no caso $I_{0}=0$ e $u_{1}=0$ - Brasil 1981/90.

$1000 t$

\begin{tabular}{|c|c|c|c|c|}
\hline \multirow{2}{*}{$\begin{array}{c}\text { Elasticidade Preço } \\
\text { da Demanda }\end{array}$} & \multicolumn{4}{|c|}{ Elasticidade Preço da Oferta ${ }^{(1)}$} \\
\hline & 0,2 & 0,3 & 0,4 & 0,5 \\
\hline$\eta_{D}=-0,2$ & & & & \\
\hline $\bar{I}_{1}$ & $1.427,733$ & $1.469,715$ & $1.499,109$ & $1.526,233$ \\
\hline$i_{12}$ & 790,222 & 882,809 & 971,203 & $1.038,334$ \\
\hline$i_{13}$ & 475,935 & 490,165 & 499,740 & 488,110 \\
\hline$i_{14}$ & 161,625 & 97,299 & 28,276 & \\
\hline$\eta_{D}=-0,3$ & & & & \\
\hline $\bar{I}_{1}$ & $1.257,087$ & $1.299,596$ & $1.339,381$ & $1.361,597$ \\
\hline$i_{12}$ & 812,159 & 885,961 & 944,679 & 999,080 \\
\hline$i_{13}$ & 419,293 & 414,772 & 394,560 & 362,410 \\
\hline$i_{14}$ & 26,427 & & & \\
\hline$\eta_{D}=-0,4$ & & & & \\
\hline $\bar{I}_{1}$ & $1.131,402$ & $1.173,410$ & $1.206,829$ & $1.234,319$ \\
\hline$i_{12}$ & 801,431 & 861,716 & 917,724 & 970,750 \\
\hline$i_{13}$ & 329,969 & 311,694 & 289,105 & 263,427 \\
\hline$\eta_{D}=-0,5$ & & & & \\
\hline $\bar{I}_{1}$ & $1.024,684$ & $1.059,640$ & $1.088,308$ & $1.112,553$ \\
\hline$i_{12}$ & 787,350 & 844,112 & 897,754 & 949,149 \\
\hline$i_{13}$ & 237,331 & 215,533 & 190,601 & 163,404 \\
\hline
\end{tabular}

Fonte: Dados da simulação (1) Aleatoriamente escolhidas 
Tabela A.5: Estimativas das quantidades de arroz a serem armazenadas $\left(I_{1}\right)$ e dos volumes a serem liberados $\left(i_{12}, i_{13}, \ldots, i_{1 n}\right)$ no caso $I_{0}<I_{00}$ e $u_{1}=0$ - Brasil $1981 / 90$.

$1000 t$

\begin{tabular}{|c|c|c|c|c|}
\hline \multirow{2}{*}{$\begin{array}{l}\text { Elasticidade Preço } \\
\text { da Demanda }\end{array}$} & \multicolumn{4}{|c|}{ Elasticidade Preço da Oferta (1) } \\
\hline & 0,2 & 0,3 & 0,4 & 0,5 \\
\hline \multicolumn{5}{|l|}{$\eta_{D}=-0,2$} \\
\hline $\bar{I}_{1}$ & $1.562,423$ & $1.580,708$ & $1.593,413$ & $1.604,843$ \\
\hline$i_{12}$ & 835,148 & 919,621 & $1.002,103$ & $1.007,311$ \\
\hline$i_{13}$ & 520,842 & 526,754 & 531,138 & 527,272 \\
\hline$i_{14}$ & 206,532 & 133,888 & 59,674 & \\
\hline \multicolumn{5}{|l|}{$\eta_{D}=-0,3$} \\
\hline $\bar{I}_{1}$ & $1.414,304$ & $1.426,869$ & $1.450,354$ & $1.468,888$ \\
\hline$i_{12}$ & 894,520 & 949,147 & $1.000,188$ & $1.048,742$ \\
\hline$i_{13}$ & 501,653 & 477,723 & 450,166 & 420,146 \\
\hline$i_{14}$ & 108,787 & & & \\
\hline \multicolumn{5}{|l|}{$\eta_{D}=-0,4$} \\
\hline $\bar{I}_{1}$ & $1.288,556$ & $1.312,996$ & $1.332,549$ & $1.348,550$ \\
\hline$i_{12}$ & 880,010 & 931,508 & 980,584 & $1.027,872$ \\
\hline$i_{13}$ & 408,546 & 381,487 & 351,965 & 320,678 \\
\hline \multicolumn{5}{|l|}{$\eta_{D}=-0,5$} \\
\hline $\bar{I}_{1}$ & $1.190,132$ & $1.209,227$ & $1.225,012$ & $1.238,266$ \\
\hline$i_{12} \quad-\quad-$ & 870,086 & 918,912 & 966,098 & $1.012,016$ \\
\hline$i_{13}$ & 319,979 & 290,312 & 258,905 & 226,248 \\
\hline
\end{tabular}

Fonte: Dados da simulação

(1) Aleatoriamente escolhidas 
Tabela A.6: Estimativas das quantidades de arroz a serem armazenadas $\left(I_{1}\right)$ e dos volumes a serem liberados $\left(i_{12}, i_{13}, \ldots, i_{1 n}\right)$ no caso $I_{0} \geq 0$ e $u_{1}=0$ - Brasil 1981/90.

$1000 t$

\begin{tabular}{|c|c|c|c|c|}
\hline \multirow{2}{*}{$\begin{array}{c}\text { Elasticidade Preço } \\
\text { da Demanda }\end{array}$} & \multicolumn{4}{|c|}{ Elasticidade Preço da Oferta (1) } \\
\hline & 0,2 & 0,3 & 0,4 & 0,5 \\
\hline \multicolumn{5}{|l|}{$\eta_{D}=-0,2$} \\
\hline $\bar{I}_{1}$ & $1.864,519$ & $1.851,056$ & $1.829,144$ & $1.796,493$ \\
\hline$i_{12}$ & 936,149 & $1.009,886$ & $1.081,179$ & $1.148,869$ \\
\hline$i_{13}$ & 621,880 & 617,020 & 609,715 & 598,831 \\
\hline$i_{14}$ & 307,530 & 224,153 & $-138,250$ & 48,792 \\
\hline \multicolumn{5}{|l|}{$\eta_{D}=-0,3$} \\
\hline $\bar{I}_{1}$ & $1.724,818$ & $1.697,402$ & $1.674,359$ & $1.659,127$ \\
\hline$i_{12}$ & 967,806 & $1.037,224$ & $1.106,121$ & $1.143,823$ \\
\hline$i_{13}$ & 574,939 & 565,800 & 556,100 & 515,267 \\
\hline$i_{14}$ & 182,073 & 94,377 & 12,078 & \\
\hline \multicolumn{5}{|l|}{$\eta_{D}=-0,4$} \\
\hline $\bar{I}_{1}$ & $1.577,136$ & $1.561,825$ & $1.552,565$ & $1.537,889$ \\
\hline$i_{12}$ & 997,176 & $1.055,923$ & $1.090,592$ & $1.122,521$ \\
\hline$i_{13}$ & 525,711 & 505,902 & 461,974 & 415,328 \\
\hline$i_{14}$ & 54,248 & & & \\
\hline \multicolumn{5}{|l|}{$\eta_{D}=-0,5$} \\
\hline $\bar{I}_{1}$ & $1.463,083$ & $1.456,189$ & $1.443,657$ & $1.462,847$ \\
\hline$i_{12} \quad-$ & $1.006,561$ & $1.042,392$ & $1.075,426$ & $1.106,307$ \\
\hline$i_{13}$ & 465,520 & 413,797 & 368,232 & 320,540 \\
\hline
\end{tabular}

Fonte: Dados da simulação

(1) Aleatoriamente escolhidas 
Apêndice B 
Tabela B.1: Estimativas dos preços esperados para o arroz no caso $I_{0}=0$ e $u_{1} \neq 0$ - Brasil 1981/90.

\begin{tabular}{|c|c|c|c|c|}
\hline \multirow{2}{*}{$\begin{array}{c}\text { Elasticidade Preço } \\
\text { da Demanda }\end{array}$} & \multicolumn{4}{|c|}{ Elasticidade Preço da Oferta ${ }^{(1)}$} \\
\hline & 0,2 & 0,3 & 0,4 & 0,5 \\
\hline$\eta_{D}=-0,2$ & & & & \\
\hline $\bar{P}_{1}$ & $42.325,71$ & $45.723,53$ & $48.102,00$ & $49.859,86$ \\
\hline $\bar{P}_{2}$ & $48.135,71$ & $51.533,53$ & $53.912,00$ & $55.669,85$ \\
\hline $\bar{P}_{3}$ & $53.945,71$ & $57.343,53$ & $59.722,00$ & $61.479,85$ \\
\hline$\vec{P}_{4}$ & $59.755,71$ & $63.153,53$ & $65.532,00$ & $67.289,85$ \\
\hline \multicolumn{5}{|l|}{$\eta_{D}=-0,3$} \\
\hline$\vec{P}_{1}$ & $47.250,00$ & $49.297,14$ & $50.832,50$ & $52.026,67$ \\
\hline $\bar{P}_{2}$ & $53.060,00$ & $55.107,14$ & $56.642,50$ & $57.836,67$ \\
\hline $\bar{P}_{3}$ & $58.870,00$ & $60.917,14$ & $62.452,50$ & $63.646,67$ \\
\hline $\bar{P}_{4}$ & $64.680,00$ & $66.727,14$ & $68.262,50$ & $69.456,67$ \\
\hline \multicolumn{5}{|l|}{$\eta_{D}=-0,4$} \\
\hline $\bar{P}_{1}$ & $50.383,64$ & $51.727,20$ & $52.782,86$ & $53.634,19$ \\
\hline $\bar{P}_{2}$ & $56.193,64$ & $57.537,20$ & $58.592,86$ & $59.444,19$ \\
\hline $\bar{P}_{3}$ & $62.003,64$ & $63.347,20$ & $64.402,86$ & $65.254,19$ \\
\hline $\bar{P}_{4}$ & $67.813,64$ & $69.157,20$ & $70.212,86$ & $71.064,19$ \\
\hline \multicolumn{5}{|l|}{$\eta_{D}=-0,5$} \\
\hline $\bar{P}_{1}$ & $52.553,07$ & $53.486,89$ & $54.245,62$ & $54.874,28$ \\
\hline $\bar{P}_{2} \quad-\quad \cdots$ & $58.368,07$ & $59.296,89$ & $60.055,62$ & $60.684,28$ \\
\hline $\bar{P}_{3}$ & $64.173,07$ & $65.106,89$ & $65.865,62$ & $66.494,28$ \\
\hline$\ddot{P}_{4}$ & $69.983,07$ & $70.916,89$ & $71.765,62$ & $72.304,28$ \\
\hline
\end{tabular}

Fonte: Dados da simulação

(1) Aleatoriamente escolhidas . 
Tabela B.2: Estimativas dos preços esperados para o arroz no caso $I_{0}<I_{00}$ e $u_{1} \neq 0$

- Brasil 1981/90.

$\mathrm{Cr} \$ / \mathrm{t}$

\begin{tabular}{|c|c|c|c|c|}
\hline \multirow{2}{*}{$\begin{array}{c}\text { Elasticidade Preço } \\
\text { da Demanda }\end{array}$} & \multicolumn{4}{|c|}{ Elasticidade Preço da Oferta (1) } \\
\hline & 0,2 & 0,3 & 0,4 & 0,5 \\
\hline \multicolumn{5}{|l|}{$\eta_{D}=-0,2$} \\
\hline $\bar{P}_{1}$ & $43.517,67$ & $46.267,40$ & $48.233,23$ & $49.662,77$ \\
\hline $\bar{P}_{2}$ & $49.327,67$ & $52.077,40$ & $54.043,23$ & $55.472,77$ \\
\hline$\tilde{P}_{3}$ & $55.137,67$ & $57.887,40$ & $59.853,23$ & $61.282,77$ \\
\hline $\bar{P}_{4}$ & $60.947,67$ & $63.697,40$ & $65.663,23$ & $67.092,77$ \\
\hline $\bar{P}_{5}$ & $66.757,67$ & $69.507,40$ & $71.473,23$ & $72.902,77$ \\
\hline $\bar{P}_{6}$ & $72.567,67$ & & · & \\
\hline \multicolumn{5}{|l|}{$\eta_{D}=-0,3$} \\
\hline $\bar{P}_{1}$ & $47.236,28$ & $49.019,84$ & $50.420,03$ & $51.706,50$ \\
\hline $\bar{P}_{2}$ & $53.046,28$ & $54.829,84$ & $56.230,03$ & $57.516,50$ \\
\hline $\bar{P}_{3}$ & $58.856,28$ & $60.639,84$ & $62.040,03$ & $63.326,50$ \\
\hline $\bar{P}_{4}$ & $64.666,28$ & $66.449,84$ & $67.850,03$ & $69.136,50$ \\
\hline $\bar{P}_{5}$ & $70.476,28$ & $72.259,84$ & & \\
\hline$\eta_{D}=-0,4$ & & & & \\
\hline $\bar{P}_{1}$ & $49.679,79$ & $51.198,78$ & $52.368,27$ & $53.301,70$ \\
\hline $\bar{P}_{2}$ & $55.489,79$ & $57.008,78$ & $58.178,27$ & $59.111,70$ \\
\hline $\bar{P}_{3}$ & $61.299,79$ & $62.818,78$ & $63.988,27$ & $64.921,70$ \\
\hline $\bar{P}_{4}$ & $67.109,79$ & $68.628,78$ & $69.798,27$ & $70.731,70$ \\
\hline$\eta_{D}=-0,5$ & w & & & \\
\hline $\bar{P}_{1}$ & $51.915,35$ & $52.988,86$ & $53.088,41$ & $54.052,06$ \\
\hline $\bar{P}_{2}$ & $57.725,35$ & $58.798,86$ & $58.898,41$ & $59.862,06$ \\
\hline $\bar{P}_{3}$ & $63.535,35$ & $64.608,86$ & $64.708,41$ & $65.672,06$ \\
\hline $\bar{P}_{4}$ & $69.345,35$ & $70.418,86$ & & \\
\hline
\end{tabular}

Fonte: Dados da simulação 
Tabela B.3: Estimativas dos preços esperados para o arroz no caso $I_{0}>I_{00}$ e $u_{1} \neq 0$ - Brasil 1981/90.

\begin{tabular}{|c|c|c|c|c|}
\hline \multirow{2}{*}{$\begin{array}{c}\text { Elasticidade Preço } \\
\text { da Demanda }\end{array}$} & \multicolumn{4}{|c|}{ Elasticidade Preço da Oferta ${ }^{(1)}$} \\
\hline & 0,2 & 0,3 & 0,4 & 0,5 \\
\hline \multicolumn{5}{|l|}{$\eta_{D}=-0,2$} \\
\hline $\bar{P}_{1}$ & $42.329,28$ & $45.237,37$ & $47.488,38$ & $49.393,34$ \\
\hline $\bar{P}_{2}$ & $48.139,28$ & $51.047,37$ & $53.298,38$ & $55.203,34$ \\
\hline $\bar{P}_{3}$ & $53.949,27$ & $56.857,37$ & $59.108,38$ & $61.013,34$ \\
\hline $\bar{P}_{4}$ & $59.759,27$ & $62.667,37$ & $64.918,38$ & $66.823,34$ \\
\hline $\bar{P}_{5}$ & $65.569,27$ & $68.477,37$ & $70.728,38$ & $72.633,34$ \\
\hline $\bar{P}_{6}$ & $71.379,27$ & & & \\
\hline \multicolumn{5}{|l|}{$\eta_{D}=-0,3$} \\
\hline $\bar{P}_{1}$ & $46.038,42$ & $48.159,00$ & $49.674,28$ & $51.087,82$ \\
\hline$\tilde{P}_{2}$ & $51.848,42$ & $53.969,00$ & $55.484,28$ & $56.897,82$ \\
\hline $\bar{P}_{3}$ & $57.658,42$ & $59.779,00$ & $61.294,28$ & $62.707,82$ \\
\hline $\bar{P}_{4}$ & $63.468,42$ & $65.589,00$ & $67.104,28$ & $68.517,82$ \\
\hline $\bar{P}_{5}$ & $69.278,42$ & $71.399,00$ & $72.914,28$ & \\
\hline \multicolumn{5}{|l|}{$\eta_{D}=-0,4$} \\
\hline $\bar{P}_{1}$ & $48.771,62$ & $50.252,52$ & $51.642,04$ & $52.749,98$ \\
\hline $\bar{P}_{2}$ & $54.581,62$ & $56.062,52$ & $57.452,04$ & $58.559,98$ \\
\hline $\bar{P}_{3}$ & $60.391,62$ & $61.872,52$ & $63.262,04$ & $64.369,98$ \\
\hline $\bar{P}_{4}$ & $66.201,62$ & $67.682,52$ & $69.072,04$ & $70.179,98$ \\
\hline $\bar{P}_{5}$ & $72.011,62$ & & & \\
\hline$\eta_{D}=-0,5$ & & . & & \\
\hline $\bar{P}_{1} \quad-\quad \ldots$ & $50.861,89$ & $52.162,40$ & $53.197,28$ & $54.045,20$ \\
\hline $\bar{P}_{2}$ & $56.671,89$ & $57.972,40$ & $59.007,28$ & $59.855,20$ \\
\hline $\bar{P}_{3}$ & $62.481,89$ & $63.782,40$ & $64.817,28$ & $65.665,20$ \\
\hline $\bar{P}_{4}$ & $68.291,89$ & $69.592,40$ & $70.627,28$ & $71.475,20$ \\
\hline
\end{tabular}

Fonte: Dados da simulação (1) Aleatoriamente escolhidas 
Tabela B.4: Estimativas dos preços esperados para o arroz no caso $I_{0}=0$ e $u_{1}=0$

- Brasil 1981/90.

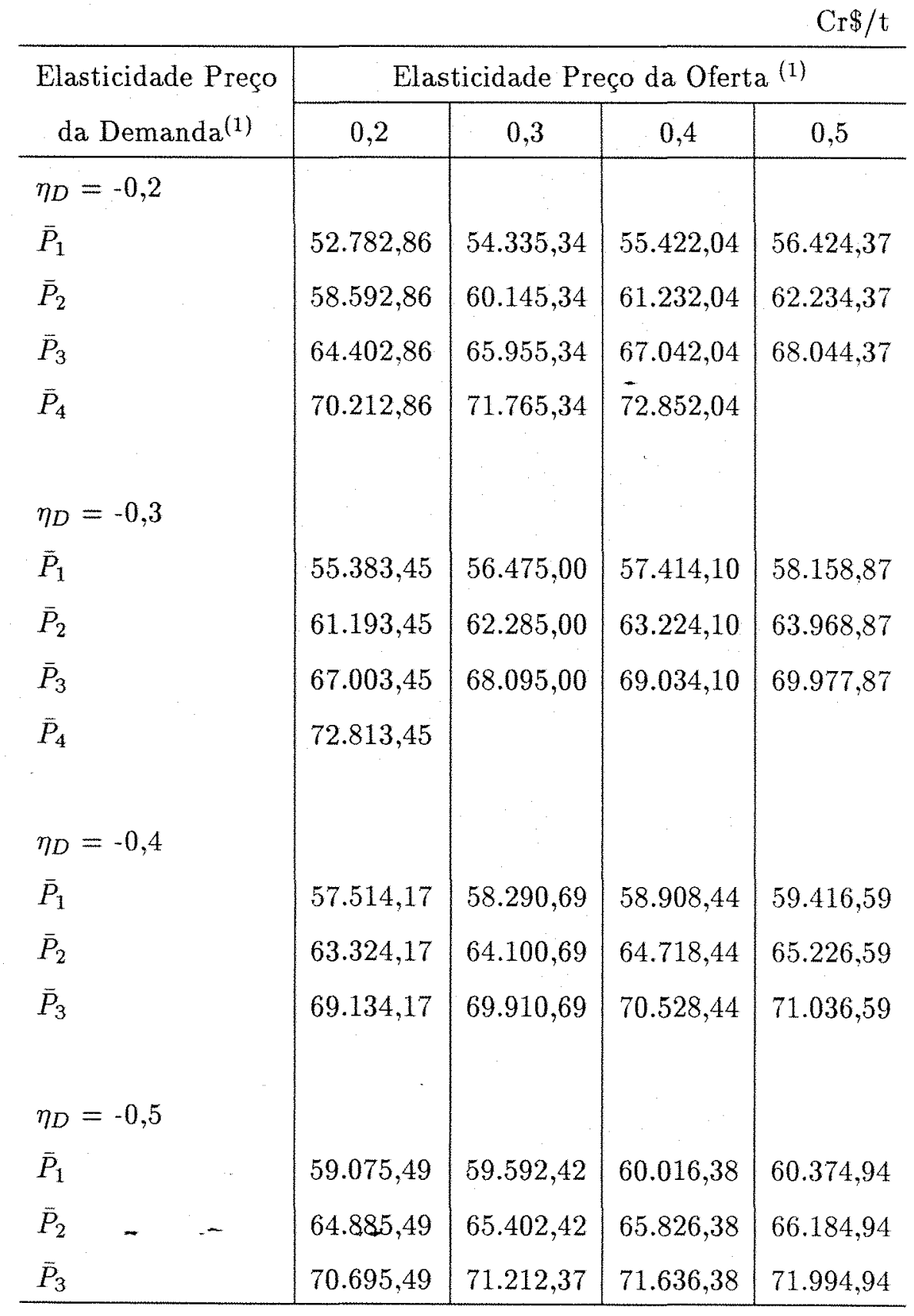

Fonte: Dados da simulação (1) Aleatoriamente escolhidas 
Tabela B.5: Estimativas dos preços esperados para o arroz no caso $I_{0} \leq I_{00}$ e $u_{1}=0$ - Brasil 1981/90.

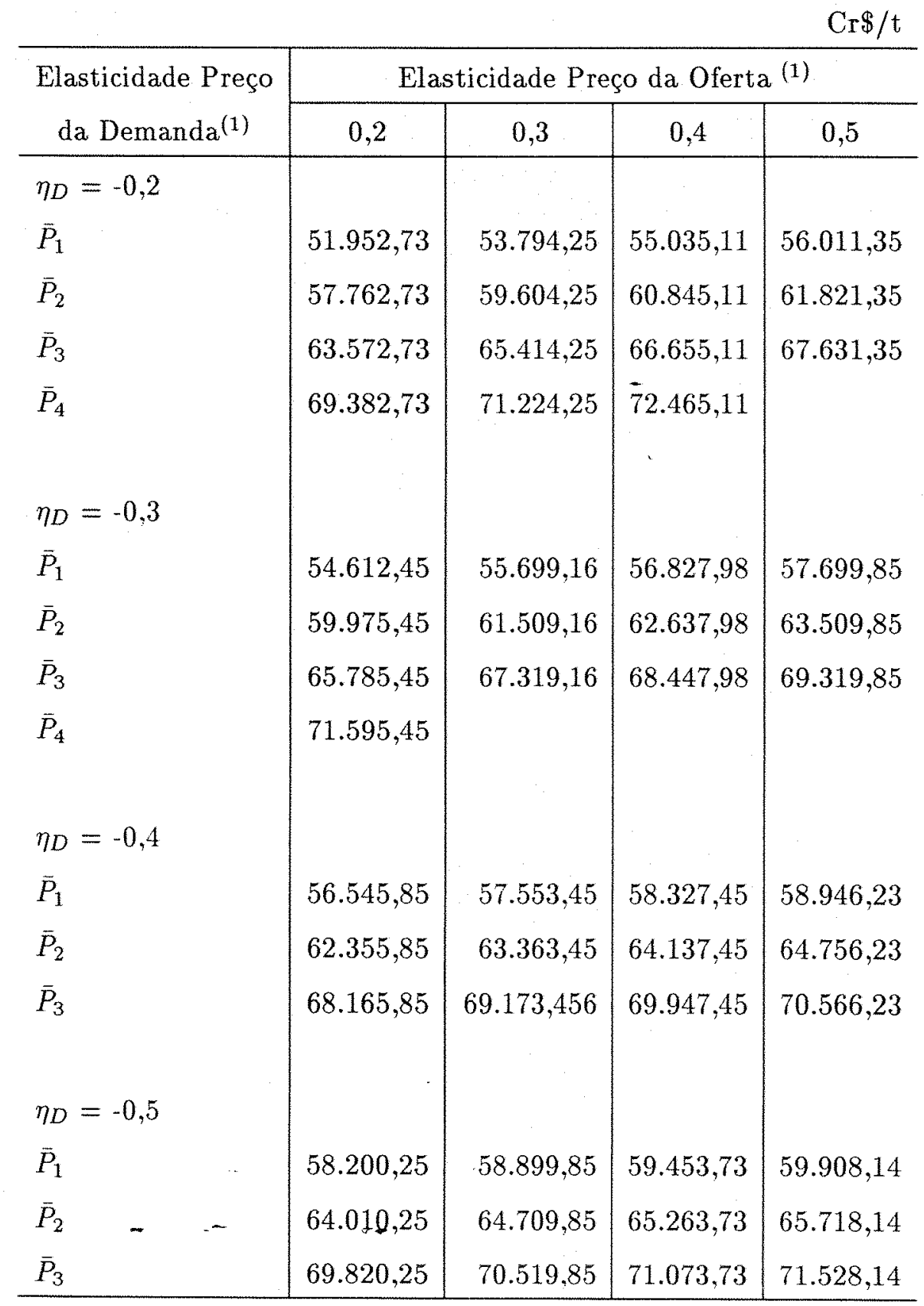

Fonte: Dados da simulação (1) Aleatoriamente escolhidas 
Tabela B.6: Estimativas dos preços esperados para o arroz no caso $I_{0}>I_{00}$ e $u_{1}=0$

- Brasil 1981/90.

$\mathrm{Cr} \$ / \mathrm{t}$

\begin{tabular}{|c|c|c|c|c|}
\hline \multirow{2}{*}{$\begin{array}{c}\text { Elasticidade Preço } \\
\text { da. Demanda } \\
(1)\end{array}$} & \multicolumn{4}{|c|}{ Elasticidade Preço da Oferta ${ }^{(1)}$} \\
\hline & 0,2 & 0,3 & 0,4 & 0,5 \\
\hline \multicolumn{5}{|l|}{$\eta_{D}=-0,2$} \\
\hline $\bar{P}_{1}$ & $50.085,80$ & $52.459,33$ & $54.066,78$ & $55.255,48$ \\
\hline $\bar{P}_{2}$ & $55.895,80$ & $58.269,33$ & $59.876,78$ & $61.065,48$ \\
\hline $\bar{P}_{3}$ & $61.705,80$ & $64.079,33$ & $65.686,78$ & $66.875,48$ \\
\hline $\bar{P}_{4}$ & $67.515,80$ & $69.889,33$ & $71.496,78$ & $72.685,48$ \\
\hline \multicolumn{5}{|l|}{$\eta_{D}=-0,3$} \\
\hline $\bar{P}_{1}$ & $53.081,64$ & $54.613,66$ & $55.708,98$ & $56.820,66$ \\
\hline $\bar{P}_{2}$ & $58.891,64$ & $60.423,66$ & $61.518,98$ & $62.630,66$ \\
\hline $\bar{P}_{3}$ & $64.701,64$ & $66.233,66$ & $67.328,98$ & $68.440,66$ \\
\hline $\bar{P}_{4}$ & $70.511,64$ & $72.043,66$ & $73.138,98$ & \\
\hline \multicolumn{5}{|l|}{$\eta_{D}=-0,4$} \\
\hline $\bar{P}_{1}$ & $55.101,98$ & $56.239,23$ & $57.310,70$ & $58.168,63$ \\
\hline $\bar{P}_{2}$ & $60.911,98$ & $62.049,23$ & $63.120,70$ & $63.978,63$ \\
\hline $\bar{P}_{3}$ & $66.721,98$ & $67.859,23$ & $68.930,70$ & $69.788,63$ \\
\hline $\bar{P}_{4}$ & $72.531,98$ & & & \\
\hline \multicolumn{5}{|l|}{$\eta_{D}=-0,5$} \\
\hline $\bar{P}_{1}$ & $56.758,67$ & $57.758,54$ & 58.555 .55 & $59.210,95$ \\
\hline $\bar{P}_{2}$ & $62.56 \overline{8}, 67$ & $63.568,54$ & $64.365,55$ & $65.020,95$ \\
\hline $\bar{P}_{3}$ & $68.378,67$ & $69.378,54$ & $70.175,55$ & $70.830,95$ \\
\hline
\end{tabular}

Fonte: Dados da simulação

(1) Aleatoriamente escolhidas 
Apêndice $\mathrm{C}$ 
Tabela C.1: Estimativas das quantidades de arroz que se espera que sejam demandadas no caso $I_{0}=0$ e $u_{1} \neq 0$ - Brasil 1981/90.

$1000 t$

\begin{tabular}{|c|c|c|c|c|}
\hline \multirow{2}{*}{$\begin{array}{c}\text { Elasticidade Preço } \\
\text { da Demanda }\end{array}$} & \multicolumn{4}{|c|}{ Elasticidade Preço da Oferta ${ }^{(1)}$} \\
\hline & 0,2 & 0,3 & 0,4 & 0,5 \\
\hline \multicolumn{5}{|l|}{$\eta_{D}=-0,2$} \\
\hline $\bar{D}_{1}$ & $8.755,124$ & $8.663,216$ & $8.598,880$ & $8.551,330$ \\
\hline $\bar{D}_{2}$ & $10.577,968$ & $10.486,060$ & $10.421,724$ & $10.374,186$ \\
\hline $\bar{D}_{3}$ & $10.420,813$ & $10.328,904$ & $10.264,569$ & $10.217,021$ \\
\hline $\bar{D}_{4}$ & $10.263,657$ & $10.171,749$ & $10.107,413$ & $10.059,806$ \\
\hline$\eta_{D}=-0,3$ & & & . & \\
\hline $\bar{D}_{1}$ & $8.972,889$ & $8.889,829$ & $8.827,534$ & $8.779,082$ \\
\hline $\bar{D}_{2}$ & $10.717,156$ & $10.634,095$ & $10.571,800$ & $10.523,348$ \\
\hline $\bar{D}_{3}$ & $10.481,422$ & $10.398,362$ & $10.336,067$ & $10.287,615$ \\
\hline$\tilde{D}_{4}$ & $10.245,688$ & $10.162,628$ & $10.100,333$ & $10.051,881$ \\
\hline \multicolumn{5}{|l|}{$\eta_{D}=-0,4$} \\
\hline $\bar{D}_{1}$ & $9.154,329$ & $9.081,643$ & $9.024,534$ & $8.978,478$ \\
\hline $\bar{D}_{2}$ & $10.820,036$ & $10.747,332$ & $10.690,222$ & $10.644,167$ \\
\hline $\bar{D}_{3}$ & $10.505,727$ & $10.433,020$ & $10.375,911$ & $10.329,855$ \\
\hline$\breve{D}_{4}$ & $10.191,418$ & $10.118,709$ & $10.061,599$ & $10.015,544$ \\
\hline \multicolumn{5}{|l|}{$\eta_{D}=-0,5$} \\
\hline $\bar{D}_{1}$ & $9.316,206$ & $9.253,058$ & $9.201,751$ & $9.159,239$ \\
\hline $\bar{D}_{2}$ & $10.903,316$ & $10.840,169$ & $10.788,861$ & $10.746,349$ \\
\hline $\bar{D}_{3}$ & $10.510,427$ & $10.447,279$ & $10.395,972$ & $10.353,460$ \\
\hline $\bar{D}_{4}$ & $10.117,538$ & $10.054,390$ & $10.003,083$ & $9.960,570$ \\
\hline
\end{tabular}

Fonte: Dados da simulação

(1) Aleatoriamente escolhidas. 
Tabela C.2: Estimativas das quantidades de arroz que se espera que sejam demandadas no caso $I_{0} \leq I_{00}$ e $u_{1} \neq 0-$ Brasil $1981 / 90$.

$1000 t$

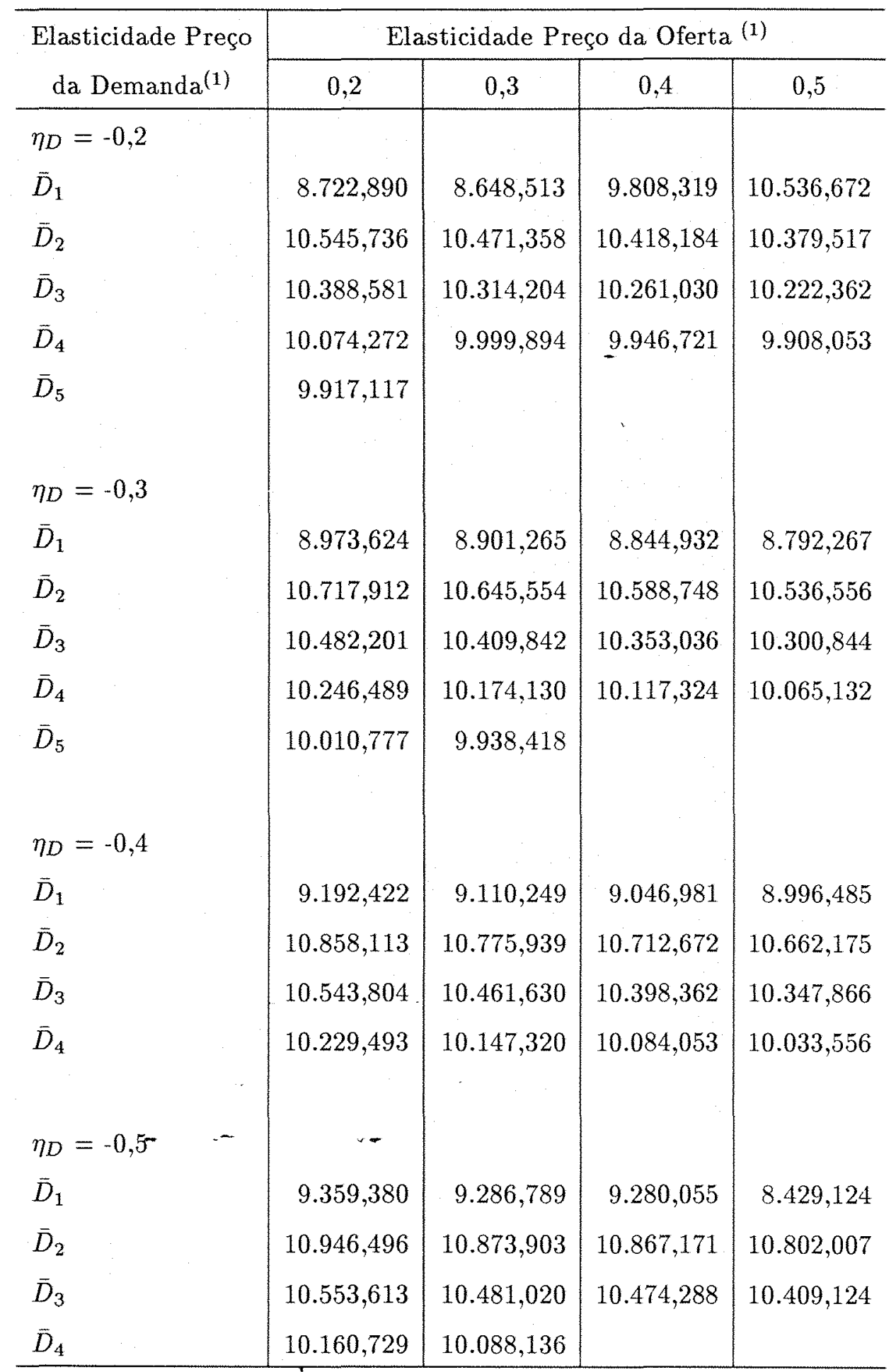

Fonte: Dados da simulação 
Tabela C.3: Estimativas das quantidades de arroz que se espera que sejam demandadas no caso $I_{0}>I_{00}$ e $u_{1} \neq 0$ - Brasil 1981/90.

$1000 t$

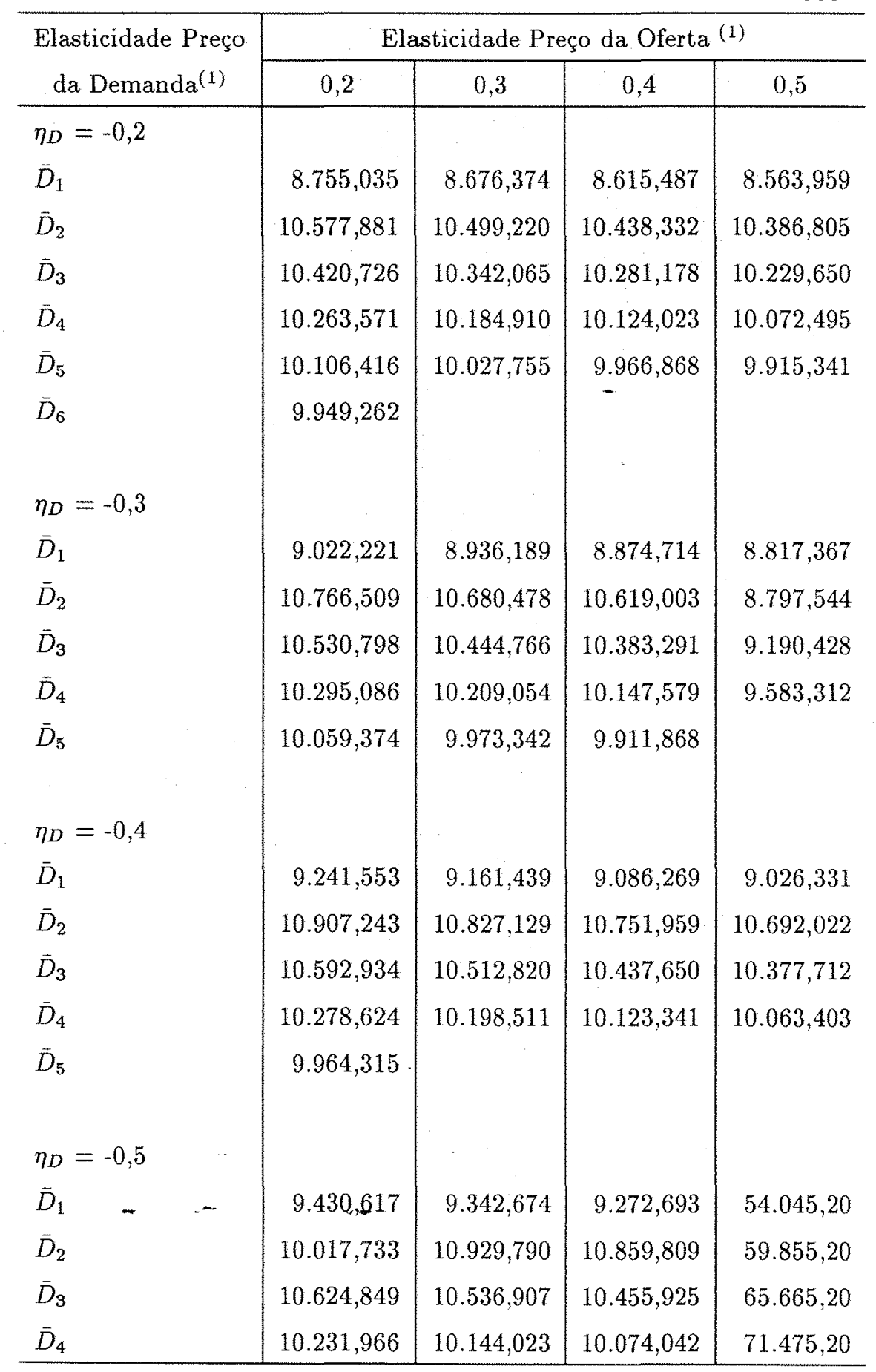

Fonte: Dados da simulação (1) Aleatoriamente escolhidas 
Tabela C.4: Estimativas das quantidades de arroz que se espera que sejam demandadas no caso $I_{0}=0$ e $u_{1}=0-$ Brasil 1981/90.

$1000 t$

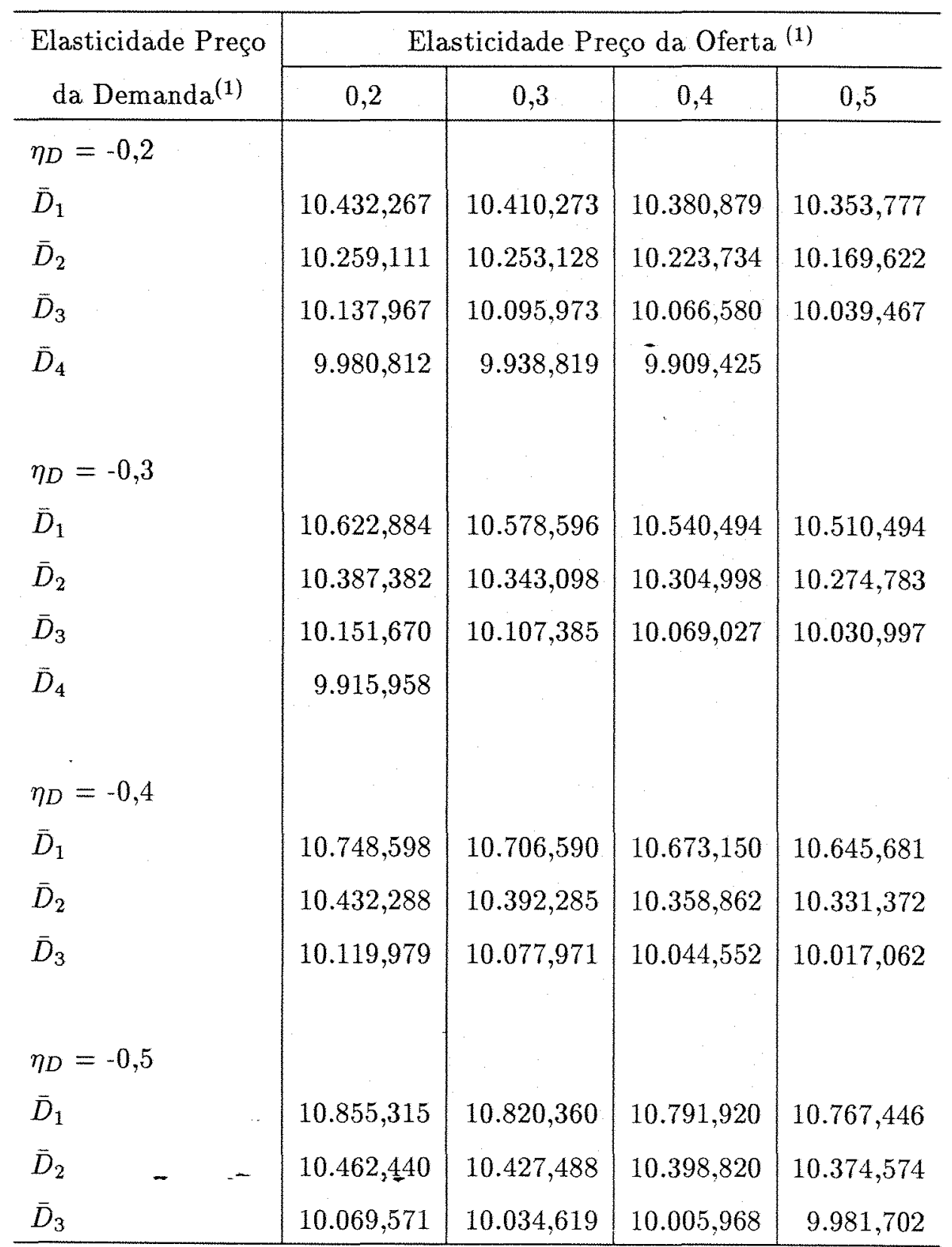

Fonte: Dados da simulação

(1) Aleatoriamente escolhidas 
Tabela C.5: Estimativas das quantidades de arroz que se espera que sejam demandadas no caso $I_{0} \leq I_{00}$ e $u_{1}=0$ - Brasil 1981/90.

$1000 t$

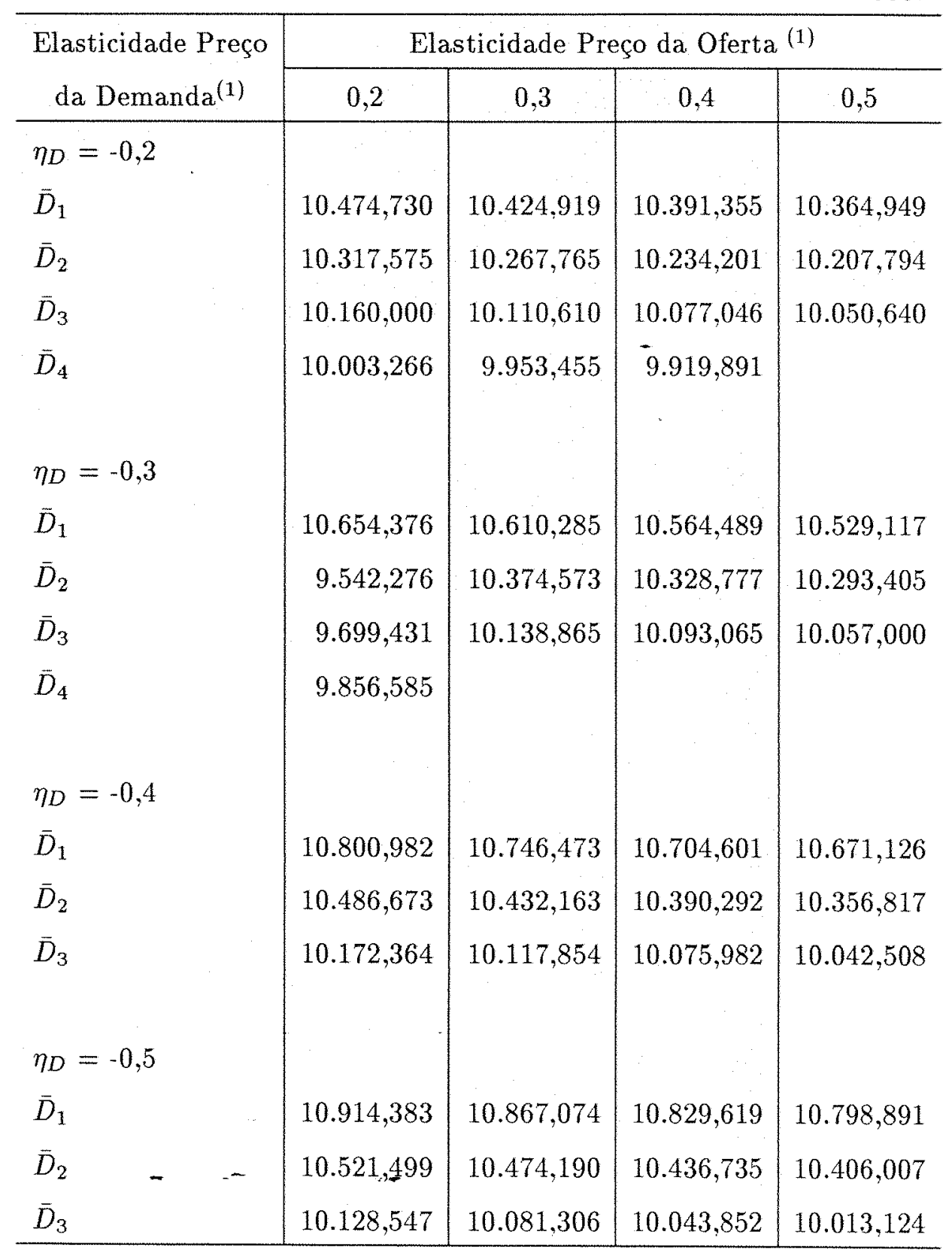

Fonte: Dados da simulação

(1) Aleatoriamente escolhidas 
Tabela C.6: Estimativas das quantidades de arroz que se espera que sejam demandadas no caso $I_{0}>I_{00}$ e $u_{1}=0$ - Brasil 1981/90.

\begin{tabular}{|c|c|c|c|c|}
\hline \multirow{2}{*}{$\begin{array}{c}\text { Elasticidade Preço } \\
\text { da Demanda }\end{array}$} & \multicolumn{4}{|c|}{ Elasticidade Preço da Oferta ${ }^{(1)}$} \\
\hline & 0,2 & 0,3 & 0,4 & 0,5 \\
\hline \multicolumn{5}{|l|}{$\eta_{D}=-0,2$} \\
\hline $\bar{D}_{1}$ & $10.525,229$ & $10.461,028$ & $10.417,548$ & $10.385,394$ \\
\hline $\bar{D}_{2}$ & $10.368,074$ & $10.303,873$ & $10.260,393$ & $10.228,240$ \\
\hline $\bar{D}_{3}$ & $10.210,920$ & $10.146,718$ & $10.103,238$ & $10.071,085$ \\
\hline $\bar{D}_{4}$ & $10.053,765$ & $9.989,563$ & $-9.946,083$ & $9.915,930$ \\
\hline$\eta_{D}=-0,3$ & & & & \\
\hline $\bar{D}_{1}$ & $10.716,477$ & $10.654,324$ & $10.609,886$ & $10.564,785$ \\
\hline $\bar{D}_{2}$ & $10.480,766$ & $10.418,612$ & $10.374,175$ & $10.329,074$ \\
\hline $\bar{D}_{3}$ & $10.245,054$ & $10.182,900$ & $10.138,463$ & $10.093,362$ \\
\hline $\bar{D}_{4}$ & $10.009,342$ & $9.947,188$ & $9.908,751$ & \\
\hline \multicolumn{5}{|l|}{$\eta_{D}=-0,4$} \\
\hline $\bar{D}_{1}$ & $10.879,0093$ & $10.817,569$ & $10.759,605$ & $10.713,193$ \\
\hline$\tilde{D}_{2}$ & $10.564,784$ & $10.503,260$ & $10.445,296$ & $10.398,884$ \\
\hline $\bar{D}_{3}$ & $10.250,474$ & $10.188,951$ & $10.130,987$ & $10.084,574$ \\
\hline$\widetilde{D}_{4}$ & $9.936,165$ & & & \\
\hline \multicolumn{5}{|l|}{$\eta_{D}=-0,5$} \\
\hline $\bar{D}_{1}$ & $11.011,865$ & $10.944,252$ & $10.890,357$ & $10.864,037$ \\
\hline $\bar{D}_{2}$ & $10.618, \overline{9} 81$ & $10.551,168$ & $10.497,473$ & $10.453,153$ \\
\hline $\bar{D}_{3}$ & $10.226,097$ & $10.158,484$ & $10.104,589$ & $10.060,270$ \\
\hline
\end{tabular}

Fonte: Dados da simulação

(1) Aleatoriamente escolhidas 
Apêndice D 
Tabela D.1: Estimativas das quantidades de arroz que se espera que sejam produzidas no caso $I_{0}=0$ e $u_{1} \neq 0-$ Brasil 1981/90.

$1000 t$

\begin{tabular}{|c|c|c|c|c|}
\hline \multirow{2}{*}{$\begin{array}{c}\text { Elasticidade Preço } \\
\text { da Demanda }\end{array}$} & \multicolumn{4}{|c|}{ Elasticidade Preço da Oferta ${ }^{(1)}$} \\
\hline & 0,2 & 0,3 & 0,4 & 0,5 \\
\hline \multicolumn{5}{|l|}{$\eta_{D}=-0,2$} \\
\hline $\bar{S}_{1}$ & $11.880,000$ & $11.880,000$ & $11.880,000$ & $11.880,000$ \\
\hline $\bar{S}_{2}$ & $9.222,019$ & $9.020,681$ & $8.856,526$ & $8.714,507$ \\
\hline $\bar{S}_{3}$ & $9.379,174$ & $9.256,393$ & $9.170,835$ & $9.107,390$ \\
\hline $\bar{S}_{4}$ & $9.536,328$ & $9.492,104$ & $9.485,145$ & $9.500,274$ \\
\hline \multicolumn{5}{|l|}{$\eta_{D}=-0,3$} \\
\hline $\bar{S}_{1}$ & $11.880,000$ & $11.880,000$ & $11.880,000$ & $11.880,000$ \\
\hline $\bar{S}_{2}$ & $9.355,190$ & $9.165,644$ & $9.004,209$ & $8.860,991$ \\
\hline $\bar{S}_{3}$ & $9.512,345$ & $9.401,136$ & $9.318,519$ & $9.253,875$ \\
\hline $\bar{S}_{4}$ & $9.669,499$ & $9.637,067$ & $9.632,828$ & $9.646,758$ \\
\hline \multicolumn{5}{|l|}{$\eta_{D}=-0,4$} \\
\hline $\bar{S}_{1}$ & $11.880,000$ & $11.880,000$ & $11.880,000$ & $11.880,000$ \\
\hline $\bar{S}_{2}$ & $9.439,981$ & $9.264,284$ & $9.109,756$ & $8.969,735$ \\
\hline $\bar{S}_{3}$ & $9.597,147$ & $9.499,995$ & $9.424,065$ & $9.755,502$ \\
\hline $\bar{S}_{4}$ & $9.754,291$ & $9.735,707$ & $9.738,375$ & $9.755,502$ \\
\hline \multicolumn{5}{|l|}{$\eta_{D}=-0,5$} \\
\hline $\bar{S}_{1}$ & $11.880,000$ & $11.880,000$ & $11.880,000$ & $11.880,000$ \\
\hline $\bar{S}_{2}$ & $9.498,559$ & $9.335,561$ & $9.188,722$ & $9.053,400$ \\
\hline $\bar{S}_{3}$ & $9.655,714$ & $9.571,272$ & $9.503,031$ & $9.446,284$ \\
\hline $\bar{S}_{4}$ & $9.812,869$ & $9.806,984$ & $9.817,340$ & $9.839,168$ \\
\hline
\end{tabular}

Fonte: Dados da simulação

(1) Aleatoriamente escolhidas. 
Tabela D.2: Estimativas das quantidades de arroz que se espera que sejam produzidas no caso $I_{0} \leq I_{00}$ e $u_{1} \neq 0$ - Brasil 1981/90.

$1000 t$

\begin{tabular}{|c|c|c|c|c|}
\hline \multirow{2}{*}{$\begin{array}{c}\text { Elasticidade Preço } \\
\text { da Demanda } \\
\end{array}$} & \multicolumn{4}{|c|}{ Elasticidade Preço da Oferta (1) } \\
\hline & 0,2 & 0,3 & 0,4 & 0,5 \\
\hline \multicolumn{5}{|l|}{$\eta_{D}=-0,2$} \\
\hline $\bar{S}_{1}$ & $11.722,845$ & $11.691,318$ & $11.670,461$ & $11.655,483$ \\
\hline $\bar{S}_{2}$ & $9.254,264$ & $9.042,780$ & $8.863,631$ & $8.701,179$ \\
\hline $\bar{S}_{3}$ & $9.411,419$ & $9.278,492$ & $9.177,940$ & $9.094,063$ \\
\hline $\bar{S}_{4}$ & $9.568,574$ & $9.514,203$ & $9.492,249$ & $9.486,947$ \\
\hline $\bar{S}_{5}$ & $9.725,728$ & $9.749,915$ & $9.806,559$ & $9.879,831$ \\
\hline $\bar{S}_{6}$ & $9.882,883$ & & & \\
\hline \multicolumn{5}{|l|}{$\eta_{D}=-0,3$} \\
\hline$\vec{S}_{1}$ & $11.754,372$ & $11.722,845$ & $11.700,534$ & $11.683,697$ \\
\hline $\bar{S}_{2}$ & $9.354,849$ & $9.154,446$ & $8.981,932$ & $8.839,381$ \\
\hline $\bar{S}_{3}$ & $9.512,003$ & $9.390,158$ & $9.296,241$ & $9.232,264$ \\
\hline $\bar{S}_{4}$ & $9.669,158$ & $9.625,869$ & $9.610,551$ & $9.625,148$ \\
\hline $\bar{S}_{5}$ & $9.826,312$ & $9.861,581$ & & \\
\hline \multicolumn{5}{|l|}{$\eta_{D}=-0,4$} \\
\hline $\bar{S}_{1}$ & $11.775,230$ & $11.745,156$ & $11.722,845$ & $11.705,368$ \\
\hline $\bar{S}_{2}$ & $9.420,943$ & $9.242,846$ & $9.087,328$ & $8.947,251$ \\
\hline$\tilde{S}_{3}$ & $9.578,098$ & $9.478,558$ & $9.401,638$ & $9.340,135$ \\
\hline $\bar{S}_{4}$ & $9.735,253$ & $9.714,269$ & $9.715,947$ & $9.733,019$ \\
\hline \multicolumn{5}{|l|}{$\eta_{D}=-0,5$} \\
\hline $\bar{S}_{1}$ & $11.790,207$ & $11.761,993$ & $11.740,322$ & $11.722,845$ \\
\hline $\bar{S}_{2}$ & $9.481,413$ & $9.315,470$ & $9.126,286$ & $8.997,992$ \\
\hline $\bar{S}_{3}$ & $9.638,567$ & $9.551,181$ & $9.144,595$ & $9.390,876$ \\
\hline $\bar{S}_{4}$ & $9.795,722$ & $9.786,893$ & & \\
\hline
\end{tabular}

Fonte: Dados da simulação

(1) Aleatoriamente escolhidas 
Tabela D.3: Estimativas das quantidades de arroz que se espera que sejam produzidas no caso $I_{0}>I_{00}$ e $u_{1} \neq 0$ - Brasil 1981/90.

\begin{tabular}{|c|c|c|c|c|}
\hline \multirow{2}{*}{$\begin{array}{c}\text { Elasticidade Preço } \\
\text { da Demanda }{ }^{(1)}\end{array}$} & \multicolumn{4}{|c|}{ Elasticidade Preço da Oferta ${ }^{(1)}$} \\
\hline & 0,2 & 0,3 & 0,4 & 0,5 \\
\hline \multicolumn{5}{|l|}{$\eta_{D}=-0,2$} \\
\hline $\bar{S}_{1}$ & $11.604,980$ & $11.526,319$ & $11.460,924$ & $11.396,120$ \\
\hline $\bar{S}_{2}$ & $9.222,119$ & $9.000,992$ & $8.823,335$ & $8.660,768$ \\
\hline $\bar{S}_{3}$ & $9.379,274$ & $9.236,703$ & $9.137,644$ & $9.051,317$ \\
\hline $\bar{S}_{4}$ & $9.536,428$ & $9.472,415$ & $9.451,953$ & $9.441,865$ \\
\hline $\bar{S}_{5}$ & $9.693,583$ & $9.708,127$ & $9.766,263$ & $9.832,413$ \\
\hline $\bar{S}_{6}$ & $9.850,738$ & & & \\
\hline \multicolumn{5}{|l|}{$\eta_{D}=-0,3$} \\
\hline $\bar{S}_{1}$ & $11.655,501$ & $11.565,702$ & $11.498,478$ & $11.438,145$ \\
\hline $\bar{S}_{2}$ & $9.322,448$ & $9.119,522$ & $8.941,588$ & $8.797,544$ \\
\hline $\bar{S}_{3}$ & $9.479,602$ & $9.355,234$ & $9.255,897$ & $9.190,428$ \\
\hline $\bar{S}_{4}$ & $9.636,757$ & $9.590,946$ & $9.570,207$ & $9.583,312$ \\
\hline $\bar{S}_{5}$ & $9.793,912$ & $9.826,657$ & $9.884,516$ & \\
\hline \multicolumn{5}{|l|}{$\eta_{D}=-0,4$} \\
\hline $\bar{S}_{1}$ & $11.670,461$ & $11.593,627$ & $11.526,403$ & $11.465,274$ \\
\hline$\tilde{S}_{2}$ & $9.396,378$ & $9.204,456$ & $9.048,040$ & $8.909,943$ \\
\hline $\bar{S}_{3}$ & $9.553,533$ & $9.440,168$ & $9.362,349$ & $9.302,827$ \\
\hline $\bar{S}_{4}$ & $9.710,688$ & $9.675,880$ & $9.676,383$ & $9.695,711$ \\
\hline $\bar{S}_{5}$ & $9.867,842$ & & & \\
\hline$\eta_{D}=-0,5$ & & . & & \\
\hline $\bar{S}_{1} \quad-$ & $11.689,180$ & $11.614,673$ & $11.548,246$ & $11.487,116$ \\
\hline $\bar{S}_{2}$ & $9.452,918$ & $9.281,940$ & $9.132,176$ & $8.997,528$ \\
\hline $\bar{S}_{3}$ & $9.610,072$ & $9.517,652$ & $9.446,485$ & $9.390,412$ \\
\hline $\bar{S}_{4}$ & $9.767,227$ & $9.753,363$ & $9.760,795$ & $9.783,296$ \\
\hline
\end{tabular}

Fonte: Dados da simulação

(1) Aleatoriamente escolhidas 
Tabela D.4: Estimativas das quantidades de arroz que se espera que sejam produzidas no caso $I_{0}=0$ e $u_{1}=0-$ Brasil 1981/90.

$1000 t$

\begin{tabular}{|c|c|c|c|c|}
\hline \multirow{2}{*}{$\begin{array}{c}\text { Elasticidade Preço } \\
\text { da Demanda } \\
\end{array}$} & \multicolumn{4}{|c|}{ Elasticidade Preço da Oferta } \\
\hline & 0,2 & 0,3 & 0,4 & 0,5 \\
\hline \multicolumn{5}{|l|}{$\eta_{D}=-0,2$} \\
\hline $\bar{S}_{1}$ & $11.880,000$ & $11.880,000$ & $11.880,000$ & $11.880,000$ \\
\hline $\bar{S}_{2}$ & $9.504,889$ & $9.370,320$ & $9.252,531$ & $9.158,288$ \\
\hline $\bar{S}_{3}$ & $9.662,032$ & $9.605,809$ & $9.566,840$ & $9.551,358$ \\
\hline$\tilde{S}_{4}$ & $9.819,187$ & $9.841,520$ & $9.881,149$ & \\
\hline \multicolumn{5}{|l|}{$\eta_{D}=-0,3$} \\
\hline $\bar{S}_{1}$ & $11.880,000$ & $11.880,000$ & $11.880,000$ & $11.880,000$ \\
\hline $\bar{S}_{2}$ & $9.575,222$ & $9.457,137$ & $9.360,319$ & $9.275,703$ \\
\hline $\bar{S}_{3}$ & $9.732,376$ & $9.692,614$ & $9.674,631$ & $9.668,587$ \\
\hline $\bar{S}_{4}$ & $9.889,531$ & & & \\
\hline \multicolumn{5}{|l|}{$\eta_{D}=-0,4$} \\
\hline $\bar{S}_{1}$ & $11.880,000$ & $11.880,000$ & $11.880,000$ & $11.880,000$ \\
\hline $\bar{S}_{2}$ & $9.632,856$ & $9.530,565$ & $9.441,138$ & $9.360,622$ \\
\hline $\bar{S}_{3}$ & $9.790,010$ & $9.766,277$ & $9.755,447$ & $9.753,636$ \\
\hline \multicolumn{5}{|l|}{$\eta_{D}=-0,5$} \\
\hline $\bar{S}_{1}$ & $11.880,000$ & $11.880,000$ & $11.880,000$ & $11.880,000$ \\
\hline $\bar{S}_{2}$ & $9.675,087$ & $9.583,376$ & $9.501,075$ & $9.425,425$ \\
\hline $\bar{S}_{3}$ & $9.832,240$ & $9.819,086$ & $9.815,368$ & $9.818,298$ \\
\hline
\end{tabular}

Fonte: Dados da simulação

(1) Aleatoriamente escolhidas 
Tabela D.5: Estimativas das quantidades de arroz que se espera que sejam produzidas no caso $I_{0} \leq I_{00}$ e $u_{1}=0-$ Brasil 1981/90.

\begin{tabular}{|c|c|c|c|c|}
\hline \multirow{2}{*}{$\begin{array}{c}\text { Elasticidade Preço } \\
\text { da Demanda } \\
\end{array}$} & \multicolumn{4}{|c|}{ Elasticidade Preço da Oferta ${ }^{(1)}$} \\
\hline & 0,2 & 0,3 & 0,4 & 0,5 \\
\hline \multicolumn{5}{|l|}{$\eta_{D}=-0,2$} \\
\hline $\bar{S}_{1}$ & $11.722,845$ & $11.691,310$ & $11.670,461$ & $11.655,480$ \\
\hline $\bar{S}_{2}$ & $9.482,428$ & $9.348,144$ & $9.231,598$ & $9.130,483$ \\
\hline $\bar{S}_{3}$ & $9,639,579$ & $9.583,856$ & $9.545,908$ & $9.523,367$ \\
\hline $\bar{S}_{4}$ & $9.796,733$ & $9.819,567$ & $\overline{9} .860,217$ & \\
\hline \multicolumn{5}{|l|}{$\eta_{D}=-0,3$} \\
\hline $\bar{S}_{1}$ & $11.754,372$ & $11.722,845$ & $11.700,534$ & $11.683,657$ \\
\hline $\bar{S}_{2}$ & $9.542,276$ & $9.425,426$ & $9.328,589$ & $9.244,663$ \\
\hline $\bar{S}_{3}$ & $9.699,431$ & $9.661,138$ & $9.642,899$ & $9.637,547$ \\
\hline $\bar{S}_{4}$ & $9.856,585$ & & & \\
\hline \multicolumn{5}{|l|}{$\eta_{D}=-0,4$} \\
\hline $\bar{S}_{1}$ & $11.775,230$ & $10.746,473$ & $11.722,845$ & $11.705,368$ \\
\hline $\bar{S}_{2}$ & $9.606,663$ & $9.500,655$ & $9.409,708$ & $9.368,945$ \\
\hline$\widetilde{S}_{3}$ & $9.763,818$ & $9.736,367$ & $9.724,017$ & $9.721,830$ \\
\hline \multicolumn{5}{|l|}{$\eta_{D}=-0,5$} \\
\hline $\bar{S}_{1}$ & $11.790,207$ & $11.761,993$ & $11.740,322$ & $11.722,845$ \\
\hline - & $9.651,413$ & $9.555,278$ & $9.470,637$ & $9.393,992$ \\
\hline $\bar{S}_{3}$ & $9.808,568$ & $9.790,990$ & $9.784,947$ & $9.786,876$ \\
\hline
\end{tabular}

Fonte: Dados da simulação

(1) Aleatoriamente escolhidas 
Tabela D.6: Estimativas das quantidades de arroz que se espera que sejam produzidas no caso $I_{0}>I_{00}$ e $u_{1}=0$ - Brasil 1981/90.

$1000 t$

\begin{tabular}{|c|c|c|c|c|}
\hline \multirow{2}{*}{$\begin{array}{c}\text { Elasticidade Preço } \\
\text { da Demanda }{ }^{(1)}\end{array}$} & \multicolumn{4}{|c|}{ Elasticidade Preço da Oferta ${ }^{(1)}$} \\
\hline & 0,2 & 0,3 & 0,4 & 0,5 \\
\hline$\eta_{D}=-0,2$ & & & & \\
\hline $\bar{S}_{1}$ & $11.605,981$ & $11.526,319$ & $11.460,924$ & $11.396,120$ \\
\hline $\bar{S}_{2}$ & $9.431,925$ & $9.293,987$ & $9.179,214$ & $9.079,370$ \\
\hline $\bar{S}_{3}$ & $9.589,080$ & $9.529,698$ & $9.493,523$ & $9.472,254$ \\
\hline $\bar{S}_{4}$ & $9.746,235$ & $9.765,410$ & $9.807,833$ & $9.865,138$ \\
\hline$\eta_{D}=-0,3$ & & & & \\
\hline$\tilde{S}_{1}$ & $11.655,501$ & $11.565,702$ & $11.498,478$ & $11.438,145$ \\
\hline $\bar{S}_{2}$ & $9.512,960$ & $9.381,388$ & $9.268,054$ & $9.185,211$ \\
\hline$\tilde{S}_{3}$ & $9.670,115$ & $9.617,100$ & $9.582,363$ & $9.578,095$ \\
\hline $\bar{S}_{4}$ & $9.827,269$ & $9.852,811$ & $9,869,673$ & \\
\hline$\eta_{D}=-0,4$ & & & & \\
\hline $\bar{S}_{1}$ & $11.670,461$ & $11.593,627$ & $11.526,403$ & $11.465,274$ \\
\hline $\bar{S}_{2}$ & $9.567,608$ & $9.447,337$ & $9.354,704$ & $9.276,363$ \\
\hline $\bar{S}_{3}$ & $9.724,763$ & $9.683,049$ & $9.669,013$ & $9.669,146$ \\
\hline $\bar{S}_{4}$ & $9.881,917$ & & & \\
\hline$\eta_{D}=-0,5$ & & & & \\
\hline $\bar{S}_{1}$ & $11.689,180$ & $11.614,673$ & $11.548,246$ & $11.487,116$ \\
\hline $\bar{S}_{2}$ & $9.612, \overline{4} 20$ & $9.508,976$ & $9.422,047$ & $9.346,846$ \\
\hline $\bar{S}_{3}$ & $9.796,577$ & $9.744,687$ & $9.736,357$ & $9.739,730$ \\
\hline
\end{tabular}

Fonte: Dados da simulação (1) Aleatoriamente escolhidas 
Apêndice E 
Tabela E.1: Efeitos distributivos da armazenagem competitiva no mercado de arroz no caso $I_{0}=0$ e $u_{1} \neq 0$ - Brasil 1981/90.

bilhão Cr\$

\begin{tabular}{|c|c|c|c|c|}
\hline \multirow{2}{*}{$\begin{array}{l}\text { Elasticidade Preço } \\
\text { da Demanda }\end{array}$} & \multicolumn{4}{|c|}{ Elasticidade Preço da Oferta (1) } \\
\hline & 0,2 & 0,3 & 0,4 & 0,5 \\
\hline$\eta_{D}=-0,2$ & & & & \\
\hline$E\left(W_{P}\right)$ & 816,548 & 958,547 & $1.057,342$ & $1.110,088$ \\
\hline$E\left(W_{C}\right)$ & $-603,512$ & $-739,485$ & $-380,055$ & $-879,571$ \\
\hline$E\left(W_{S}\right)$ & 213,036 & 219,062 & 227,287 & 231,517 \\
\hline$\eta_{D}=-0,3$ & & & & \\
\hline$E\left(W_{P}\right)$ & 434,597 & 521,273 & 585,761 & 635,755 \\
\hline$E\left(W_{C}\right)$ & $-307,587$ & $-389,986$ & $-451,340$ & $-498,794$ \\
\hline$E\left(W_{S}\right)$ & 127,010 & 131,287 & 134,421 & 136,961 \\
\hline$\eta_{D}=-0,4$ & & & & \\
\hline$E\left(W_{P}\right)$ & 272,026 & 329,169 & 373,891 & 409,870 \\
\hline$E\left(W_{C}\right)$ & $-185,362$ & $-239,811$ & $-282,319$ & $-316,424$ \\
\hline$E\left(W_{S}\right)$ & 86,664 & 89,358 & 91,572 & 93,446 \\
\hline$\eta_{D}=-0,5$ & & & & \\
\hline$E\left(W_{P}\right)$ & 186,527 & 226,492 & 262,886 & 285,667 \\
\hline$E\left(W_{C}\right)$ & $-123,159$ & $-161,185$ & $-195,918$ & $-217,146$ \\
\hline$E\left(W_{S \downarrow} \downarrow\right.$ & 63,368 & 65,307 & 66,968 & 68,521 \\
\hline
\end{tabular}

Fonte: Dados da simulação

(1) Aleatoriamente escolhidas 
Tabela E.2: Efeitos distributivos da armazenagem competitiva no mercado de arroz no caso $I_{0} \leq I_{00}$ e $u_{1} \neq 0-$ Brasil 1981/90.

bilhão Cr\$

\begin{tabular}{|c|c|c|c|c|}
\hline \multirow{2}{*}{$\begin{array}{c}\text { Elasticidade Preço } \\
\text { da Demanda }\end{array}$} & \multicolumn{4}{|c|}{ Elasticidade Preço da Oferta $(1)$} \\
\hline & 0,2 & 0,3 & 0,4 & 0,5 \\
\hline \multicolumn{5}{|l|}{$\eta_{D}=-0,2$} \\
\hline$E\left(W_{P}\right)$ & 841,604 & 954,800 & $1.065,260$ & $1.131,395$ \\
\hline$E\left(W_{C}\right)$ & $-650,640$ & $-759,320$ & $-868,032$ & $-931,137$ \\
\hline$E\left(W_{S}\right)$ & 190,964 & 195,480 & 197,228 & 200,258 \\
\hline \multicolumn{5}{|l|}{$\eta_{D}=-0,3$} \\
\hline$E\left(W_{P}\right)$ & 453,122 & 534,779 & 594,832 & 639,408 \\
\hline$E\left(W_{C}\right)$ & $-335,626$ & $-415,882$ & $-474,626$ & $-520,848$ \\
\hline$E\left(W_{S}\right)$ & 117,496 & 118,897 & 120,206 & 121,560 \\
\hline \multicolumn{5}{|l|}{$\eta_{D}=-0,4$} \\
\hline$E\left(W_{P}\right)$ & 283,824 & 339,915 & 383,084 & 417,509 \\
\hline$E\left(W_{C}\right)$ & $-203,103$ & $-258,152$ & $-300,394$ & $-333,976$ \\
\hline$E\left(W_{S}\right)$ & 80,721 & 81,763 & 82,690 & 83,533 \\
\hline \multicolumn{5}{|l|}{$\eta_{D}=-0,5$} \\
\hline$E\left(W_{P}\right)$ & 196,289 & 235,911 & 263,544 & 290,624 \\
\hline$E\left(W_{C}\right)$ & $-158,403$ & $-175,687$ & $-202,687$ & $-228,981$ \\
\hline$E\left(W_{S}\right)$ & 37.886 & 60,224 & 60,857 & 61,643 \\
\hline
\end{tabular}

Fonte: Dados da simulação

(1) Aleatoriamente escolhidas 
Tabela E.3: Efeitos distributivos da armazenagem competitiva no mercado de arroz no caso $I_{0}>I_{00}$ e $u_{1} \neq 0$ - Brasil 1981/90.

bilhão Cr\$

\begin{tabular}{|c|c|c|c|c|}
\hline \multirow{2}{*}{$\begin{array}{c}\text { Elasticidade Preço } \\
\text { da Demanda }\end{array}$} & \multicolumn{4}{|c|}{ Elasticidade Preço da Oferta (1) } \\
\hline & 0,2 & 0,3 & 0,4 & 0,5 \\
\hline \multicolumn{5}{|l|}{$\eta_{D}=-0,2$} \\
\hline$E\left(W_{P}\right)$ & 911,317 & $1.035,237$ & $1.113,693$ & $1.174,089$ \\
\hline$E\left(W_{C}\right)$ & $-739,252$ & $-866,371$ & $-948,284$ & $-1.012,927$ \\
\hline$E\left(W_{S}\right)$ & 172,065 & 268,866 & 165,409 & 161,162 \\
\hline \multicolumn{5}{|l|}{$\eta_{D}=-0,3$} \\
\hline$E\left(W_{P}\right)$ & 492,783 & 569,603 & 623,244 & 696,065 \\
\hline$E\left(W_{C}\right)$ & $-405,617$ & $-489,210$ & $-547,252$ & $-625,406$ \\
\hline$E\left(W_{S}\right)$ & 87,166 & 80,393 & 75,992 & 70,659 \\
\hline \multicolumn{5}{|l|}{$\eta_{D}=-0,4$} \\
\hline$E\left(W_{P}\right)$ & 308,210 & 362,394 & 402,010 & 431,373 \\
\hline$E\left(W_{C}\right)$ & $-237,323$ & $-292,000$ & $-333,002$ & $-363,752$ \\
\hline$E\left(W_{S}\right)$ & 70,887 & 70,394 & 69,008 & 667,621 \\
\hline$\eta_{D}=-0,5$ & & & & \\
\hline$E\left(W_{P}\right)$ & 213,492 & 262,270 & 281,364 & 303,649 \\
\hline$E\left(W_{C}\right)$ & $-160,827$ & $-210,813$ & $-230,701$ & $-253,969$ \\
\hline$E\left(W_{S}\right)_{-}$ & 52,665 & 51,457 & 50,663 & 49,680 \\
\hline
\end{tabular}

Fonte: Dados da simulação

(1) Aleatoriamente escolhidas 
Tabela E.4: Efeitos distributivos da armazenagem competitiva no mercado de arroz no caso $I_{0}=0$ e $u_{1}=0$ - Brasil 1981/90.

bilhão Cr\$

\begin{tabular}{|c|c|c|c|c|}
\hline \multirow{2}{*}{$\begin{array}{c}\text { Elasticidade Preço } \\
\text { da Demanda }(1)\end{array}$} & \multicolumn{4}{|c|}{ Elasticidade Preço da Oferta (1) } \\
\hline & 0,2 & 0,3 & 0,4 & 0,5 \\
\hline \multicolumn{5}{|l|}{$\eta_{D}=-0,2$} \\
\hline$E\left(W_{P}\right)$ & 367,836 & 435,428 & 480,420 & 515,682 \\
\hline$E\left(W_{C}\right)$ & $-324,050$ & $-390,375$ & $-431,152$ & $-465,672$ \\
\hline$E\left(W_{S}\right)$ & 43,786 & 45,054 & 49,268 & 50,010 \\
\hline \multicolumn{5}{|l|}{$\eta_{D}=-0,3$} \\
\hline$E\left(W_{P}\right)$ & 186,509 & 224,976 & 255,271 & 277,349 \\
\hline$E\left(W_{C}\right)$ & $-160,854$ & $-198,255$ & $-227,629$ & $-247,086$ \\
\hline$E\left(W_{S}\right)$ & 25,655 & 26,721 & 27,642 & 30,263 \\
\hline \multicolumn{5}{|l|}{$\eta_{D}=-0,4$} \\
\hline$E\left(W_{P}\right)$ & 111,968 & 136,868 & 156,733 & 172,972 \\
\hline$E\left(W_{C}\right)$ & $-95,507$ & $-117,888$ & $-138,994$ & $-154,735$ \\
\hline$E\left(W_{S}\right)$ & 16,461 & 18,080 & 18,739 & 19,237 \\
\hline \multicolumn{5}{|l|}{$\eta_{D}=-0,5$} \\
\hline$E\left(W_{P}\right)$ & 73,884 & 90,510 & 104,216 & 115,728 \\
\hline$E\left(W_{C}\right)$ & $-62,549$ & $-78,701$ & $-91,998$ & $-103,147$ \\
\hline$E\left(W_{S}\right)$ & 11,355 & 11,809 & 12,218 & 12,581 \\
\hline
\end{tabular}

Fonte: Dados da simulação

(1) Aleatoriamente escolhidas 
Tabela E.5: Efeitos distributivos da armazenagem competitiva no mercado de arroz no caso $I_{0} \leq I_{00}$ e $u_{1}=0-$ Brasil 1981/90.

bilhão Cr\$

\begin{tabular}{|c|c|c|c|c|}
\hline \multirow{2}{*}{$\begin{array}{c}\text { Elasticidade Preço } \\
\text { da Demanda }\end{array}$} & \multicolumn{4}{|c|}{ Elasticidade Preço da Oferta ${ }^{(1)}$} \\
\hline & 0,2 & 0,3 & 0,4 & 0,5 \\
\hline$\eta_{D}=-0,2$ & & & & \\
\hline$E\left(W_{P}\right)$ & 395,256 & 457,323 & 498,408 & 529,180 \\
\hline$E\left(W_{C}\right)$ & $-359,570$ & $-422,796$ & $-462,037$ & -492.498 \\
\hline$E\left(W_{S}\right)$ & 34,686 & 35,527 & 36,371 & 36,682 \\
\hline$\eta_{D}=-0,3$ & & & & \\
\hline$E\left(W_{P}\right)$ & 192,699 & 241,818 & 270,307 & 292,362 \\
\hline$E\left(W_{C}\right)$ & $-171,139$ & $-220,823$ & $-249,265$ & $-271,259$ \\
\hline$E\left(W_{S}\right)$ & 20,560 & 20,995 & 21,042 & 21,103 \\
\hline$\eta_{D}=-0,4$ & & & & \\
\hline$E\left(W_{P}\right)$ & 125,201 & 150,114 & 169,347 & 184,769 \\
\hline$E\left(W_{C}\right)$ & $-111,551$ & $-136,457$ & $-155,661$ & $-171,033$ \\
\hline$E\left(W_{S}\right)$ & 13,650 & 13,657 & 13,686 & 13,736 \\
\hline$\eta_{D}=-0,5$ & & & & \\
\hline$E\left(W_{P}\right)$ & 84,364 & 101,354 & 115,600 & 126,024 \\
\hline$E\left(W_{C}\right)$ & $-74,883$ & $-91,869$ & $-105,378$ & $-122,126$ \\
\hline$E\left(W_{\S}\right)$ & 9,481 & 9,485 & 10,222 & 10,898 \\
\hline
\end{tabular}

Fonte: Dados da simulação

(1) Aleatoriamente escolhidas 
Tabela E.6: Efeitos distributivos da armazenagem competitiva no mercado de arroz no caso $I_{0}>I_{00}$ e $u_{1}=0-$ Brasil $1981 / 90$.

\begin{tabular}{|c|c|c|c|c|}
\hline \multirow{2}{*}{$\begin{array}{c}\text { Elasticidade Preço } \\
\text { da Demanda }\end{array}$} & \multicolumn{4}{|c|}{ Elasticidade Preço da Oferta ${ }^{(1)}$} \\
\hline & 0,2 & 0,3 & 0,4 & 0,5 \\
\hline \multicolumn{5}{|l|}{$\eta_{D}=-0,2$} \\
\hline$E\left(W_{P}\right)$ & 465,267 & 522,191 & 558,290 & 575,368 \\
\hline$E\left(W_{C}\right)$ & $-442,584$ & $-501,838$ & $-539,969$ & $-559,042$ \\
\hline$E\left(W_{S}\right)$ & 22,683 & 20,353 & 18,320 & 16,326 \\
\hline \multicolumn{5}{|l|}{$\eta_{D}=-0,3$} \\
\hline$E\left(W_{P}\right)$ & 246,972 & 292,435 & 304,806 & 320,557 \\
\hline$E\left(W_{C}\right)$ & $-234,099$ & $-280,883$ & $-294,571$ & $-311,493$ \\
\hline$E\left(W_{S}\right)$ & 12,872 & 11,592 & 10,235 & 9,064 \\
\hline \multicolumn{5}{|l|}{$\eta_{D}=-0,4$} \\
\hline$E\left(W_{P}\right)$ & 150,451 & 174,551 & 191,988 & 205,986 \\
\hline$E\left(W_{C}\right)$ & $-142,521$ & $-167,450$ & $-185,777$ & $-299,728$ \\
\hline$E\left(W_{S}\right)$ & 7,930 & 7,101 & 6,211 & 6,158 \\
\hline \multicolumn{5}{|l|}{$\eta_{D}=-0,5$} \\
\hline$E\left(W_{P}\right)$ & 101,771 & 119,498 & 131,498 & 140,408 \\
\hline$E\left(W_{C}\right)$ & $-95,559$ & $-114,540$ & $-127,556$ & $-137,030$ \\
\hline$E\left(W_{\mathrm{s}}\right)$ & 6,212 & 4,958 & 3,942 & 3,378 \\
\hline
\end{tabular}

Fonte: Dados da simulação (1) Aleatoriamente escolhidas 